\title{
ALTURA DE VÔO DE SCOLYTIDAE EM REFLORESTAMENTO COM PINHEI- ROS TROPICAIS NA REgiÃo DE AGUDOS, ESTADO DE SÃO PAULO,
}

\author{
CARIOS ALBERTO HECTOR FLECHTMANN \\ Engenheiro Agrônomo
}

Orientador: EVONEO BERTI FILHO

\begin{abstract}
Dissertação apresentada à Escola Superior de Agricultura "Luiz de Queiroz", da Universidade de Säo Paulo, para obtenção do Título de Mestre em Ciēncias Biológicas - Area de Concentração: Ento mologia.
\end{abstract}

\footnotetext{
PIRACICABA

Estado de São Paulo - Brasil

Dezembro - iуy8
} 
.ii.

Aos meus pais

e familiares,

OFEREÇO

À Tina,

DEDICO 


\section{AGRADECIMENTOS}

- Ao Prof. Dr. Evoneo Berti Filho, pela iniciacão neste cam po e pela orientação dispendida;

- Ao Conselho Nacional de Desenvolvimento Cientifico e Tec nolōgico (CNPq) e à Freudenberg Agroflorestal pela concessão das bolsas;

- Ao Prof. Dr. José Henrique Pedrosa-Macedo, pelos constan tes estimulos e valioso auxỉio na taxonomia de Scolytidae;

- Ao Prof. Dr. Hilton Thadeu Zarate do Couto, pelo inestimāvel auxîlio na realização das anālises estatisticas e sugestões;

- A Freudenberg Agroflorestal pela infra-estrutura de campo fornecida, que permitiu a realizacão deste trabalho, em especial ao Eng. Florestal José L. S. Maia, e a todos os funcionārios que nele colaboraram;

- A todos que direta ou indiretamente contribuiram para o desenvolvimento deste trabalho. 


\section{INDICE}

Página

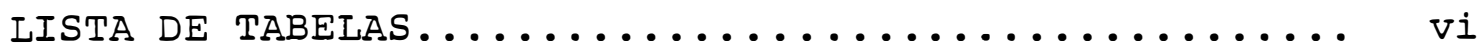

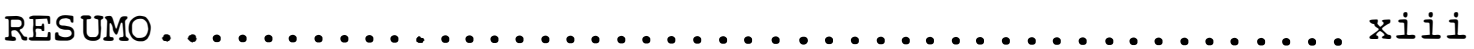

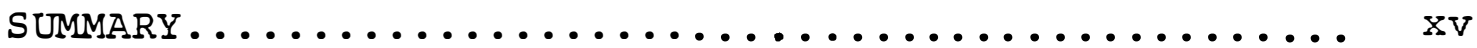

ZUSAMMENEASSUNG.....................................

1. INTRODUÇÃO ............................ 1

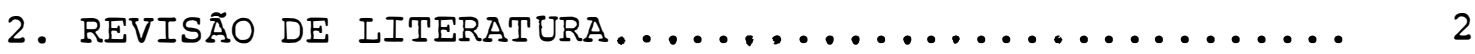

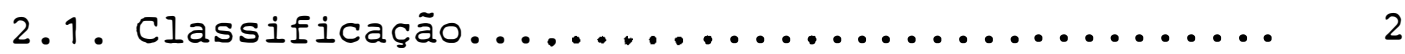

2.2. Atividades biológicas................. 4

a) Classificação ecológica.............. 4

b) Associação com fungos................ 7

c) Vôo e dispersão...................... 13

d) Atração ao hospedeiro................. 18

2.3. Armadilhas........................ 28

2.4. Danos.......................... 30

2.5. Situação no Brasil.................. 33

3. MATERIAL E METODOS..................... 37

a) Localização e caracterização da ãrea de pesquí-

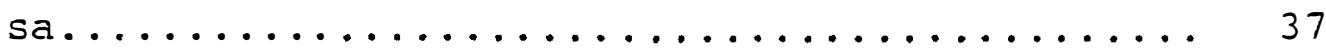

b) Metodologia da pesquisa............... 38

c) Análise dos dä̉os.................... 39 
Página

4. RESULTADOS E DISCUSSÃO.................... 41

4.1. Scolytidae capturados................... 41

a) Sub-familia Hylesininae Erichson, 1836....44 41

b) Sub-familia Scolytinae Latreille, 1807.... 42

4.2. Altura de vôo........................ 47

4.3. Altura de armadilha por talhão........... 70

4.4. Considerações sobre o coeficiente de variação 71

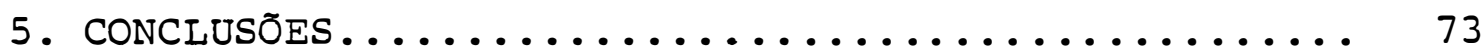

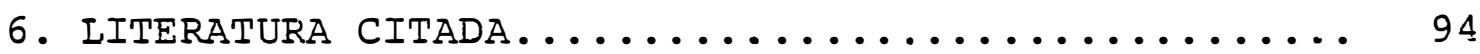

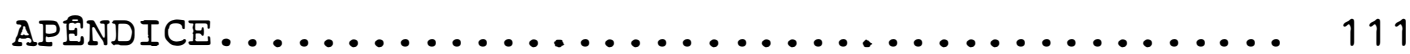




\section{IISTA DE TABELAS}

TABELA

Página

Caracterização dos talhões reflores tados com pinheiros tropicais, apresentando suas respectivas espécies, área, espaçamento, data de plantio, densidade de sub-bosque e desbastes realizados. Agudos, são

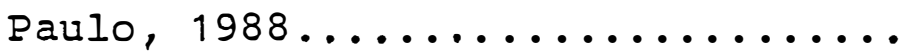

Resultado de análise de variância e teste de comparação de médias de capturas mensais de espécies de Sco lytidae para diferentes alturas de armadilhas de etanol. Agudos (SP), abril de 1984 a março de $1987 \ldots . .$.

$$
\begin{aligned}
& \text { Resultado de anälise de variância e } \\
& \text { teste de comparação de médias de } \\
& \text { capturas mensais de espécies de sco } \\
& \text { lytidae para diferentes alturas de } \\
& \text { armadilhas de etanol. Agudos (SF), } \\
& \text { abril de } 1984 \text { a março de } 1985 \ldots . . .
\end{aligned}
$$


Resultado de análise de variância e teste de comparação de médias de capturas mensais de espécies de Scolytidae para diferentes alturas de armadilhas de etanol. Agudos (SP), abril de 1985 a março de $1986 \ldots . .$.

Resultado de análise de variância e teste de comparação de médias de capturas mensais de espécies de Sco lytidae para diferentes alturas de armadilhas de etanol. Agudos (SP), abril de 1986 a março de $1987 \ldots . .$.

Resultado de análise de variância e teste de comparação de médias de capturas mensais de espécies de Sco lytidae para diferentes alturas de armadilhas de etanol. Agudos (SP), estação Priver (outubro a março), a bril de 1984 a março de $1987 \ldots . .$. 
Resultado de análise de variância e teste de comparação de médias de capturas mensais de espécies de Sco lytidae para diferentes alturas de armadilhas de etanol. Agudos (SP), estação Priver (outubro a março), a bril de 1984 a março de $1985 \ldots . .$. .

Resultado de análise de variância e teste de comparação de médias de capturas mensais de espécies de Sco lytidae para diferentes alturas de armadilhas de etanol. Agudos (SP), estação Priver (outubro a março), a bril de 1985 a março de $1986 \ldots . .$.

Resultado da análise de variância e teste de comparação de médias de capturas mensais de espécies de Sco lytidas para diferentes alturas de armadilhas de etanol. Agudos (SP), estação Priver (oluibro a março), a bril de 1986 a março de $1987 \ldots \ldots$. 
Resultado de análise de variância e teste de comparação de médias de capturas mensais de espécies de Sco lytidae para diferentes alturas de armadilhas de etanol. Agudos (SP), estação Outinv (abril a setembro), a bril de 1984 a março de $1987 \ldots . . .$.

Resultado de análise de variância e teste de comparação de médias de capturas mensais de espécies de Sco lytidae para diferentes alturas de armadilhas de etanol. Agudos (SP), estação outinv (abril a setembro), a . bril de 1984 a março de $1985 \ldots . .$.

Resultado de análise de variância e teste de comparação de médias de capturas mensais de espécies de sco lytidae para diferentes alturas de armadilinas de etanol. Agudos (SP), estzção Outinv (abril a setembro), a bril de 1985 a março de $1986 \ldots . .$. 
Resultado de análise de variância e teste de comparação de médias de capturas mensais de espécies de Sco lytidae para diferentes alturas de armadilhas de etanol. Agudos (SP), estação Outinv (abril a setembro), $\underline{a}$ bril de 1986 a março de $1987 \ldots . .$.

Resultado de análise de variância e teste de comparação de médias de capturas mensais de espécies de Sco lytidae para diferentes talhões, na altura de $40 \mathrm{~cm}$ da armadilha de eta nol. Agudos (SP), abril de 1984 a

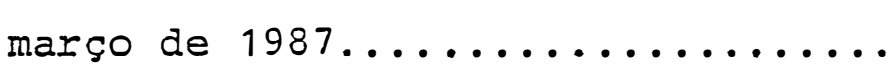

Resultado de análise de variāncia e teste de comparação de médias de capturas mensais de espécies de Sco lytidae para diferentes taliões, na altura de $60 \mathrm{~cm}$ da armacilha de eta nol. Agucios (SP), abril de 1984 a março de $1987 \ldots \ldots \ldots \ldots \ldots \ldots \ldots$ 
Resultado de análise de variância e teste de comparação de médias de capturas mensais de espécies de Sco lytidae para diferentes talhões, na altura de $80 \mathrm{~cm}$ da armadilha de eta nol. Agudos (SP), abril de 1984 a

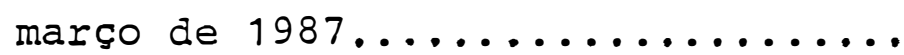

Resultado de análise de variância e teste de comparação de médias de capturas mensais de espécies de Sco lytidae para diferentes talhōes, na altura de $100 \mathrm{~cm}$ da armadilha de etanol. Agudos (SP), abril de 1984 a

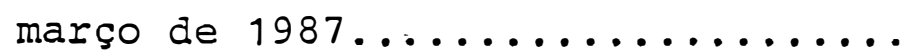

Resultado de análise de variância e teste de comparação de médias de capturas mensais do total de espécies de scolyticae para diferentes taihões e alturas de armadilias ae etanol. Agudos (SP), abril de 1984 a março de $1987 \ldots \ldots \ldots \ldots \ldots$ 
ALTURA DE VÔO DE SCOLYTIDAE EM REFLORESTAMENTO COM PINHEIROS TROPICAIS NA REgIÃO DE AGUDOS, ESTADO DE SÃO PAULO,

\section{AUTOR: CARLOS ALBERTO HECTOR FLECHTMANN ORIENTADOR: EVONEO BERTI FILHO}

\section{RESUMO}

Este trabalho trata da determinação da altura preferencial de vôo para 30 espécies de scolytidae ocor rentes em reflorestamento com pinheiros tropicais na região de Agudos, Estado de são Paulo. Para tanto, foram ins taladas armadilhas modelo ESALQ-84, iscadas com etanol, a quatro diferentes alturas $(40,60,80$ e $100 \mathrm{~cm})$ do solo, em cinco talhões distintos de Pinus: P, oocarpa, P. caribaea var. bahamensis, P. caribaea var. caribaea, P. caribaea var. hondurensis, $P$. caribaea var. hondurensis $e$ P. oocarpa consorciado com Liquidambar styracijzua. A frequên cia de coleta, num total de 188 armadilhas emeregadas, foi semanal, inicianco-se em abril de 1984 e encerrancio-se em março de 1987. O etanol mostrou ser um ötimo atraente primärio, tenco siäo possivel a identificagão de 37 das $8 j$ es 
pécies capturadas, em sua maioria xilomicetófagas. Houve espécies que apresentaram preferência por voar nas alturas superiores, outras nas inferiores, e aquelas em que não houve preferência. Para certas espécies as condições climáticas influenciaram na altura preferencial de vōo, e para outras, não. Praticamente todas as espécies mostraram preferência por atacar um ou mais talhões, e caracteristicas destes como idade, espaçamento e densidade de sub-bosque não influenciaram na altura de vōo desenvolvida. Foram recomendadas as alturas ideais de instalação de armadilhas de etanol, para maior captura de scolytidae, em cada talhão. 
FLIGHT HEIGHT OF SCOLYTIDAE IN REFORESTATION WITH TROPICAL PINES IN THE REgION OF AGUDOS, STATE OF SÃO PAULO, BRAZIL

\author{
AUTHOR: CARLOS ALBERTO HECTOR FLECHTMANN \\ ADVISER: EVONEO BERTI FILHO
}

\title{
SUMMARY
}

This research deals with the determination of the preferencial flight of 30 species of Scolytidae occurring in stands of tropical pines in the region of Agudos, State of São Paulo, Brazil. A total of 188 ethanol traps model ESALQ-84 were set up at four different heights above the ground level $(40,60,80$ and $100 \mathrm{~cm})$ in five stands of Pinus: P. oocarpa, P. caribaea var. bahamensis, P. caribaea caribaea, P. caribaea var, hondurensis, P. caribaea var. hondurensis and $P$. oocarpa intercropped with Liquidambar styraciflua. The insects were weekly collected from april 1984 to march 1987. The ethanol showed to be an excellent primary attractant, and it was possible to identizy j7 0I the 85 catcined species, xylomycetophagous in the majority. There were species that showed oreference to Ely at the uD- 
per heights, others at the lower heights, while others showed no preference at all. The climatic conditions have influenced the preferential flight of some species. It was also observed that most of the species showed preference to attack one or more pinus stands. On the other hand, stand features like age, spacing and underbrush density did not influence the flight height. The ideal heights to set up the ethanol traps for higher collectings of scolyti dae species are recommended for each site. 
FLUGHÖHE VON SCOLYTIDAE IN AUFFORSTUNGEN MIT TROPISCHEN KIEFERNARTEN IN DER GEGEND VON AGUDOS, STAAT SÃO PAULO, BRASILIEN,

\section{VERFASSER: CARLOS ALBERTO HECTOR FLECHTMANN DOKTORVATER: EVONEO BERTI FILHO}

\section{ZUSAMMENFASSUNG}

Diese Arbeit handelt von der bevorzugten Flugh hhe fur 30 Scolytidae Arten, die in Aufforstungen von tropischen Kiefernarten der Gegend Agudos, Staat São Pau10, Brasilien, vorkomen. Aus diesem Grund wurden Fallen Modell ESALQ-84 mit Athanol gekddert, in vier verschiedenen Hohen $(40,60,80$ und $100 \mathrm{~cm})$ ab vom Boden installiert, in funf verschiedenen Stünden von Pinus: P. oocarpa, P. caribaea var. bahamensis, P. caribaea var. caribaea, P. caribaea var. hondurensis, P. caribaea var. hondurensis und P. oocarpa mit zwischenkultur von Liquiuambar styracijlur. Die Einsamiung von 183 Falien geschah wöchentlich, beginnend im April 1984 und endend im Murz 1987. Das Athanol erwies sich als alisgezeichneter Primar- 
duftstoff; so war es moglich die Identifizierung von 57 der 85 gefangenen Arten durchzufuhren, hauptsăchlich Holzbruter. Es gab Arten die bevorzugten in groberen Hohen zu fliegen, andere in den niederen Hohen, und solche die keinen Vorzug zeigten. Bei einigen Arten beeinflussten die klimatischen Verhaltnisse die bevorzugte Flughthe, und fulr andere nicht. Praktisch zeigten alle Arten Vorzug ein oder mehr stände zu befallen, deren charakteristiken wie Alter, Abstand und Unterstrauchdichte nicht die beobachtete Flughthe beeinflussten. Es waren die idealen Hohen, welche fur Athanolfallenaufstellung empfohlen wurden, um einen groberen Fang von scolytidae in jedem stand zu haben. 


\section{INTRODUÇÃO}

Por muito tempo, a exploração da madeira no Brasil foi baseada no extrativismo, exaurindo suas reservas nativas. Assim, na década de 60, o governo criou os incentivos fiscais, havendo a introdução de essências exóticas de rápido crescimento.

As essências florestais predominantes são constituidas por Pinus elliottii, $P$. taeda, $P$. caribaea, P. oocarpa, Eucalyptus spp. e Acacia mearnsii...

Os insetos são considerados os principais responsāveis por danos em florestas. Em äreas reflorestadas com coniferas, as coleobrocas da familia scolytidae destacam-se como seus principais agentes destruidores.

Em vista disto, e considerando-se a escassa literatura pertinente ao assunto no Brasil, foi realiza do um estudo básico relacionando a ocorrência de repre sentantes de Scolytidae às essências exóticas de pinheiros aqui plantados, uma vez que a prevenção é, indiscutivelmente, o melhor método de se resguardar a florestas de danos causados pelos insetos. 
.02

\section{REVISÃO DE LITERATURA}

\subsection{Classificação}

Na décima edição do "Systema Naturae" de Linnaeus, em 1758, constavam 5 espécies de Scolytidae, tra tados no gênero Dermestes. Até 0 ano de 1982, wOOD estima em 6000 o número de espécies conhecidas no mundo.

IIMA (1956) descreveu os Scolytidae como insetos geralmente pequenos, podendo variar de meio milimetro, como em Hypothenemus, até mais de um centímetro, como em Phloeborus. O corpo é bem esclerosado, sendo em geral cilindrico, com a porção terminal dos élitros quase sempre

com declive acentuado ou truncado. A cabeŗa pode ser visí vel ou não em vista dorsal, sendo neste último caso parcialmente encaixada no protórax, cujo pronoto se apresenta algo alongado. As tíbias apresentam ou pequenos dentes na margem externa ou um gancho robusto apenso ao àngulo apical externo. Os olhos são geralmente grandes, achatados, ovais ou reniformes. Nos élitros, em geral providos de estrias mais ou menos distintas, inserem-se pêlos ou escamas. O abdome apresenta 5 esternitos visiveis. Atualmenta são consideradas duas como as sub- 
-familias de Scolytidae, Hylesininae e Scolytinae. Os Hylesininae têm como principais caracteristicas a margem basal dos élitros pró-curvada e armada com uma sērie de crenula ções marginais, usualmente com uma emarginação "scut.ellar" entre eles; a cabeça è usualmente visivel em vista dorsal. Os scolytinae já apresentam as margens basais dos élitros formando uma linha transversa reta pelo corpo, sem as crenulações; a cabeça è geralmente parcial ou totalmente ocul ta em vista dorsal (WOOD, 1982).

De um modo geral, dados relacionados à nomeclatura e classificação precedem a expansão do conhecimento, nos organismos vivos. Porēm para os scolytidae isto não occrreu, devido à necessidade premente de se tomar medidas práticas relacionadas ao manejo de sua população. Alēm disto, a indisponibilidade momentânea de taxonomistas treinados aparentemente levou técnicos florestais a identi ficar espēcies, a fim de suprir suas necessidades (WOOD, i986).

Este fato, aliado ao pequeno tamanho apresen tado normalmente por estas coleobrocas, onde certos grupos apresentam enormes e frequlentes semelhanças entre as espécies e outros uma variabilidade muito grande de caracteres numa mesma espēcie, fez com que muitas esp̣écies 三̃ossem des critas mais de uma vez (SCHONHERR, 1985). Tim bail exemplo - aoresentado por BRIGHT Jr. (1968), onde Xulzousuj 
ferrugineus pode variar de 2,1 a $3,0 \mathrm{~mm}$ em tamanho, além de poderem haver variações na estrutura.

WOOD (1986), através do exame das espécies-tipo de praticamente todos os grupos genéricos, contribuiu grandemente no sentido de dar um ordenamento maior na iden tificação de exemplares desta familia. Foram incluídos, as sim, 215 gêneros válidos e 273 nomes genéricos e sub-gené ricos inválidos.

Para os representantes de Scolytidae da Amé rica do Sul, a situação é um pouco mais delicada. Além da ausência de uma chave taxonômica específica para as espécies neotropicais, Karl Schedl, que foi o maior taxonomista de espécies desta região, simplificou por demais a iden tificação, ao dar como espécie nova aquela que não constava de sua coleção (SCHONHERR, 1985). O autor sugere, assim, o uso da genitália como mais uma ferramenta a auxiliar na identificação das espécies sul-americanas.

\subsection{Atividades biológicas}

a) Classificação ecológica Afora a classificłção baseada em características morfológicas, os Scolytidae podem ser classificados quanto às suas caracteristicas ecológicas. Assin, tomando- se como dase o häbito alimentar, poderiam ser agruacacos, 
seçundo ATKINSCN \& EQUIHUA-MARTINEZ (1986), em:

- espécies fleófagas: aquelas que se alimentam de tecidos do floema da parte inferior da casca. A este grupo pertencem os chamados besouros da casca ("bark beetles"), ti dos como os mais perigosos e maiores causa dores de danos econômicos em áreas reflorestadas.

- espécies xilomicetófagas: aquelas que tēm como principal alimento fungos simbió ticos, que introduzem e cultivam na planta hospedeira. Scolytidae com este hábito ali mentar são denominados de besouros da ambrosia ("ambrosia beetles") .

- espécies xilófagas: aquelas que vivem e alimentam-se diretamente do xilema ou madeira [aparentemente todas estão associadas com fungos, porém estes não se constituem na fonte principal de alimento (WOOD, 1982)] .

- espécies mielófagas: aquelas que se alimentam da medula de pequenos ramos. Algumas destas espécies são muito destrutivas.

- espécies herbifáyas: aquelas que se alimen tam de plantas não lenhosas. são raras en- 
tre os Scolytidae.

- espécies espermófagas: aquelas que se ali mentam de sementes, cones ou partes de fru tos. Há espécies que causam danos econômi$\cos$.

Os principais grupos são constituidos pelos fleófagos e xilomicetófagos. Aos fleófagos pertencem as principais pragas, sendo que têm um alto grau de espefici dade hospedeira, sendo geralmente associados a hospedeiros que produzem látex, resina ou goma. Assim, são espécies ge ralmente monófagas, sendo este considerado como o hábito alimentar dominante em āreas temperadas (GRAY, 1974; ATKINSON \& EQUIHUA-MARTINEZ, 1986).

Os xilomicetófagos, como mencionado acima, estão intimamente relacionados a fungos simbiontes. Este hábito alimentar é basicamente resposta a uma alta umidade relativa, favorável ao desenvolvimento dos fungos. Talvez seja este um fator para que o grupo predomine mais nas regiões neotropical e tropical (BRIGHT Jr., 1968; GRAY, 1974; BEAVER， 1976a; CARRANO-MOREIRA， 1985; PEDROSA-MACEDO, 1985; ATKINSON \& EQUIHUA-MARTINEZ, 1986). ATKINSON \& EQUIHUA-MARTINEZ (1986) consicieram como provável o surgimento des te hábito devicio a uma competição entre besouros a micrcorganismos pelo mesmo substrato. Estas espécies, apesar de selecionarem seus hospedeiros, são extremamente políagas, 
devido ao fato de se alimentarem de fungos e não de tecido do hospedeiro, o que é tambēm confirmado por DOUROJEANNI (1965) •

Os Scolytidae poderiam tambēm ser classifica dos através de outras de suas caracteristicas ecológicas mais tipicas, como quanto ao tipo de galeria construido (ESTADOS UNIDOS. DEPARTMENT OF AGRICULTURE, 1985), quanto ao hábito de reprodução (ATKINSON \& EQUIHUA-MARTINEZ, 1986) ou mesmo de acordo com o material de criação (RUDINSKY, 1962).

\section{b) Associação com fungos}

Quase todos os Scolytidae são associados com fungos. A relação pode variar de um contato casual a uma associação Intima, onde a sobrevivência de um organismo é dependente do outro (WOOD, 1982).

De um modo geral, os besouros da casca habi tam um tecido da planta rico em proteinas e carbohidratos, tecido este completo o suficiente para propiciar um desenvolvimento adequado destas coleobrocas (BATRA, 1963). Muitos destes estão relacionados a fungos, que são em sua maio ria leveduras e fungos manchadores. Esta relação pode ser especiffica ou não.

São vários os trajalhos mostrancio que hospedeiros dcentes predispoem o ataque destes por besouros da casca. GOHEEN et alii (1985) dão como causa desta prefierên 
cia mudanças fisiológicas produzidas no hospedeiro, resultando na produção de atraente primário. Os mesmos autores mostraram que Dendroctonus ponderosae e 0 . brevicomis são capturados em maior quantidade em Pinus ponderosa infectados por Ceratocystis wageneri que nos pinos sadios.

Os fungos manchadores são responsáveis também pela depreciação da madeira, uma vez que altera sua co loração natural. Mas, uma vez que os fungos atuam somente no conteúdo celular, suas propriedades mecânicas e físicas não sofrem grandes variaçōes (FISHER et alii, 1953; CIANCIULI, 1978 ; WOOD, 1982).

Muitos trabalhos mostram a relação existente entre a introdução de fungos por besouros da casca do hospedeiro e a maior susceptibilidade do último às pragas, de vido a estes fungos (GRAHAM, 1967).

PAINE (1984) testou os fungos ceratocystis nigracarpa e C. minor, encontrados associados a Dendrocto nus brevicomae, em seedlings de $P$. ponderosa. Os fungos fo ram capazes de reduzir o movimento de água nas plântulas, alēm de diminuir a aeração dos tecidos. Foi observado tam bém um bloqueio de traqueídeos, com consequente redução na pressão de oleoresinas, este um mecanismo de resistôncia da planta. COoK \& HAIN (1985) ootiveram dacos semelhantes com o fungo $C$. minor, associado com $D$. frontalis sm $P$. tarda. Tudo isto resulta em maiores concições das coleo- 
brocas de vencer a resistência das suas árvores hospedeiras.

Os fungos, quando são disseminados, 0 são através de estruturas especializadas denominadas de micân gias (ou micetângias). Já em 1917, Beeson ${ }^{1}$ (citado por NUNBERG, 1951) se refere a aberturas existentes no pronoto de Diapus furtivus (Platypodidae) contendo substâncias gor durosas nas quais se aderiar esporos do fungo cultivado pe lo besouro.

Em. 1956, FRANCKE-GROSMANN volta a se repor tar nestas estruturas que carregam inōculos viáveis de fun gos, desta vez em Scoltidae, e que BATRA (1963) denominou de micângias. Assim, micângia é um depósito em forma de saco ou taça, localizado geralmente no exterior do besouro, e especializado no transporte de células propagativas de fungos. Estes, na micângia, crescem às expensas do besouro, e utilizam componentes químicos no inseto como nutrientes (ABRAHAMSON \& NORRIS, 1970).

Quanto à sua localização, podem ser classifi cadas de orais (em Xyleborus affinis, x. fornicatus), pro toräcico-pleurais (em Trypodendron, Dendroctonus frontalis), prosternais-subcoxais (ern Gnathotrichus retusus, Monaritrum basciatum), pronotais (em Dactyopalpus, Scolytoplatypus), pro-mesonotais (em Xylosandrus germanus, Xyzeborus dispar)

\footnotetext{
IBEESON, C.F.C. The life-nistory OE Diapus juhtivids Sames. (Platpodidae). Indian Forest Rrcord, Calcutta, 6 , 1917 .
} 
e elitrais (em Xyleborinus saxeseni) (BATRA, 1963; FRANCKE- GROSIANIN, 1963; WOOD, 1982).

Estas micângias, que são geralmente pareadas, ocorrem mais frequentemente nas fêmeas, em ambos os sexos ou exclusivamente em machos, como foi determinado para Corthylus columbianus (GIESE, 1967).

Os Scolytidae denominados besouros da ambrosia tem como principal fonte de alimento fungos, aos quais estão intimamente associados. O nome "ambrosia" foi dado a este tipo especial de fungo por Schmidberger em 1836, e Hartig reconheceu sia natureza verdadeira de fungo em 1844 (FISHER et alii, 1953).

Os fungos da ambrosia são altamente especifi cos em relação ao inseto, e apresentam forma típica nas ga lerias onde se desenvolvem. São de cores vărias, e usualmente consistem de corpos de hifas encadeados ou cadeias de células que formam uma paliçada alinhada nas galerias (BATRA, 1963).

Nestes fungos ocorre $\circ$ fenômeno denominado de pleiomorfismo, isto é: apresentam duas formas de crescí mento, a ambrosial e a micelial (GRAHAM, 1967). BATRA (1967) denomina a citado înômeno como dimoríismo.

A fase ambrosial costuma ocorrer na presença do Scclitidae associaüo, e a micelial, em sua ausência Con sidera-se que uma forma pocie reverter na outra, e vice-ver 
sa (BATRA, 1967). Embora o autor citado tenha conseguido a indução da formação da forma ambrosial através de simples corte mecânico das hifas da forma micelial, FRENCH \& ROEPER (1972) acreditam que uma secreção produzida pelo Scolytidae leve o fungo à forma ambrosial.

FRENCH \& ROEPER (1972) observaram que somente fêmeas de pós-diapausa e pupas de Xyleborus dispar indu ziram a formação ambrosial do fungo Ambrosiella hartigii, enquanto que larvas, ovos e fêmeas de diapausa não tiveram nenhum efeito sobre o fungo. Observaram ainda que, sem a forma ambrosial, a oviposição e pupação não ocorreram.

Além do fungo da ambrosia, corpos de propaga ção de muitos outros microorganismos são presentes nas galerias dos besouros da ambrosia. Estes predominam geralmen te no início (de 4 até 10 dias da escavação das galerias) e no fim do ciclo (na pupação). Estes ocorrem também na maioria das micângias de Scolytidae, podendo este fato ser atribuido devido a haver muitos outros fungos nos túneis. Dentre os contaminantes, foram isolados inclusive sérios patógenos de plantas (BATRA, 1963).

Como citado anteriormente, a relação existen te entre os fungos da ambrosia e seus correspondentes Sco lytidae é estreita. O besouro se beneficia pelo Eato da maioria destes habitar na parte Ienhosa da árvore, sabida mente pobre em vitaminas a proteinas. O mic三llio do fungo 
consegue penetrar vários milimetros fora do limite das ga lerias à procura de nutrientes, que são assimilados quando da alimentação no fungo. Este tambēm enfraquece a madei ra pelo crescimento anterior à eclosão das larvas, facilitando assim a escavação de novas células por estas.

o fungo tambēm se beneficia nesta relação, por ser transmitido e inoculado diretamente em madeira com condições nutricionais e de umidade favoráveis, e sem precisar vencer a resistência mecânica imposta pela casca do hospedeiro. O fungo é ainda protegido na micângia contra possíveis dessecações durante o período de vôo e de hiber nação do scolytidae. Considera-se ainda que o fungo utili za a uréia e äcido ürico presentes nas excreções das coleo brocas como fonte de nitrogênio (BATRA, 1967).

Estes fungos são tambēm responsáveis, do mes mo modo que os fungos manchadores nos besouros da casca, por depreciação da madeira usada para fins nobres, devido a justamente manchá-la. Poderiam ser citados os fungos dos gêneros Pichia, Ceratocystis, Graphium, Fusarium, Gliocladium e Rhizoctonia como representantes de fungos da ambrosia (KABIR \& GIESE, 1966).

Ertre os besouros da amorosia há também representantes capazes de serem vetores de fungos patogênicos. Xyleboius jerrugineus é muitas vêzes citado como vetor do fungo Caratocusitis jimoriata, responsävel pela seca do cacaueiro, Th2ojioma cacao (EARA \& SHENEEEIT, I965; SAUNDERS \& KNOKE, 1967; BEAVER, 1976a). 
Tambëm pode ser citados Monarthrum fasciatum, associado à seca do carvalho (ROIING \& KEARBY, 1974), Xylosandrus morigerus associado ao fungo Lasiodiplodia theobromae em cacaueiro (NAKAYAMA \& TERRA, 1986) e Hypocry phalus mangiferae associado à seca da mangueira (Mangifera indica), causada por cieratocystis fimbriata (BEAVER, 1976 b).

c) Vôo e dispersão

Os Scolytidae são dependentes do vôo para se translocarem do hospedeiro no qual se criaram a novas plan tas. Os besouros ditos pioneiros los primeiros a chegarem a um novo hospedeiro) são atraídos por oleoresinas voláteis, terpenos, álcoois ou outras substâncias liberadas pe lo hospedeiro. Quando estes odores estão presentes no ar - vôo é dirigido, e quando não detectados, torna-se aleató rio (WOOD, 1982).

A atividade de vôo é confinada a relativamente poucas horas por ano, e é vital para seu sucesso e importante na extensão e localização das ăreas de infestação (ATKINS, 1959; CHAPMAN \& NIJHOLT, 1980).

Embora sejam capazes de vôos longos, em con dições naturais os Scolytidae nãu precisam voar longas dis tâncias (RUDINSKY, 1962). ATKINS (1961) deteminou que Dendroctonus pseudotsugae voa normalmente na faixa de 1,4 $\mathrm{km}$, podenco alcançar até $32 \mathrm{~km}$, quanảo em dias sem vento. 
Esta distância pode aumentar consideravelmente se o inseto é arrastado numa corrente de ar.

são vārios os fatores relacionados à ativida de de vôo. Os principais fatores abióticos são os componen tes temperatura, umidade relativa do ar, intensidade luminosa e direção e velocidade dos ventos.

Os Scolytidae geralmente têm um limiar míni mo de temperatura, acima do qual o vôo pode ser iniciado. Para Dendroctonus pseudotsugae, este está em torno de $220 \mathrm{C}$, mas esta temperatura pode ser inferior, caso haja estimulos extras como a luz do sol, por exemplo (ATKINS, 1959).

Para Trypodendron lineatum, RUDINSKY \& DATERMAN (1964) determinaram 14,40C como o limiar de temperatura, muito próximo ao obtido por CHAPMAN \& KINGHORN (1958a) e CHAPMAN \& NIJHOLT (1980), que foi de 15,60C. Gna thotrichus sulcatus e $G$. retusus têm um limiar semelhante, situado entre $14,40 \mathrm{C}$ e 15,60C (RUDINSKY \& SCHNEIDER, 1969). Dados indiretos relacionados à temperatura são mostrados por MOSER \& DELL (1979), HOSKING \& KNIGHT (1975), relacionando-a ao numero de scolytidae capturados em armadilhas.

Porém, convém ressaltar que o fator temperatura não age isoladamente. O limiar pode ser menor quando hà suficiente intensidade luminosa, como mostra ATKINKS (1959) para D. pseudotsugar, ou quando a umiadie relativa 
é alta (ATKINS, 1960).

A temperatura, umidade e intensidade luminosa atuam na frequência de batidas de asas, sendo esta de natureza diretamente proporcional para . 0 . pseudotsugae (ATKINS, 1960).

A velocidade de reação ao vôo aumenta com a intensidade luminosa, sendo que ATKINS (1959) não observou nenhum 0 . pseudotsugae voando a menos de 5,35 lúmens $/ \mathrm{m}^{2}$. RUDINSKY \& SCHNEIDER (1969) determinaram o intervalo de 1070 a 2140 lúmens $/ \mathrm{m}^{2}$ como o ótimo ao vôo de Gnathotrichus retusus $e G$. sulcatus.

o vento é mais um fator limitante. Trypoden dron lineatum não voa quando a velocidade atinge $7,4 \mathrm{~km} / \mathrm{h}$ (CHAPMAN, 1962), sendo que voa melhor com ar sem vento (CHAPMAN \& NIJHOLT, 1980). RUDINSKY \& DATERMAN (1964) Observaram que a referida espécie tem o comportamento de voar próximo ao solo, onde a velocidade do vento é menor, quando venta muito. Velocidades maiores que $1,6 \mathrm{~km} / \mathrm{h}$ afetam ne gativamente 0 vôo de Dendroctonus terebrans, a quando estas atingem $8 \mathrm{~km} / \mathrm{h}$, deixam de voar (FATZINGER, 1985). GRAY (1974) e ROLING \& KEARBY (1977) relataram que, em seus experimentos, os Scolytidae foram mais capturados nas faces norte e leste, mas atribuiram isto à direção do vento, que direcionava a emissão da isna atrativa. Trypodendron lineatum orienta seu vôo contra o vento (CHAPMAN, 1962). 
A chuva tem uma correlação negativa com o vôo de Scolytidae, como observado por FATZINGER (1965) e MOSER \& DELL (1979), que obtiveram menos Scolytidae capturados em épocas chuvosas.

Todos os fatores acima citados, com maior ou menor intensidade, vão influir no ato de Scolytidae de ini ciar ou continuar o vôo. Outra característica interessante a ser mencionada é o horărio em que este vôo é iniciado.

$$
\text { MILANEZ et alii (1982) observaram que, em }
$$
plantações de cacaueiros na Bahia, as populações de Hypothenemus obscurus e $H$. eruditus iniciam seus vôos próximo das 8:00h, atingindo o pico entre 10:00 e 14:00h, decrescen do a partir das 20:00h.

RUDINSKY \& DATERMAN (1964) relataram que Gnathotrichus, voa somente no fim da tarde, mas pesquisas posteriores (RUDINSKY \& SCHNEIDER, 1969), mostrando capturas ocasionais pela manhã e meio-dia, levam a crer que nes te gênero o comportamento de vôo depende muito da interação entre a temperatura e a intensidade luminosa.

$$
\text { GRAY (1974) obteve dados relacionando o vôo }
$$
de xylebonus ferrugineus a hăbitos crepusculares, e a maior parte dos Scolytidae capturados o foram durante 0 dia. Browne (I961) ${ }^{2}$, citado pelo mesmo autor, afirma ser o comportamento de vôo de grande parte dos scolytidae crepuscu-

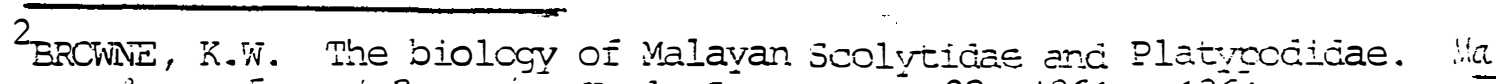

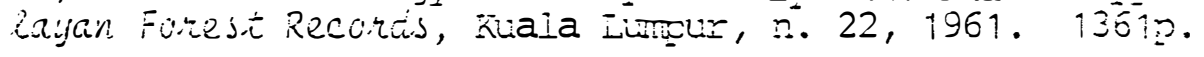


lar ou noturno.

Em relação à altura em que ocorre este vôo, tambëm podem ser feitas algumas considerações. CHAPMAN \& KINGHORN (1958a) testaram várias alturas de armadilhas, e verificaram que Trypodendron lineatum foi capturado nas mais baixas. Observaram ainda que, numa ārea onde havia troncos caídos, a maior atividade de vôo foi perto do nível do solo.

CARRANO-MOREIRA (1985) testou as alturas de armadilhas de 0,5 e 1,3 m e obteve, em Araucaria angustifó lia, maior captura na altura mais alta. Já em Pinus elliottii e $P$. taeda não houve diferenças significativas, embora a altura inferior tivesse capturado mais Scolytidae.

Hylastes dissimilis foi mais capturado em ar madilhas, por TURNBOW \& FRANKLIN (1980), nas alturas de 6 e $8 \mathrm{~m}$.

HOSKING \& KNIGHT (1975), observando a altura de vôo de Trypodendron bivittatum e de Xyloterinus politus, fizeram interessantes ponderações. o primeiro voa próximo ao solo, e costuma atacar a parte inferior do tronco do hospedeiro, coincidindo com dados de CHAPMAN \& KINGHORN (1958a) com T. Lineaium, enquanto que o segundo scolytidae é capturado desde alturas de 1,5 até 7,5 m do solo, atacan do todas as partes do hospedeiro

$$
\text { Deste modo, correlacionaram a aljurz mais }
$$


frequente de vôo dos scolytidạe com a zona de ataque na árvore hospedeira, correlação esta também feita por TURNBow \& FRANKLIN (1980). Foram ainda mais além, levantando a hipótese de que a dispersão esteja relacionada a um simples exercício de vôo, requerido por muitas espécies antes de construir novas galerias.

Como pôde ser visto, a afirmação feita por GRAY (1974) de que a atividade de vôo das diferentes espécies de scolytidae pode diferir grandemente em alguns ou muitos aspectos, é plenamente correta.

d) Atração ao hospedeiro

Uma vez que o Scolytidae emerge do seu local de criação, ou de onde se manteve durante a hibernação, ele voa à procura de novos hospedeiros. Denomina-se de atração primária a atração exercida pelo hospedeiro, através de substâncias próprias emanadas. O besouro atraído por estas substâncias é denominado de pioneiro, o qual pode, dependendo da espécie, liberar feromônio de agregação, dando-se assim a atração secundária. Neste item, procurar-se-á ater à atração primária.

Há Scolytidae que não respondem inicialmente a estimulos olfativos, requerendo inicialmente de um exer Cício de vôo para depois reagirem positivamente a atrativos. Esta tendência contribui a leválos para fora do raio de ação do atrativo, aumentando sua disp̣ersão (RUDINSKY, 
1962; ATKINS, 1966; CHAPMAN, 1966; ATKINS, 1968).

Uma vez detectado um atraente, os Scolytidae constumam responder com um vôo direto à fonte, e contra o vento (BOUTZ et alii, 1985). SAMANIEGO \& GARA (1970) dizem que o vôo dos besouros da ambrosia é dirigido à fonte atraente. Para Trypodendron lineatum o vôo é firme, sem mo vimentos rápidos de mudança de direção; desvios à esquerda ou direita são firmes, usualmente não ultrapassando 1,8 m, e retornam rapidamente, até atingir a fonte de emissão (RUDINSKY \& DATERMAN, 1964).

A atração primária é, pois, exercida pelo hospedeiro, podendo atrair ambos os sexos, embora geralmen te um deles seja mais sensivel, para cada espécie. Usual mente quando estes pioneiros são machos a espécie é políga ma, e quando são fêmeas, a espécie é monógama (GIL et alii, 1985).

As oleoresinas e os produtos de transforma ção por oxidação ou polimerização são essenciais na atração primăria. Das oleoresinas destacam-se em importância os produtos terpênicos, originados da condensação de uma ou mais unidades do isopreno, dando nos monoterpenos, ses quiterpenos e seus derivados, dos quais se destacam os ésteres, aldeídos, álcoois e cetonas. Os terpenos mais Ëreqüences em coniferas são $\circ \alpha$ - oineno, 3 -pineno, mirceno, canfeno e $\lrcorner-3$ careno (CHARARAS, 1971; CHARARAS, 1975; 
GIL et alii, 1985).

o poder de atração (primária) do hospedeiro resulta da ação sinērgica de vários componentes terpênicos, sendo estes eficazes a grandes distâncias e muitas vezes especificos ao inseto, permitindo a ele identificar assim um possivel hospedeiro e verificar seu estado fisiológico (GIL et alii, 1985).

DUNN et alii (1986) estabeleceram que a natureza dos atraentes primários do hospedeiro depende antes de mais nada de, se o inseto é um saprófago ou fitófago, e consequentemente, se é atraído a odores de plantas em deca dência ou vivas. O etanol, um componente de atração primá ria, formado naturalmente pela fermentação anaeróbica no floema úmido e alburno de troncos ou árvores doentes, é tido pelos autores como um atraente primário de saprófagos obrigatórios de plantas mortas ou à morte.

Aparentemente, a percepção do etanol representa um mecanismo crucial na localização da planta hospe deira para muitos insetos que vivem em tecidos sub-corticais, particularmente os besouros da ambrosia, que depender da cultivação de fungos simbiontes.

Uma das primeiras referencias associando 0 álcool como atrativo a Scolytidae ミ a de FROST \& DIETRICH, em 1929. Estes usaram błicies de lata contendo solução de melaço ou açücar em fermentação, e notaram que esta isca 
atraía principalmente coleópteros, dentre os quais repre sentantes de Scolytidae.

PERSON (1931) testou vários produtos, e a casca de Pinus ponderosa em fermentação foi o mais atrati vo a Dendroctonus brevicomis. O autor atribuiu a atração primária a produtos formados e liberados da fermentação em āryores anormais, produtos estes que supôs serem aldeídos ou èsteres.

Pela injeção de etanol em troncos de olmos vivos, BUCHANAN (1942) fez com que estes se tornassem atra tivos a Xylosandrus germanus, que normalmente não ataca ār vores vivas e sadias.

Atravēs da indução de condições anaerōbicas em material vegetal de Tsuga heterophylla e Pseudotsuga menziesie, GRAHAM (1968) -teorizou que o mecanismo causal para a formação de atraente primārio para Trypodendron linea tum poderia derivar da supressão de oxigênio nos cen tros de atividade da desidrogenase, causando uma mudança do processo oxidativo ao fermentativo.

CADE et alii (1970) tambëm atribuíram como o autor acima, a substâncias formadas durante o processo de decomposição a atração de Gnathothichus sulcatus a ärvores à morte ou rortas. Consideraram tambéri estas substâncias como essenciais em guiar os besouros da ambrosia a seus hospedeiros. Testes posteriores revelaram ser o etanol o principal 
atraente formado, e que este agia também como estimulante de perfuração inicial das galerias.

MOECK (1970) identificou, em extratos de mä deira e casca de Tsuga heterophylla, Pseudotsuga menziesii e Abies amabilis, atrativos a Trypodendron lineatum, os componentes metanol, acetaldeído e etanol. Em experimento complementar de tratamento anaeróbico induzido de floema e alburno, verificou ser o etanol o componente de maior atração. Este componente foi atrativo e ambos os sexos do Scolytidae, embora a atração maior tivesse ocorrito na menor concentração testada. Observou também que o etanol, em condições de campo, foi atrativo a outras espécies de Scó lytidae.

SAMANIECO \& GARA (1970) obtiveram resultados que evidenciaram a eficácia do etanol como atraente primä rio a besouros da ambrosia, e que quanto maior a concentra ção usada, maior a atratividade.

ROLING \& KEARBY (1975), usando de armadilhas tipo "janela" iscadas com etanol 50\%, capturaram 15 gêneros (25 espécies) de Scolytidae, sendo que o etanol foi se letivo para machos de Monarthrum basciatum, M. mali e Corthylus columbianus. Através da injeção de etanol $95 \%$ em árvores sadias de quercus velutina, conseguiu que estas se tornassem atrativas a Xylebonus saxeseni e H. Jasciatum, que normalmente só são encontracos em árvores muito Eracas 
ou mortas. GAGNE \& KEARBY (1978) tạmém provaram ser o etạ nol atrativo a $M$. fasciatum.

Troncos de hibridos de Picea, pulverizados por MOECK (1981) com etanol 95\% foram atacados por 0. rufipennis, enquanto que as testemunhas quase não foram atacadas.

TURNBOW \& FRANKLIN (1980) usaram o etanol co mo isca atrativa em armadilhas na Geórgia, e capturaram 44 espēcies de scolytidae.

Etanol 50\% foi usado como isca para capturar Scolytidae em floresta de carvalho por MONTGOMERY \& WARGO (1983), e os representantes capturados foram os associados a ărvores quase à morte. Taxas baixas de liberação ( 2 g/dia) do etanol foram mais atrativas que as mais altas. Apesar da acetona e acetaldeído serem formados em plantas pelo me tabolismo oxidativo do etanol, não funcionaram como atraen tes.

GII et alii (1985) relataram que Hylastes. Hylurgus, Orthotomicus e xyleborus foram atraidos pelo etanol. DUNN et alii (1986) capturaram Scolytidae em arma-

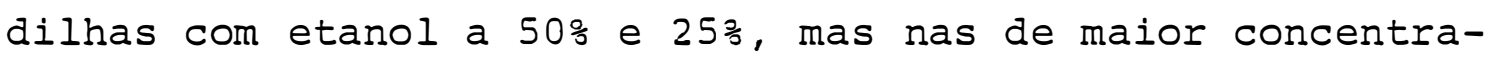
ção a captura foi maior.

$$
\text { Segunco KLIMETZEK et alii (1986), para bescul }
$$

ros da casca e besouros da ambrosia secundzrios, quanto maior a concentração do etanol empregaco, naior a atrativi 
dade. A afirmativa foi confirmada no campo aos besouros da casca Trypodendron lineatum, xyleborus dispar, $x$. saxeseni e Xylosandrus germanus.

CARRANO-MOREIRA (1985) testou o etanol em re florestamentos de pinheiros temperados, e comprovou ser es te uma excelente isca atrativa, demonstrando uma alta efi ciência para as espécies capturadas.

o etanol, além de poder funcionar como um atraente primārio em si, ele pode reagir sinergisticamente com outros produtos voláteis atrativos, tanto primários co mo secundários. Isto foi bem demonstrado por FATZINGER (1985), ao testar a mistura de turpentino e etanol 95\% na captura de 0 . terebrans. O etanol apresentou um efeito cla ramente sinergista, sendo que a mistura capturou 59\% mais individuos que o turpentino isoladamente.

Para Hylurgops palliatus (não possui feromô nio de agregação conhecido) e Trypodendron lineatum (possui feromônio de agregação), o etanol atua sinergisticamen te com a resina do hospedeiro (KIIMETZEK et alii, 1986).

Quando etanol e a-pineno são adicionados a (I) sulcatol, feromônio de Gnathotrichus sulcatus, agem sinergicamente para os machos desta espécie. Isto imitaria provavelmente a resposta de hospedeiros altamente atrativos aos machos pioneiros (BORDEN et alii, 1980). 
KLIMETZEK et alii (1986) crêem que, para as espēcies que dependem de material fresco, mas que são inca pazes de infestar árvores vivas, ocorre um padrão intermediārio, no qual baixas concentrações de etanol aumentam, e altas concentrações de etanol reduzem a atração a compoo nentes do hospedeiro e/ou feromônios. Isto fica claro para Tomicus piniperda e Ips typographus, onde adicionando-se con centrações maiores nos monoterpenos e feromônio destes, res pectivamente, a atração é reduzida. o mesmo é válido para Leperesinus varius, onde somente o etanol a baixa concentração age sinergicamente com exo-brevicomin.

GIL et alii (1985) fizeram uma interessante relação entre o grau de importância do etanol aos scolyti dae e seus hospedeiros. Assim, as espēcies. que não são atraídas pelo etanol são aquelas capazes de vencer a resistência da árvore e colonizā-la. Aquelas atraídas tanto pelo etanol como por material vegetal seriam as capazes de se desenvolver sobre tecidos frescos ou ligeiramente degradados, e aquelas que são atraídas em maior proporção pe lo etanol são as que requerem uma forte degradação vegetal.

KLIMETZEK et alii (1986) sugeriram que uma depencència decrescente pelo etanoi coincide com um aumento na especialização na seleção hospedeira, e classificaram os scolytidae em relação a esta dependência, de modo 
muito semelhante a GIL et alii (1985):

- o etanol representa o principal atraente: são as espécies polifagas, como Xyleborus germanus, Hylecoetus dermestoides.

- o etanol sinergiza odores do hospedeiro: Hylurgops palliatus, Hylurgops spp., Hylas tes spp.

- o etanol sinergiza odores do hospedeiro el lou feromônios: Oryocoetes autographus, Try podendron spp., Gnathotrichus spp.

- o sinergismo depende da dosagem entre etanol, feromônios e/ou odores do hospedeiro: este grupo abrange desde pragas de baixa agressividade (Leperesinus, Tomicus), e possivelmente também os "besouros do turpen tino" (Dendroctonus terebrans, D. valens), até pragas agressivas ( 0 . pseudotsugae).

- o etanol não influi na atração: principais pragas dos besouros da casca, como $D$. frontalis, Ips typographus, que atacam e vencem a resistência de hospedeiros sadios. Para algumas espécies, a resposta do feromônio parece que é reduzida pelo etanol.

Os atraentes, tanto os primärios (relaciona nados a componentes liderados pelas áryores hosoedeinas) 
como os secundārios (feromônios de agregação, liberados pe los scolytidae pioneiros), são estímulados olfativos relacionados principalmente à orientação ao hospedeiro.

Uma vez nas proximidades do hospedeiro, o Scolytidae agora vai proceder à sua seleção, tomando impor tância agora os estímulos visuais, alēm dos olfativos. Assim, fatores como estrutura, cor e espessura da casca, diâ metro do tronco, vitalidade do hospedeiro etc atuam na se leção.

ROIING \& KEARBY (1977) citaram o diâmetro, aspecto e tempo de morte das árvores hospedeiras como exercendo influência na atração de besouros da casca. Monarthrum fasciatum, M. mali, xyleborus ferrugineus;, $x$. saxeseni $e$ x. xylographus, segundo os mesmos, têm preferência por ārvores de maior diâmetro. $X$. celsus tem preferência por diâa metros maiores de troncos, segundo GAGNE \& KEARBY (1978).

Pityogenes bidentatus e $P$. quadridens, segun do GIL et alii (1985), mostraran preferência por ramos, em detrimento de troncos. Os autores analisaram tambēm a influência da cor, e relataram que Ips acuminatus necessitou de um estímulo cromático para pousar na planta hospedeira, e que Hylasites atir e $H$. a.tt2nuatus eram fortemente atraI dos pela cor verde, enquanto que para ohtinotumicus 2hosus, 
a cor mais atraente era a laranja.

Para Trypodendron lineatum (CHAPMAN \& KINGHORN, 1958a; SCHMUTZENHOFER, 1985b), Pityogenes bidentatus e P. quadridens (GIL et alii, 1985), a cor não tem influência na seleção.

CHAPMAN (1972), estudando o número de omatí deos presentes nos scolytidae, concluiu que os olhos compostos destes eram simples, mais que os da maioria dos be souros. Levando em conta que, de modo geral, quanto maior a necessidade e frequência de vôo de um inseto, maior seu número de omatídeos, e que todos os scolytidae ficam a maior parte do seu estágio adulto dentro de tecido hospedeiro, o pequeno número de omatídeos indicaria que estes insetos não dependem da visão no mesmo grau que muitos besouros.

Assim é de se esperar que os estimulos quimi cos (olfativos) sejam os preponderantes também no processo de seleção hospedeira. Isto entra em conflito com a recomendação feita por SCHMUTZENHOFER (1985b), que recomenda o uso de armadilhas negras para a maior eficiência de captura de Ips typographus.

\subsection{Armadilhas}

o controle com sucesso de um surto de uma 
praga depende não somente do método de controle empregado, mas também do conhecimento da situação desta na ārea. Do mesmo modo, um registro contínuo da presença e abundância das espécies secundárias é útil no sentido de se determinar se, quando e onde atingem niveis de danos econômicos (ESTADOS UNIDOS. DEPARTMENT OF AGRICULTURE, 1985). E, para - monitoramento destas populações de Scolytidae, o uso de armadilhas com iscas è altamente recomendável(SCHMUTZENHOFER, $1985 b)$.

De acordo com o princípio de captura, as ar madilhas para capturar Scolytidae podem ser classificadas em armadilhas de pouso, armadilhas de vôo ou impacto e armadilhas combinadas. De modo geral, as armadilhas de pouso e as combinadas são empregadas na captura de certos besou ros da casca e dos besouros da ambrosia do gênero Trupodendron.

As armadilhas de impacto são as mais frequen temente citadas na literatura na captura de scolytidae. A armadilha tipo "janela" ("window trap") foi idealizada por CHAPMAN \& KINGHORN (1958b), e os próprios autores citaram a limitação desta a insetos de corpo leve, que não são ca p̣ turados, além do fato da refilexão da luz do sol na chapa de vidro causar repelância. Desde então, tem sica Erequlente mente usada, na descrição original ou com modificações, em vărios experimentos com scolytiaae (CHAPMAN \& IINGHORN, 
1958a; NIJHOLT \& CHAPMAN, 1968; HOSKING \& KNIGHT, GAGNE \& KEARBY, 1978; TURNBOW \& FRANKLIN, 1980; GIL et alii, 1985).

Armadilhas de aletas tambēm são utilizadas, destacando-se no Brasil os modelos Escolitideo/Curitiba , Marques/Carrano e ESALQ-84 (MONTGOMERY \& WARGO, 1983 ; MARQUES, 1984; CARRANO-MOREIRA, 1985; BERTI Filho \& FLECHTMANN , 1986).

Independente do tipo de amadilina usada ou a es pécie de Scolytidae que se visa capturar, deve-se ater a certas particularidades. Armadilhas instaladas próximas a locais dè criação de besouros, vão capturar individualmente mais scolytidae que armadilhas postadas mais distantes destes locais. Portanto, armadilhas isoladas não podem explicar a variação no número de Scolytidae capturados, hạ vendo a necessidade de um grande número destas, adequadamente distribuidas, para se determinar corretamente as tendêricias populacionais destes insetos (CHAPMAN, 1962; HOSKING \& KNIGHT, 1975).

\section{4. DANOS}

Como refariajo anteriormente, 90\% da mortalidade de ártôres no mundo è caisuada por insetos, $60 \%$ dos quais são atribuicios aos ScoIytidae (NOOD, 1982). De um mo 
do genérico, as principais pragas estão representadas nos grupos dos besouros da casca e besouros da ambrosia.

Dendroctonus frontalis, ocorrente na América do Norte e Central, é considerada uma das principais pragas nos Estados Unidos. Segundo LEUSCHNER (1982), além do impacto primărio causado (morte de árvores), este Scoly tidae causa impactos secundários na floresta, afetando sua hidrologia, estética e recreação. Estima-se que, de 1948 a 1975, mais de 14 milhões de metros cúbicos de madeira de pinos foram mortos no sul dos Estados Unidos, e que num surto no inicio dos anos 60 em Honduras, mais de 55 milhões de metros cúbicos de pinos foram mortos (ESTADOS UNIDOS. DEPARTMENT OF AGRICULTURE, 1985) •

WOOD (1982) estimou as perdas causadas por 0 . brevicomis em mais de 2 milhões de "board feet" ( 1 "board feet" $=30 \times 30 \times 2,5 \mathrm{~cm})$ de madeira em pé por ano, e 0 . ponderosae, 0 . rufipennis, 0 . frontalis e talvez 0 . pseudotsugae sejam responsáveis, cada um, por cerca de $500 \mathrm{mi-}$ lhões de "board feet" perdidos por ano. Outras espécies de Dendroctonus, Scolytus e Ips causam menos, porém significantes perdas em florestas de coniferas.

Como já referido anteriormente, na região tro pical destacam-se mais os besouros da ambrosia, e vai-se dar atenção maior a este grupo de insetos (DEDROSE-VIACEDO, 1984; SCHMUTZENHOFER, 1985a). FOOOD (1982) considera as per 
das econômicas causadas por Scolytidae nas āreas tropicias menores e mais dificeis de serem medidas que nas áreas tem peradas. Estes danos são causados pela destruição de toras após o corte e transmissão de doenças por besouros da am brosia.

Há também os espermófagos, que destroem frutos e sementes, e os danos refletidos na redução de crescí mento e produtividade, causados por mielófagos.

FISHER et alii (1953) dizem que os besouros da ambrosia não são responsáveis primários por morte de ăr vores, e que mesmo nos trópicos não podem ser considerados, de modo geral, como as principais pragas florestais, embora sejam um incômodo constante.

Esta afirmação contrasta com os dados de DOUROJEANNI (1965), que mostram que na região da selva do Peru não há madeira absolutamente imune aos besouros da am brosia, e que a atividade destes insetos é a que mais repercute no desenvolvimento florestal peruano.

Vale a pena mencionar que, fora do âmbito das coniferas, há scolytidae que causam prejuizos econômi cos também. Hypocryphalus mangif́erae é considerado o prin cipal vetor do fungo da seca da mangueira, Ceratocystis jimbriata, o qual também causa a seca do cacaueino, onde xyleborus ferrugineds $e x$. afóinis são considerados os 
principais vetores (LARA \& SHENEFELT, 1965; WOOD, 1982; YAMASHIRO \& MYAZAKI, 1985). Também não pode ser esquecida a broca do café, Hypothenemus hampei, bastante prejudicial ao cafeeiro (WOOD, 1982), e H. obscurus, atacando ponteiros de maniçoba, Manihot glaziovii (BASTOS, 1981). X. ferrugineus e xylosandrus morigerus são consideradas pragas primárias em cacaueiros jovens na Bahia (MILANEz et alii, 1982).

SAMANIEGO \& GARA (1970) consideram que anual mente se perdem quantidades incalculáveis de madeira devido ao ataque dos besouros da ambrosia, dos quais a tribo Xyleborini è a mais importante economicamente nos trópicos (BEAVER, 1976), destacando-se o gênero Xyleborus (KUMAR \& CHANDRA, 1977).

Sua importância econômica advēm da degradação da madeira, sua depreciação devido a manchá-la (intro dução de fungos) e perfurá-la (buracos de galerias), tornando-a imprópria a fins mais nobres (FISHER et alii, 1953; BLETCHLY, 1961; DOUROJEANNI, 1965; KUMAR \& CHANDRA, 1977; NOBUCHI, 1983). PEDROSA-MACEDO (1984) chega a quantificar a depreciação, estimando uma desvalorização de 5 dólares por metro cúbico de madeira bruta apresentando orificios de galerias.

\subsection{SITUACุÃO NO BRASIL}


Em contraste evidente com os paises europeus e da Amērica do Norte, onde hã mais de cem anos se pesquisa os representantes de Scolytidae, no Brasil trabalha-se pouco nesta ărea. Em se tratando especificamente da broca do café, Hypothenemus hampei, e mais recentemente de Hypo cryphalus mangiferae, vetor do fungo da seca da mangueira, e em menor extensão os associados à seca do cacaueiro, mui to pouco se sabe da biologia dos scolytidae que aqui se de senvolvem .

Os trabalhos mais antigos encontrados referem-se geralmente à citação de espécies de scolytidae en contradas sobre seus referidos hospedeiros, tal como pode ser visto em BONDAR (1922), CARVALHO (1938), CARVALHO \& CARVALHO (1939), PICKEL (1939), BONDAR (1940), CARVALHO (1940), CARVALHO, (194I).

Beaver, numa incursão ao Mato Grosso, coleta vărios Scolytidae, relaciona-os a plantas hospedeiras e ci ta aspectos biológicos dos mesmos. Da tribo Bothrosternini encontra 4 espécies, todas secundárias, atacando ramos mortos ou à morte (BEAVER, 1973), e em Xyleborini foram 30 as espécies relatadas, distribuídas em 5 gêneros. A maioria destas espécies era, novamente, secundäria (BEAVER, $1976 a)$

Com o impulso dado pela criação dos incentivos fiscais na segunda metade da cécac̉a de 60 , vastas äræas 
passaram a ser reflorestadas, a maioria delas com espécies exóticas, principalmente pinheiros temperados, pinheiros tropicais e eucaliptos.

Pode-se considerar que estas coniferas não tiveram até agora sérios problemas com pragas. SCHONHERR (1974) ponderou que os reflorestamentos no Brasil eram ain da jovens, e previu que nas próximas gerações os problemas de proteção e prevenção seriam bem maiores. Devido ainda aos reflorestamentos serem jovens, os fatores abióticos de sempenham 0 maior papel (SCHONHERR \& PEDROSA-MACEDO, 1979).

Deve-se ainda levar em conta que estes pinheiros exóticos foram introduzidos em ăreas onde estes não existem naturalmente, e até agora pôde-se evitar a introdução de pragas. Em relação à migração de importantes pragas ocorrentes na América Central, considera-se a floresta amazônica como uma barreira natural. Todos estes fatores levaram a um crescimento dos pinos quase sem a exis tência de pragas (SCHONHERR \& PEDROSA-MACEDO, 1979).

Assim, devido a não haver espécies nativas de Pinus, as espécies de Scolytidae que viessem a ocorrer nas exóticas precisariam vir das folhosas e da araucária nativa (SCHC̈NHERR \& PEDROSA-MACEDO, 1979; SCHONHERR \& PEDROSA-MACEDO, 1981). Os autores relataram que, descie a introdução de Pinus até 1974, das 30 aspécies na época conhecidas de Scolytidae, 14 passaram aos pinos, e considera 
ram que algumas destas viriam ainda a se tornar pragas, num espaço de 20 anos. SCHONHERR (1986) confirma esta progressão, ao listar os scolytidae ocorrentes em Araucaria angustifolia, e observar que a maioria destes ataca também as novas florestas de Pinus taeda e P. elliottii no Paraná.

Os trabalhos com scolytidae permitem mostrar que ocorreu um constante incremento de suas espécies nos reflorestamentos brasileiros, e que a densidade populacional de algumas espécies é consideravelmente maior do que hã 12 anos. Dos trabalhos iniciais, relacionando-se as pou cas espécies de scolytidae ocorrentes nas espécies exóticas (PINHEIRO, 1962; BERTI Filho, 1979; SCHÖNHERR \& PEDROSA-MACEDO, 1981), chega-se a dados de 115 espécies ocorren tes em reflorestamentos no sul e sudeste do Brasil (SCHON HERR, 1985) .

Nos anos 80 surgem trabalhos mais complexos, testando-se armadilhas de captura de scolytidae, fazendo-se flutuações populacionais e correlacionando-as a fatores bióticos e abióticos, anălises faunisticas e listagens de espécies ocorrentes de Scolytidae (MARQUES, 1984; PEDRO SA-MACEDO, 1984; PEDROSA-MACEDO, 1985; CARRANO-WOREIRA, 1985). 


\section{MATERIAL E MÉTODOS}

a) Localização e caracterização da área de pesquisa

O presente trabalho foi conduzido na Freuden berg Agroflorestal, localizada no município de Agudos, São Paulo. Agudos está posicionado a uma latitude de $22^{\circ} 29^{\prime}$ Sul e longitude de $48^{\circ} 59^{\prime}$ Oeste, estando a uma altitude de $594 \mathrm{~m}$.

Segundo a classificação de köppen, Agudos pertence à classe climatológica Cwa, caracterizada por apresentar um tipo climatológico quente, com inverno seco. A precipitação pluviométrica anual média é de $1300 \mathrm{~mm}$, sendo esta concentrada $75 \%$ no periodo de outubro a março. A temperatura anual média è de $21,1^{\circ} \mathrm{C}$, sendo de $18,6^{\circ} \mathrm{C}$ no in verno e $23,3^{\circ} \mathrm{C}$ no verão.

A vegetação natural antigamente prevalecente no local era a do tipo cerrado.

o experimento foi conduzido em 5 talhões dis tintos, reflorestados com pinhecros tropicais, cujas principais caracteristicas estão condensadas na Tabela 1. 
b) Metodologia da pesquisa

$$
\text { Procurou-se determinar, neste experimento, }
$$

aspectos relativos à altura de vôo desenvolvida por representantes da familia scolytidae. Para tanto, empregou-se a armadilha modelo ESALQ-84 (BERTI Filho \& FLECHMANN, 1986), iscada com etanol puro para análise.

Foram usadas 4 alturas distintas* de armadi lhas, ou seja: a $40,60,80$ e $100 \mathrm{~cm}$, sendo estas alturas referentes à distância do solo à boca do funil coletor. Estas armadilhas funcionaram em conjunto, sendo que um conjunto tinha a disposição de um quadrado de $25 \mathrm{~m}$ de lado. Em cada vértice do quadrado havia uma armadilha, cada uma com uma das alturas anteriormente citadas.

A disposição destes conjuntos de armadilhas foi aleatória, de modo tal a cobrir o melhor possivel os talhões usados no experimento. Os conjuntos distaram $100 \mathrm{~m}$ dos carreadores, e foram em número de 14 no talhão I, 5 no talhão II, 8 no talhão III, 9 no talhão IV e 11 no talhão $V$, perfazendo um total de 188 armadilhas.

* estas alturas foram baseadas na altura mäxima reccmendada por pedro sa-Maceco (iñoomaçäo হesscal), que foi de 1,00 m co solo. 
As coletas foram iniciadas em abril de 1984, encerrando-se em março de 1987. Sua frequência foi semanal, e o material capturado contido no recipiente coletor (contendo água e álcooll enviado ao Departamento de Entomologia da ESALQ/USP, para identificação. O volume volatilizado de etanol no campo era reposto na mesma data em que se faziam as coletas, que perduraram por 3 anos.

A identificação dos scolytidae capturados foi feita através de comparação direta com os exemplares da co leção Schönherr/Pedrosa, depositada no Laboratōrio de Proteção Florestal da Universidade Federal do Paraná, e que tem por base a coleção de Schedl (Viena). Para tanto, contou-se com a inestimável colaboração do Prof. Dr. José Henrique Pedrosa-Macedo.

\section{c) Análise dos dados}

Como mencionado anteriormente, as coletas fo ram realizadas semanalmente, mas para efeito de maior faci lidade em se trabalhar com tal volume de dados, estes foram agrupados em meses.

Para a análise da variável altura, foram selecionadas as 30 espécies mais freqüentes de scolytidae identificadas até o nível de gônero e espécie. Devido ao 
to dos dados de captura mensal terem uma distribuição bino mial, e por existirem dados de valor zero, estes foram trans formados em $\sqrt{x+0,5}$.

A variāvel altura foi analisada em combinação com as variāveis anos (ano 1: 1984-1985, ano 2: 1985-1986, ano 3: 1986-1987), talhões (I, II, III, IV e V; Tabela 1) e estações, para as 30 espécies selecionadas. Por ser o Brasil um país de clima tropical, onde as 4 estações tradicionais (primavera, verão, outono e inverno) não apre sentars uma diferenciação bem nitida, dividiu-se o ano em duas estações, somente. A estação Priver, correspondente aos meses de outubro a março, caracterizaria a estação quen te e chuvosa, enquanto que a estação Outinv, correspondente aos meses de abril a setembro, caracterizaria a estação fria e seca.

Os dados de captura, devidamente transformados, foram comparados, para as diversas variāveis, através da anälise de variância e teste de Tukey, ao nível de 1\% e 5\% de probabilidade. 


\section{RESULTADOS E DISCUSSÃO}

\subsection{Scolytidae capturados}

No período de 3 anos em que durou 0 experimento, foram capturadas 85 espécies distintas de scolytidae, e destas foi possivel a identificação de 57, a maioria até o nivel de espécie. Comprovounse que haviam representantes das duas sub-familias, distribuídas em 6 tribos.

a) Sub-familia Hylesininae Erichson, 1836

Nesta sub-familia só foram capturados representantes da tribo Bothrosternini Blandford, 1896. Segundo WOOD (1982), estes são representados por espécies monógamas, sendo que a maioria das espécies broqueia a medula de galhos e pequenos ramos (mielófagos). As espécies captu radas e identificadas foram:

- Cnzsinus dougraphus sched1, 1951

- Cnesinus nova-teutonicus Schedl, 1951

- Cnesinus soo. (2 espécies) 
b) Sub-familia Scolytinae Latreille, 1807 .

Aqui encontra-se a maioria dos Scolytidae cap turados nas armadilhas de etanol nos pinheiros tropicais na região de Agudos (SP).

\section{$\left.b_{1}\right)$ Tribo Corthylini Leconte, 1876}

Os representantes desta tribo caracterizam -se por serem monófagos e apresentarem poligamia heterossangrinea. A sub-tribo Pityophthorina (Äraptus, Pityophthorus) inclui espécies fleófagas e espermófagas, enquanto que a sub-tribo Corthylina (Amphicranus, Corthylocurus, Cor thylus, Metacorthylus, Microcorthylus, Monarthrum, Tricolus) inclui espécies xilomicetófagas, onde fungos são o principal alimento (WOOD, 1982).

As espécies capturadas e identificadas foram:

- Amphicranus rasilis Schedl, 1950

- Amphicranus sp.

- Araptus alt2r (Eggers, 1931)

Araptus punctatissimus (Schedl, 1938)

- Araptus sp.

- Conthurocurus vernacurus 
- Corthylus convexicauda Eggers, 1931

- Corthylus spp. ( 2 espécies)

- Metacorthylus sp.

- Microcorthylus minimus Schedl, 1950

- Monarthrum brasiliensis Schedl, 1936

- Monarthrum minimum

- Monarthrum semipallens Schedl, 1954

- Pityophthorus sp.

- Tricolus subincisuralis Schedl, 1939

- Tricolus sp.

\section{$\mathrm{b}_{2}$ ) Tribo Cryphalini Lindemann, 1876}

Os Scolytidae desta tribo são todos monófagos, tendo como hábitos alimentares a fleofagia ou mielofa gia. A reprodução é por poligamia consangllínea e partenogê nese arrenótoca (WOOD, 1982).

As espécies capturadas e identificadas foram:

- Cryptocarenus diadematus Eggers, 1937

- Cryptocarenus heveae (Hagedorn, 1912)

- Cryptocarenus seriatus Eggers, 1933

- Cryptocarenus spp. (2 espécies)

- Hupocruphazus manginzrae (Stedoing, 1914) 
- Hypothenemus bolivianus (Eggers, 1931)

- Hypothenemus eruditus Westwood, 1836

- Hypothenemus hampei (Ferrari, 1867)

- Hypothenemus obscurus (Fabricius, 1801)

- Hypothenemus spp. (2 espécies)

$\mathrm{b}_{3}$ ) Tribo Dryocoetini Lindemann, 1876

Estes são todos polígamos, e o gênero coccotrypes tem representantes fleófagos e espermófagos. Neste gênero, a reprodução é do tipo poligamia consangưinea (WOOD, 1982) .

As espécies capturadas e identificadas foram :

- Coccotrypes carpophagus (Hornung, 1842)

- Coccotrypes palmarum Eggers, 1933

$\mathrm{b}_{4}$ ) Tribo Micracini Leconte, 1876

O material de criação destes Scolytidae são ramos pequenos e galhos de arbustos e ce árvores de madeira dura. Há espécies que são monógamas e fleósagas, e aquelas que são xilóĩagas e bigamas, como em Hulucunus (ncCD, 
$1982)$.

$$
\text { As espécies capturadas e identificadas fo- }
$$

ram:

- Hylocurus subgranulatus Schedl, 1954

- Hylocurus sp.

$b_{5}$ ) Tribo Xyleborini LeConte, 1876

Todos os representantes desta tribo são xilo micetöfagos e de poligamia consangulinea. Tanto os insetos adultos como as larvas alimentam-se de fungos simbióticos (WOOD, 1982).

As espécies capturadas e identificadas foram:

- Premnobius cavipennis Eichhoff, 1867

- Sampsonius dampfi Schedl, 1940

- Xyleborus afrinis Eichhoff, 1868

- Xyleborus biconicus Eggers, 1928

- Xyleborus biseriatus Schedl, 1963

- Xyleborus coccotrypoides Eggers, 1943

- Xyleborus ferruginzus Fabricius, 1801

- Kyleborus gracizis Eichhof , 1868

- Xyleborus hagedorni Iglesias, 1914

- Xur2borus iniricaids schedl, 1949 
, 46 .

- Xyleborus linearicollis Schedl, 1938

- Xyleborus neivai Eggers, 1928

- Xyleborus obliquus (LeConte, 1878)

- Xyleborus obtusitruncatus Schedl, 1949

- Xyleborus retusus Eichhoff, 1868

- Xyleborus sentosus Eichhoff, 1868

- Xyleborus solitarius Hagedorn, 1905

- Xyleborus spinulosus Blandford, 1898

- Xyleborus tolimanus Eggers, 1928

- Xyleborus sp.

Pela relação anteriormente mostrada dos Scolytidae capturados em armadilhas iscadas com etanol, fica clara a predominância das espécies denominadas de besouros da ambrosia (xilomicetófagos), concordando plenamente com dados existentes na literatura, dizendo ser este o grupo mais importante em regiōes tropicais (BRIGHT Jr., 1968; GRAY, 1974; BEAVER, 1976a; CARRANO-MOREIRA， 1985; PEDROSA-MACEDO, 1985; ATKINSON \& EQUIHUA-MARTINEZ, 1986).

A literatura mostra também que a maioria des tas espécies capturadas é polifaga (WOOD, 1982), e que geralmente ataca ărvores mortas ou à morte. Isto entra em concordância com associaçōes felitas por GII et ali̇ (1985) e KLIMETZEK et alii (1986), relatando ser o etarol o princi pal atraente a Scolytidae com tais caracteristicas. 
Esta predominância por espécies xilomicetófa gas não é só quanto ao número de espécies, mas também quan to ao número de individuos capturados (Tabelas 14 a 17), destacando-se o gênero xyleborus, com $x$. affinis e $x$. spinulosus como as espécies mais capturadas. Das espécies mie lófagas destaca-se o gênero Hypothenemus, com a espécie H. eruditus como a mais capturada deste grupo, e uma das mais freqtântes espécies de Scolytidae capturadas (Tabelas 14 a 17).

Este grande número de espécies capturadas, bem como sua quantidade (Tabela 19), indica ser o etanol um excelente atraente primário também para as condições de plantios de pinheiros tropicais na região de Agudos (SP), dados estes semelhantes aos obtidos por MARQUES (1984) e CARRANO-MOREIRA (1985) em Dinheiros temperados no Brasil.

\subsection{Altura de vôo}

Para maior facilidade de exposição dos resul tados, será feita uma análise por espécie das variáveis re lacionaças à altura de vôo. 


\subsubsection{Espécie Xyleborus retusus.}

Esta espécie demonstrou, para os 3 anos do experimento, uma captura tanto maior quanto maior a altura da armadilha (Tabelas 2 a 5 ). Vale a pena comentar que as variāveis climatológicas medidas (temperatura, umidade relativa e precipitação pluviométrical foram também homogêneas ao longo destes 3 anos (Apêndices 19, 21 e 23).

Esta preferência pela maior altura de vōo $(100$ cm) foi mantida tanto para a estação Priver como para a es tação Outinv (Tabelas 6 a 13), mesmo com as variáveis climatológicas analisadas para estas estações terem sido bem distintas (Apêndices 20, 22 e 24). Isto sugere que esțas variáveis não influenciaram no comportamento de vôo desta espécie.

$X$. retusus foi mais capturado nos talhões I e II, e o talhão menos atacado foi $\circ \mathrm{V}$ (Tabelas 14 a 17.).

Os valores minimos e máximos das variáveis a cima citadas encontram-se nos Apēndices 1 a 16 .

\subsubsection{Escécie Xuzeborus hagedonni}

Embora estatisticamente não houvesse uma diferenciação entre as alturas testacas, observou-se a ten- 
dência desta espécie de voar nas alturas superiores $(100$ e $80 \mathrm{~cm}$, Tabelas 2 a 5$)$.

Também não houve uma diferenciação estatístị ca para as duas estações analisadas em relação à altura de vôo, embora a tendência por alturas superiores tivesse sido mantida para as mesmas (Tabelas 6 a 13).

Os talhões onde $X$. hagedorni foi capturadoem maior quantidade foram os III e IV, e nos talhões I e II a captura foi menor (Tabelas 14 a 17).

Os valores minimos e máximos das variáveis acima citadas encontram-se nos Apêndices 1 a 16.

\subsubsection{Espécie Xyleborus ajbinis.}

Notou-se claraniente, em todos os anos de pes quisa, a preferência progressiva pelas alturas inferiores, sendo que a de $40 \mathrm{~cm}$ de altura foi a que mais capturou individuos desta espécie (Tabelas 2 a 5). O mesmo foi observado para as duas estações analisadas (Tabelas 6 a 13).

Nos talhões I e II esta espécie foi mais cap turada, sendo o taliño III o menos atacado (Tabelas 14 a $17)$

Os valores mínimos e máximos das variáveis a cima citadas encontram-se nos Apêndices 1 a 16. 


\subsubsection{Espécie Xyleborus ferrugineus}

O comportamento de vôo desta espécie seguiu - da anterior, e a altura de vôo foi igualmente não afetada pelas estações do ano (Tabelas 2 a 13).

Os talhões onde $x$. ferrugineus foi mais capturado foram os I e V, enquanto que no talhão III a captura foi a menor (Tabelas 14 a 17).

Os valores mínimos e máximos das variáveis a cima citadas encontram-se nos Apêndices 1 a 16 .

\subsubsection{Espécie Xyleborus spinulosus}

As alturas de 80 e $100 \mathrm{~cm}$ da armadilha de etanol apresentaram os maiores valores de captura desta espécie, enquanto a alturas inferiores $(40$ e $60 \mathrm{~cm})$, os meno res valores (Tabelas 2 a 5 ). Esta relação manteve-se também para as duas estações analisadas, durante os 3 anos da pesquisa (Tabelas 6 a 13 ).

$x$. spinulosus foi mais capturaco no talhão IV, sendo menos capturacin nos talhões I e III (Tabelas 14 a 17).

Os valores minimos e mürimos das variäveis acima citadas encontram-se nos Apêncices 1 a 16 , 


\subsubsection{Espécie Premnobius cavipennis}

Esta espécie não mostrou, para nenhum dos 3 anos do experimento, preferência por qualquer das alturas testadas (Tabelas 2 a 5 ). Porèm, na análise por estação, na estação outinv houve uma diferenciação estatistica, havendo a preferência por voar mais nas alturas superiores, de 100 a $80 \mathrm{~cm}$ (Tabelas 10 a 13). Isto não se repetiu para a estação Priver, não havendo nesta preferência por altura de vôo (Tabelas 6 a 9 ).

Os talhões IV, $V$ e II são onde $P$. cavipennis foi mais capturado, e os talhões I e III onde a captura foi menor (Tabelas 14 a 17).

Os valores minimos e máximos das variáveis a cima citadas encontrammse nos Apêndices 1 a 16 .

\subsubsection{Xyleborus gracilis}

X. gracilis teve maior preferência pelas alturas inferiores $(40$ e $60 \mathrm{~cm})$, sendo que esta tendência se manteve uniforme nos 3 anos de pesquisa (Tabelas 2 a 5).

A preferência de voar nas alturas inferiores se repetiu para as estações priver e Outinv (Tabelas $\sigma$ a $13)$. 
Esta espēcie foi mais capturada nos talhões IV e III, e menos capturada nos talhões I, II e V (Tabelas 14 a 17) .

Os valores minimos e māximos das variāveis a cima citadas encontram-se nos Apêndices 1 a 16 .

4.2.8. Espécie Xyleborus linearicollis.

Esta espécie não mostrou preferência porqual quer das alturas testadas em nenhum dos 3 anos do experimento, o mesmo se repetindo para as duas estações analisadas (Tabelas 2 a 13).

$x$. linearicollis foi mais capturado no taIhão I e menos capturado nos talhões III e IV (Tabelas 14 a 17) .

Os valores mínimos e máximos das variáveis a cima citadas encontram-se nos Apêndices 1 a 16.

4.2.9. Espécie Xuleborus obliauus.

A preferēncia pelas alturas superiores 1100 e $80 \mathrm{~cm}$ ) se manifestou claramente (Tabelas 2 a 5). Na anälise por estações, não houve dijerenciação estatistica pa- 
ra a estação Outinv (apenas uma tendēncia para as alturas superiores), mas para a estação Priver esta ocorreu, haven do preferência pelas alturas superiores (Tabelas 6 a 13). Esta espécie foi mais capturada nos talhões IV e V, e menos capturada no talhão II (Tabelas 14 a 17). Os valores mínimos e máximos das variáveis a cima citadas encontram-se nos Apēndices 1 a 16 .

\subsubsection{Espécie Hypothenemus bolivianus}

As alturas inferiores $(40$ e $60 \mathrm{~cm}$ ) foram as mais preferidas de vōo desta espécie (Tabelas 2 a 5), preferēncia esta mantida para a estação Priver (Tabelas 6 a 9), ao longo dos 3 anos do experimento, Para a estação Out inv " não houve diferença estatistica, embora em termos numéricos houvesse também maior captura nas alturas inferiores (Tabelas 6 a 13 ).

o talhão $\mathrm{V}$ foi o mais atacado pela espécie, e os talhões I, II, III e IV os menos atacados (Tabelas 14 a 17 ).

Os valores minimos e máximos das variáveis a cima citadas encontram-se nos Apêndices 1 a 16. 
4.2.11. Espécie Hypothenemus obscurus

Em termos estatisticos nao houve uma preferência de altura de vôo para esta espécie, embora em termos numéricos a preferência pelas alturas inferiores $140 \mathrm{e}$ $60 \mathrm{~cm}$ ) fosse manifestada (Tabelas 2 a 5 ).

Para a estação Priver houve diferenciação es tatistica, manifestando-se a preferência de vôo nas alturas inferiores (Tabelas 6 a 9), o mesmo não ocorrendo para a estação Outinv, onde não houve preferência.

o talhão I foi o mais atacado, e os talhões II e III os menos atacados (Tabelas 14 a 17).

os valores minimos e máximos das variáveis a cima citadas encontram-se nos Apêndices 1 a 16.

\subsubsection{Espécie Hypothenemus eruditus}

A altura de $100 \mathrm{~cm}$ foi a que apresentou maior captura, ao longo dos 3 anos de pesquisa (Tabelas 2 a 5). Já entre as estações isto não se expressou tão nitidamente, sendo que para a estação Priver a oreferência foi pelo conjunto de alturas superiores $(100,80$ e $60 \mathrm{~cm}$; Tabelas 6 a 9). Para a estação Outinv não liuuve diferenciação estatística entre as alturas, embora em termos numéricos a al- 
tura de $100 \mathrm{~cm}$ tivesse sido a preferida (Tabelas 10 a 13). H. eruditus foi mais capturado nos talhões III e IV, e menos capturado nos talhões I e V (Tabelas 14 a 17).

Os valores minimos e máximos das variáveis acima citadas encontram-se nos Apêndices 1 a 16 .

\subsubsection{Espécie Corthylus sp.1}

Não houve diferenciação estatistica para esta espécie, embora em termos numéricos fosse mais capturada em armadilhas de $100 \mathrm{~cm}$ de altura, para os 3 anos de pesquisa (Tabelas 2 a 5 ). Para as estações analisadas, não houve também diferenciação estatistica entre as alturas (Tabelas 6 a 13 ).

Esta espécie foi mais capturada no talhão $V$, e menos capturada nos talhões I, II e III (Tabelas 14 a 17) .

Os valores minimos e máximos das variáveis a cima citadas encontram-se nos Apêndices 1 a 16 . 
4.2.14. Espécie Cryptocarenus heveae

Esta espécie apresentou preferência por voar,

nos 3 anos do experimento, nas alturas superiores $(100$ e $80 \mathrm{~cm}$; Tabelas 2 a. 5). Quando analisada esta preferência por estações, não houve diferenças estatisticas, embora em termos numéricos na estação Outinv houvesse preferência pe las alturas superiores (Tabelas 6 a 13 ).

C. heveae foi mais capturado no talhão I, e menos capturado nos talhões III e IV (Tabelas 14 a 17).

Os valores mínimos e máximos das variäveis a cima citadas encontram-se nos Apêndices 1 a 16 .

4.2.15. Espécie Cryptocarenus diadematus.

O padrão de vôo desta espécie foi intermediā rio, sendo menos capturado somente na altura mais inferior, a de $40 \mathrm{~cm}$ (Tabelas 2 a 5 ). Esta preferência se repetiu para as duas estações analisadas, embora somente em termos numéricos (Tabelas 6 a 13 ).

A captura cesta espécie foi maior nos talhöes II e $V$, e menor nos talhöes I, III e IV (Tabelas 14 a 17 ).

$$
\text { Os valores minimos a mäximos das variáveis }
$$


acima citadas encontram-se nos Apêndices 1 a 16 .

\subsubsection{Espéciè Xyleborus biseriatus}

Para os 3 anos de pesquisa, a preferência foi manifestada para as alturas inferiores $(40$ e $60 \mathrm{~cm})$ de vôo (Tabelas 2 a 5 ). Esta preferencia se repetiu para as duas estações analisadas, embora somente em termos numéricos, não estatisticos (Tabelas 6 a 13 ).

Para o ano 1 (1984-1985), embora a análise de variância indicasse que havia, ao nivel de 1\% de probabilidade, diferença entre as médias de captura desta espécie para a estação Outinv, o teste de Tukey não foi suficientemente sensivel para mostrar estas diferenças (Tabela 11).

Os talhões II e $V$ apresentaram maior captura desta espécie, e o talhão I a menor captura (Tabelas 14 a $17)$.

Os valores minimos e máximos das variāveis acima citadas encontram-se nos Apêndices 1 a 16 . 


\subsubsection{Espécie Xyleborus tolimanus}

A preferência de altura de vôo desta espécie manifestou-se para as alturas inferiores $(40$ e $60 \mathrm{~cm})$, durante os 3 anos do experimento (Tabelas 2 a 5 ). Esta se manteve para as estações analisadas, embora somente em ter mos numéricos (Tabelas 6 a 13).

Para o ano 1 (1984-1985), embora a análise de variância indicasse que havia, ao nivel de 5\% de probabilidade, diferença entre as médias de captura desta espécie para a estação Outinv, o teste de Tukey não foi suficientemente sensivel para mostrar estas diferenças (Tabela 11).

A maior captura de $x$. tolimanus deu-se nos talhões I e II, e a menor nos talhões $V$ e III (Tabelas 14 a 17).

Os valores minimos e máximos das variáveis acima citadas encontrammse nos Apêndices 1 a 16 .

\subsubsection{Espécie Corthulocurus vernaculus}

A anālise de preferência de vôo para caca um dos 3 anos do experimento individualmente não mostrou dife renciação estatistica para nenhuma das alturas testadas 
(Tabelas 3 a 5), embora na análise dos 3 anos conjuntamente houvesse uma preferência pelas alturas de 100 e $80 \mathrm{~cm}$ (Tabela 2).

A mesma análise por estações não mostrou diferenciação estatística, embora houvesse uma tendência da espécie em voar preferencialmente mais alto, também (Tabelas 6 a 13).

Para a altura de $80 \mathrm{~cm}$ da armadilha de etanol, embora a análise de variância indicasse que havia diferença, ao nivel de 5\% de probabilidade, entre as médias de captura desta espécie entre os talhões, o teste de Tukey não foi suficientemente sensivel para mostrar estas di ferenças (Tabela 16).

C. vernaculus foi mais capturado no talhão IV, e menos capturado nos talhões I, II e III (Tabelas 14 a 17 ).

Os valores minimos e máximos das variáveis acima citadas encontram-se nos Apêndices 1 a 16 .

4.2.19. Espécie Cruptocarenus sp.1

Esta espécie não mostrou preferência por nenhuma das alturas testacas durante os 3 anos do experimento (Tabelas 2 a j), o mesmo se repetindo quanco a anjise 
foi feita por estações (Tabelas 6 a 13 ).

A espécie em questão foi mais capturada no talhão II, e menos capturada nos talhões III e $V$ (Tabelas 14 a 17).

Os valores minimos e máximos das variäveis acima citadas encontrammse nos Apêndices 1 a 16 .

\section{2,20. Espēcie Cryptocarenus $s p \cdot 2$}

A preferência de altura de voo desta espécie foi pelas alturas superiores $(80$ e $100 \mathrm{~cm})$ ao longo dos 3 anos do experimento (Tabelas 2 a 5 ).

Embora não diferindo estatisticamente, em termos numéricos a preferência de altura de vôo para as es tações Priver e outinv foi também pelas alturas superiores (Tabelas 6 a 13).

Esta espécie foi mais capturada nos talhões I e IV, e menos capturada nos talhões II e III (Tabelas 14 a 17 ).

Os valores minimos e máximos das variáveis a cima citadas encontram-se nos Apendices 1 a 16 . 


\subsubsection{Espécie Cnesinus nova-teutonicus}

Não houve preferência de altura de vôo, sendo esta espécie igualmente capturada em qualquer das alturas de armadilhas testadas (Tabelas 2 a 5), o mesmo se repetindo quando feita a análise por estações (Tabelas 6 a 13)

O talhão V apresentou maior captura desta es pécie, e os talhões I, II e IV as menores capturas (Tabelas 14 a 17).

Os valores mínimos e māximos das variáveis a cima citadas encontram-se nos Apêndices 1 a 16.

\subsubsection{Espécie Cryptocarenus seriatus}

Não houve diferenciação estatística para qual quer das alturas testadas para esta espécie ao longo dos 3 anos do experimento (Tabelas 2 a 5), o mesmo valendo para as estações analisadas (Tabelas 6 a 13).

A captura foi maior no talhão I e menor nos talhões III e IV (Tabelas 14 a 17).

Os valores minimos e máximos cas variáreis a cima citadas encontram-se nos Apêndices 1 a 16 . 
4.2.23. Espécie Tricolus subincisuralis

Embora na análise de preferência de altura de vôo para cada ano, individualmente, não houvesse uma diferença estatistica (Tabelas 3 a 5), a análise global dos 3 anos (Tabela 2) mostrou uma preferência para a altura de $60 \mathrm{~cm}$.

A anālise por estações não mostrou diferenciação estatistica por nenhuma das alturas testadas (Tabelas 6 a 13).

o talhão II foi o mais atacaco e os talhões I e IV os menos atacados por esta espécie (Tabelas 14 a 17) .

Os valores minimos e máximos das variáveis a cima citadas encontram-se nos Apêndices 1 a 16 .

\subsubsection{Espécie Cnesinus drurographus.}

Esta espécie não apresentou preferência de altura de vôo para qualquer das alturas testadas (Tabelas 2 a 5), o mesmo valendo quando analisadas as alturas nas estações (Tabelas 6 a 13), para os 3 anos de experimento.

A maior captura deurse nos talhões IV e $V$ e a menor no talnão I (Tabelas 14 a 17). 
os valores minimos e máximos das variáveis a cima citadas encontram-se nos Apêndices 1 a 16 .

\subsubsection{Espécie Xyleborus solitarius.}

Nas alturas superiores $(100$ e $80 \mathrm{~cm})$ de arma dilhas a captura foi maior (Tabelas 2 a 5 ), o mesmo se sucedendo para a estação Outinv (Tabelas 10 a 13). Já para a estação Priver não houve diferenciação estatistica, embora numericamente a captura também tivesse sido maior nas altü ras superiores (Tabelas 6 a 9 ).

Convém ressaltar que, para $\circ$ ano 2 (1985-1986), estação Priver, a análise de variância indicou que havia diferença estatistica ao nível de 5\% de probabilidade entre as alturas, embora o teste de Tukey não fosse su ficientemente sensivel para acusar estas diferenças (Tabela 8).

Esta espécie teve uma captura praticamente 느 niforme em todos os talhões, sendo que no talhão II foi me nos capturada (Tabelas 14 a 17).

os valores mínimos e máximos das variäreis a cima citadas encontram-se nos Apêndices 1 a 16 . 
.64

4.2.26. Espécie Microcorthylus minimus

Para os 3 anos do experimento analisados hou ve apenas uma tendência por uma preferência de vôo pela al tura de $100 \mathrm{~cm}$, tendência esta comprovada estatisticamente quando feita uma análise conjunta dos 3 anos (Tabelas 2 a 5 ).

Nas duas estações analisadas houve também a penas uma tendência para a altura de $100 \mathrm{~cm}$ (Tabelas 6 a 13), embora para a estação Outinv, no ano 3 (1986-1987), as alturas de 100 e $80 \mathrm{~cm}$ tivessem se diferenciado estatisticamente das demais.

Os talhöes onde mais se capturou $M$. minimus foram IV e V, sendo que a captura foi menor nos talhões I, II e III (Tabelas 14 a 17).

os valores mínimos e máximos das variáveis a cima citadas encontram-se nos Apēndices 1 a 16 .

4.2.27. Espécie Corthylus sp.2

Não houve diferenciação estatistica para qual quer dos 3 anos do experimento nas alturas analisadas (Tabelas 3 a 5), embora uma anälisa conjunta dos 3 anos (Tabe la 2) mostrasse uma tencēncia da espécie em voar preferen- 
cialmente nas alturas superiores $(80$ e $100 \mathrm{~cm})$, tendência esta igual à observada para a análise das alturas nas duas estações (Tabelas 6 a 13), embora igualmente sem diferenciação estatística.

Só para a altura de $100 \mathrm{~cm}$ da armadilha de $\underline{e}$ tanol (Tabela 17) houve uma diferenciação no número de indivíduos desta espécie capturados entre talhões, sendo neste caso o talhão II o mais atacado. Para as demais alturas, não houve diferenciação estatistica (Tabelas 14 a 16).

os valores minimos e máximos das variáveis a cima citadas encontram-se nos Apêndices 1 a 16 .

\subsubsection{Espécie xyleborus intricatus}

Também para esta espécie nao houve diferença estatistica para qualquer das alturas avaliadas (Tabelas 2 a 5), o mesmo se repetinco quando a análise foi feita para as duas estações, para cada ano individualmente (Tabelas 7 a 9 e 11 a 13), embora a análise global dos 3 anos para as duas estações (Tabelas 6 a 10 ) mostrasse valores numéricos maiores nas alturas superiores $(100$ e $80 \mathrm{~cm})$.

$x$. intricatus foi igualmente capturado em todos os talhões, que não aifferiram estatisticamente entra si (Tabelas 14 a 17). 
Os valores mínimos e máximos das variáveis a cima citadas encontram-se nos Apêndices 1 a 16.

\subsubsection{Espécie Monarthrum semipallens}

Nenhuma das alturas testadas diferiu estatis ticamente para os 3 anos do experimento (Tabelas 2 a 5), e tambēm para as duas estações analisadas (Tabelas 6 a 13).

o talhão III apresentou a maior captura para esta espécie, sendo os outros talhões igualmente menos ata cados (Tabelas 14 a 17).

Para a altura de $40 \mathrm{~cm}$ da armadilha de etanol, embora a anālise de variāncia indicasse que havia diferença, ao nivel de 5\% de probabilidade, entre as médias de captura desta espécie entre os talhões, o teste de Tukey não foi suficientemente sensivel para mostrar estas di ferenças (Tabela 14).

Os valores minimos e mäximos das variāveis a cima citadas encontram-se nos Apêndices 1 a 16 .

\subsubsection{Espécie Cortihylus convexicauda}


te houvesse diferenciação estatística entre as alturas (Tâ belas 3 a 5), a análise conjunta dos 3 anos mostrou uma diferença estatistica preferencial para as alturas superiores $(100$ e $80 \mathrm{~cm}$; Tabela 2$)$.

Para a análise dentro de estações, não houve diferença estatistica entre as alturas (Tabelas 6 a 13).

A maior captura deu-se nos talhões IV e $V$, e a menor nos talhões I e II (Tabelas 14 a 17).

Os valores minimos e máximos das variáveis a cima citadas encontram-se nos Apêndices 1 a 16.

Após a variável altura ter sido analisada pa ra cada uma das trinta espécies em questão, algumas tendên cias puderam ser observadas.

Em relação à altura de vôo das espécies de Scolytidae durante os 3 anos do experimento, pôde-se constatar que houve espécies que voaram preferencialmente mais alto, outras que voaram preferencialmente mais baixo e tam bém aquelas que não tiveram preferência por qualquer das alturas usadas no experimento.

- Eato de haver espéries que foram mais co letadas quanto maior a altura da armadilha, sugere que estas poderiam voar a alturas superiores à mäxima usada, demandando experimentos complementares, para verizicar a ve- 
racidade desta hipótese. Quanto às espécies que não apresentaram preferência por qualquer das alturas testadas, is to poderia também indicar que esta poderia ocorrer a alturas superiores às usadas.

De modo geral, o comportamento de vôo das espécies analisadas, em relação à altura, foi uniforme ao longo dos 3 anos do experimento (Tabelas 3 a 5 ). Isto pode ria ser atribuído, sem dúvida, à pouca oscilação observada nas variáveis climatológicas registradas (Apêndices 19, 21 e 23).

Outro ponto levantado foi verificar se, de acordo com a estação, um determinado scolytidae alterava ou não sua altura preferencial de vôo. Aqui os Scolytidae analisados poderiam ser divididos em dois grupos.

Ao primeiro grupo pertenceriam as espécies xyleborus retusus, $x$. affinis, $x$. ferrugineus, $x$. spinulosus $e X$. gracilis. Estas se caracterizariam por apresentar igual comportamento para as duas estações do ano analisadas (Tabelas 6 a 13). X. retusus, por exemplo, voou preferencialmente mais alto na estação Outinv, o mesmo se dando para a estação Priver. Para estas espécies, assim, as variāveis climatológicas, que foram aistintas para as duas estações (Apêndices 20,22 e 24 ), não influenciaram na altura preferencial de vôo.

Ao segundo grupo pertenceriam as espécies 
Premnobius cavipennis, xyleborus solitarius, $x$. obliquus, Hypothenemus bolivianus, H. obscurus e H. eruditus. Para estas espécies houve influência das condições climáticas locais (Apêndices 20, 22 e 24), com a altura preferencial de vôo variando de acordo com a estação. Para as duas primeiras espécies houve diferenciação estatística para a estação Outinv, e para as demais esta ocorreu na estação Priver (Tabelas 6 a 13). Para as outras estações, não houve diferenciação estatistica entre as alturas.

Mas, tanto para o primeiro como para o segun do grupo, o que se observou foi que não houve uma inversão de preferências, isto é, de uma espécie voar baixo numa de terminada estação, e alto em outra.

Mais uma vez, como já observado na análise da altura de vôo dos Scolytidae durante os 3 anos do experimento, para cada estação distinta as variáveis climatoló gicas foram semelhantes, levando os scolytidae a comportamentos igualmente semelhantes, dentro de cada estação, ao longo destes 3 anos (Tabelas 7 a 9 e 11 a 13).

Apesar da literatura considerar a maioria das espécies de Scolytidae analisadas como políagas, como já referido anteriormente, a grande maioria destas apresentou diferenças estatisticas entre os talinōes, com espécies flo restais distintas, sendo mais captrradas num ou noutro taIhão (Tabelas 14 a 17). 
o que se observou na análise de preferência dos scolytidae por talhões, para as 4 alturas distintas de armadilhas de etanol, foi que, de modo geral, a preferência por este ou aquele talhão permaneceu a mesma, qualquer que fosse a altura de armadilha analisada (Tabelas 14 a 17). Isto mostra que caracteristicas próprias de cada talhão como o espaçamento, idade e a densidade do sub-bos que (Tabela 1) não exerceram influência na altura de vôo preferencial dos scolytidae analisados.

\subsection{Altura de armadilha por talhão}

Foi feita também uma comparação de médias, por altura de armadilha, do total de scolytidae capturado em cada talhão, durante os 3 anos da pesquisa (Tabela 18). Embora o padrão preferencial de altura de vôo dos Scó lytidae analisados seja o mesmo, independente do talhão em que ocorra, como discutido anteriormente, observaram-se resultados distintos entre os talhões.

Assim, enquanto não houve diferenças esta
tisticas para os talhões II, III e $V$ entre as mëdias de
capturas mensais de scolyticae nas diferentes alturas de
armadilhas de etanol, no talhão I houve maior captura nas
alturas inferiores $(40$ e $60 \mathrm{~cm})$, e no talhão IV, nas altu-


ras superiores $(80$ e $100 \mathrm{~cm})$.

Isto é facilmente explicado ao se determinar quais espécies predominam em cada talhão (Tabelas 14 a 17). No talhão I predominam as espécies que voam preferencialmente nas alturas inferiores e no talhão IV as que voam pre ferencialmente nas alturas superiores, havendo um equilibrio destas para os demais talhões. Deste modo, os resultạ dos globais obtidos (Tabela 18) são um reflexo dos scolyti dae predominantes em cada talhão.

Analisando-se os dados totais de captura men sal de scolytidae, nas diferentes alturas, para todos os talhões somados, não houve diferença para as diferentes al turas (Tabela 19). Isto se deve ao fato de haver um equilí brio entre as espécies que voam mais alto com aquelas que voam mais baixo. Ertretanto, a altura mais baixa $(40 \mathrm{~cm}$ ) cap turou numericamente mais scolytidae que as demais, resultado este tambēm obtido por CARRANO-MOREIRA (1985).

Os valores mínimos e máximos das variáveis discutidas neste item encontram-se nos Apêndices 17 e 18 .

4.4. Considerações sobre o coeficiente de variação

O coeficiente de variação (CV) é um parâmetro usacio para dar uma idéia da precisão do experimento. 
A comparação estatistica de médias de captura de Scolytidae deu em CV correspondentes muitas vezes altos (Tabelas 2 a 17), principalmente nas espécies mais capturadas.

Estes valores indicariam, antes de uma impre cisão no experimento, um comportamento peculiar destas coleobrocas. Uma área reflorestada e explorada economicamente apresenta freqtentemente residuos florestais, resultantes de desbastes e desramas artificiais. Este material se presta muito bem para a criação de várias espécies de Scolytidae, e não tem uma distribuição uniforme nos talhões.

Assim, é de se esperar que uma armadilha ins talada próxima a um tronco caido ou ramos desbastados cole taria mais scolytidae que uma armadilha instalada numa área limpa destes resíduos. Os valores mínimos e máximos de captura de Scolytidae encontrados nos Apêndices 1 a 16 podem dar uma idéia desta variação.

Isto concorda perfeitamente com recomendação feita por CHAPMAN (1962) e F̈OSKKNG \& KNIGHT (1975), justificando os valores altos de $\mathrm{CV}$ encontrados e o grande núme ro de armadilhas (188) usado neste experimento. 


\section{CONCLUSÓES}

Através da análise dos resultados obtidos, pô de-se chegar às seguintes conclusões:

- foram identificadas 57 espécies de scolyti dae, em sua grande maioria xilomicetófagos;

- o etanol é um ótimo atraente primário para as condições do experimento;

- Hypothenemus eruditus, corthylus convexicauda, cryptocarenus heveae, cryptocarenus sp. 2 , Microcorthylus minimus, xyleborus obliquus, $x$. retusus, $x$. solitarius $e x$. spinulosus voam preferencialmente em alturas superiores $(100$ e $80 \mathrm{~cm})$.

- Hypothenemus bolivianus, xyzeborus abjinis, $x$. biseriatus, $x$. jerrugineus, $x$. gracizis e $x$. tolimanus voam preferencialmente em alturas inferiores $140 \mathrm{e}$ $60 \operatorname{cin}) ;$ 
mente na altura de $60 \mathrm{~cm}$;

- Cnesinus dryographus, C. nova-teutonicus, Corthylocurus vernaculus, Corthylus sp. 1 ' Corthylus sp.2' Cryptocarenus diadematus, cryptocarenus seriatus, Cryptoca renus $\mathrm{sp} .1$, Hypothenemus bolivianus, Monarthrum semipallens, Premnobius cavipennis, Xyleborus hagedorni, $x$. intri catus $e x$. linearicollis não apresentam preferência de altura de vôo para qualquer das alturas testadas;

- para xigleborus affinis, $x$. ferrugineus, $x$. gracilis, $x$. retusus $e x$. spinulosus as variáveis climato lógicas nas estações outinv e Priver não alteram a faixa preferencial de altura de vôo;

- para Hypothenemus bolivianus, H. eruditus, H. obscurus, xyleborus obliquus, Premnobius cavipennis e Xyleborus solitarius as variáveis climatológicas influenciam na altura preferencial do vôo, sendo que esta só ocor re na estação Priver para as 4 primeiras espécies, e na estação outinv para as demais espécies;

- as condições climáticas prevalecentes dentro

de anos e de mesmas estações permitem um compurtamento de altura oreferencial de vôo semelhante, pelos Scolytidàe, du 
rante os 3 anos do experimento;

- características dos talhões como espaçamento, idade e densidade de sub-bosque não exercem influência na altura preferencial de vôo dos Scolytidae analisados;

- para cada talhão, deve-se usar uma altura distinta de armadilha de etanol para maior captura de Scolytidae;

- coeficientes de variação altos indicam a necessidade de um grande número de armadilhas de etanol a ser usado em experimentos envolvendo Scolytidae;

- a maioria das espécies apresenta preferência por determinados talhões. 

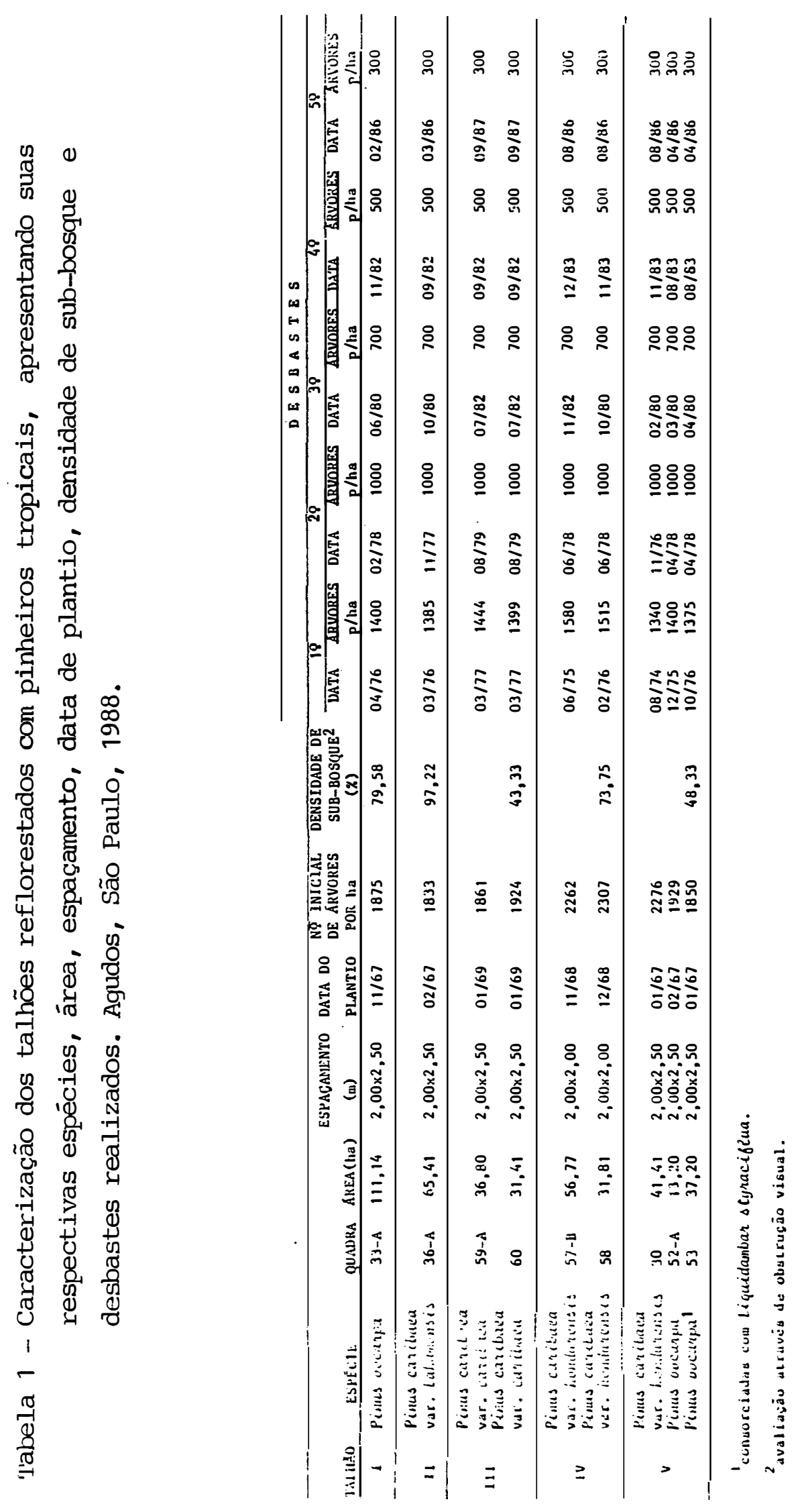

.76 
Tabela 2 - Resultado de análise de variância e teste de comparação de médias de capturas mensais de espécies de Scolytidae para di ferentes alturas de armadilhas de etanol. Agudos (SP), abril de 1984 a março de 1987.

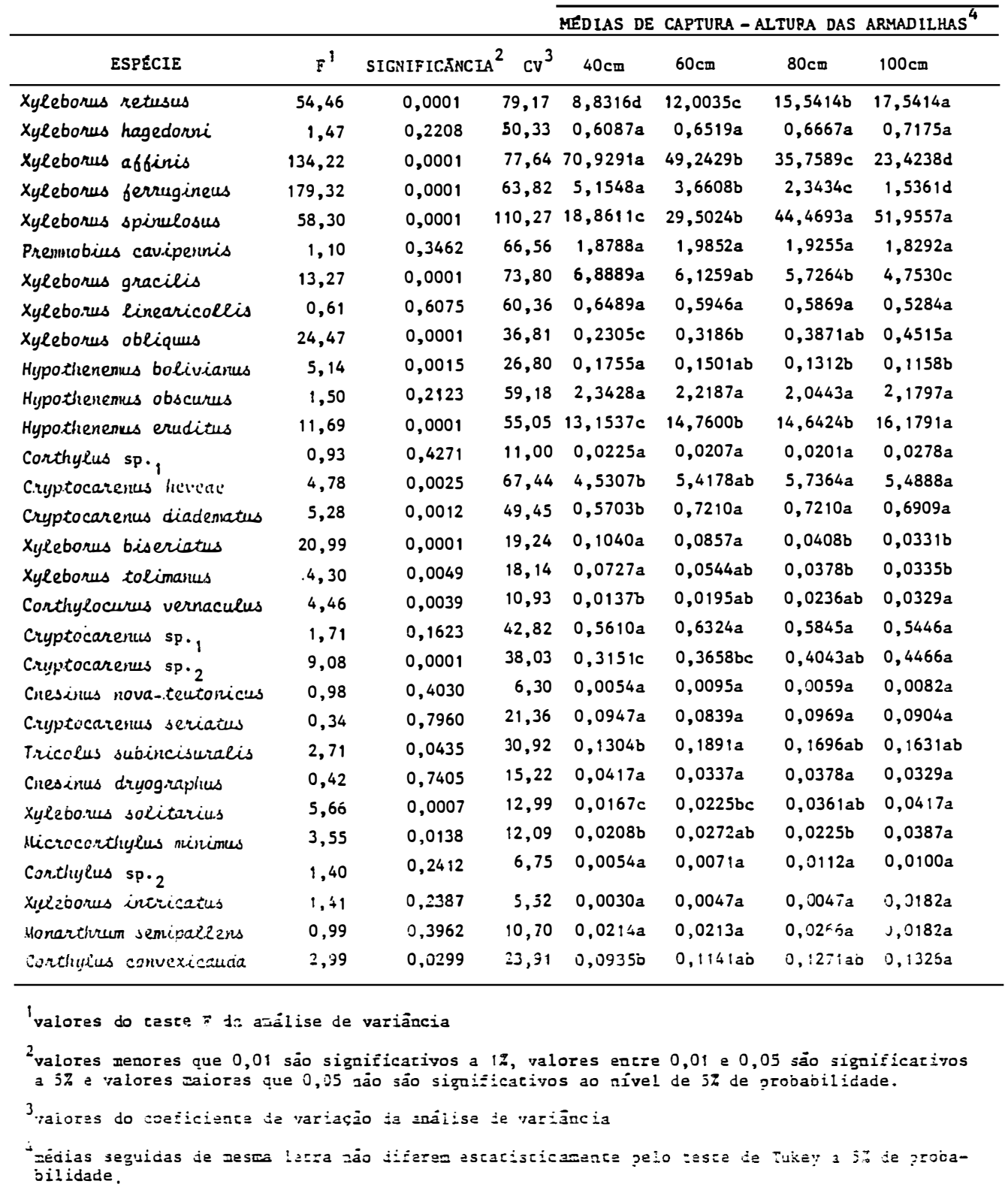


Tabela 3 - Resultado de análise de variância e teste de comparação de médias de capturas mensais de espécies de Scolytidae para di ferentes alturas de armadilhas de etanol. Agudos (SP), abril de 1984 a março de 1985.

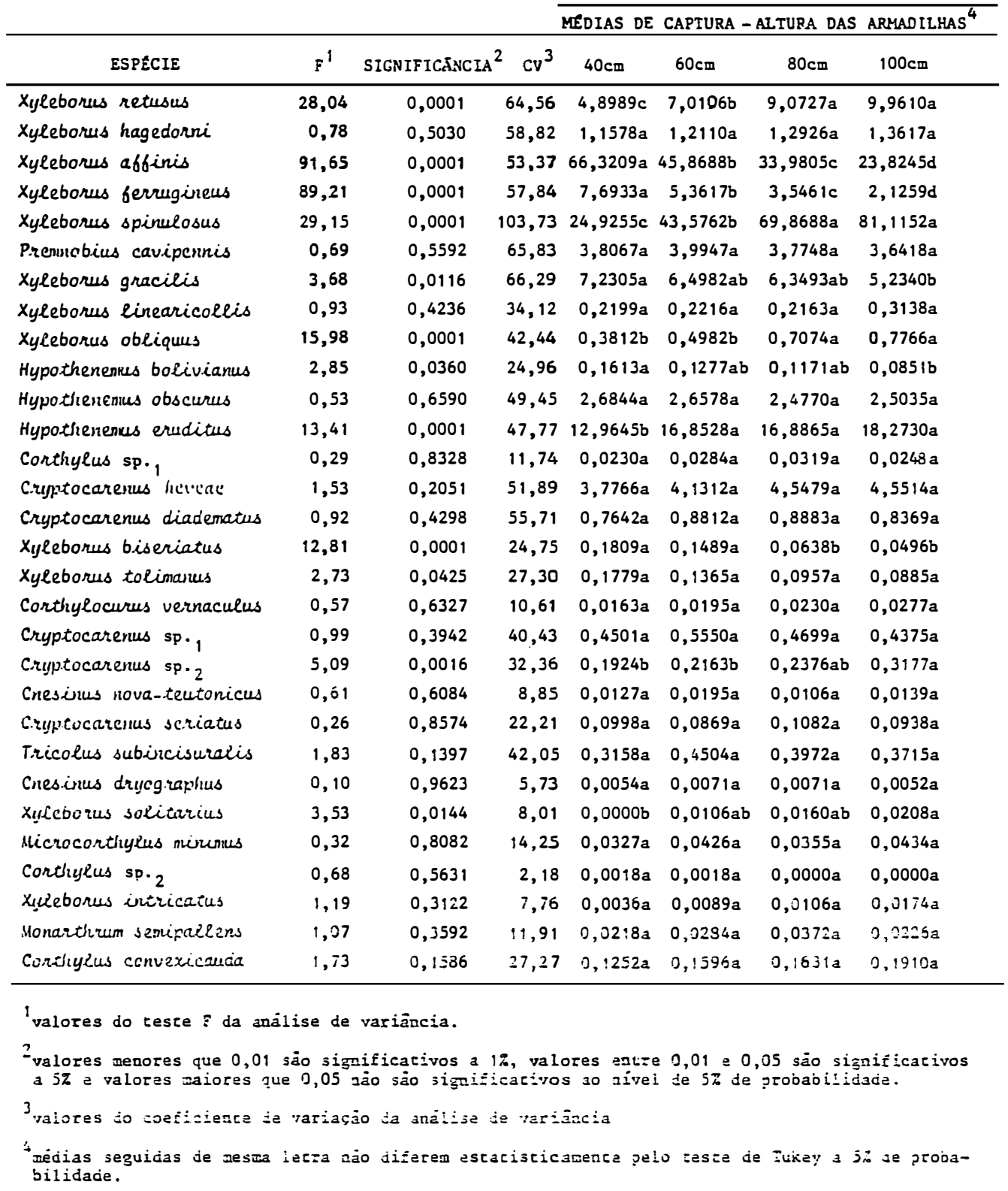


Tabela 4 - Resultado de anál.ise de variāncia e teste de comparação de médias de capturas mensais de espécies de Scolytidae para di ferentes alturas de anmadilhas de etanol. Agudos (SP), abril de 1985 a março de 1986.

MEDIAS DE CAPTURA - ALTURA DAS ARMADILHAS ${ }^{4}$

\begin{tabular}{|c|c|c|c|c|c|c|c|}
\hline ESPECIE & $F^{1}$ & SIGNIFICANCIA ${ }^{2}$ & $C v^{3}$ & $40 \mathrm{~cm}$ & $60 \mathrm{~cm}$ & $80 \mathrm{~cm}$ & $100 \mathrm{~cm}$ \\
\hline Xyleborus retusus & 15,71 & 0,0001 & 79,77 & $11,5372 b$ & $15,0922 b$ & $19,2145 a$ & $21,4699 a$ \\
\hline Xyleborus hagedorni & 0,28 & 0,8401 & 32,67 & $0,2624 a$ & $0,2855 a$ & $0,2748 a$ & $0,2589 a$ \\
\hline xylebones aboinis & 64,35 & 0,0001 & 49,09 & $12,7092 a$ & $9,2500 b$ & $7,5550 c$ & $5,7057 d$ \\
\hline xyleborus ferrugineus & 39,04 & 0,0001 & 51,33 & $1,8085 a$ & $1,3227 b$ & $0,9238 c$ & $0,6738 c$ \\
\hline Xyleborus spinulosus & 16,96 & 0,0001 & 95,46 & $5,1773 c$ & $7,6312 b$ & $11,5904 a$ & $12,3706 a$ \\
\hline Premnobius cavipennis & 2,22 & 0,0841 & 39,46 & $0,4043 a$ & $0,5106 a$ & $0,5089 a$ & $0,5230 a$ \\
\hline xyleborus gracilis & 5,23 & 0,0013 & 53,18 & $9,6578 \mathrm{a}$ & $1,4291 \mathrm{ab}$ & $1,4007 a b$ & $1,1791 b$ \\
\hline xyleborus Rinearicorlis & 1,86 & 0,1351 & 17,24 & $0,0762 a$ & $0,0567 a$ & $0,0443 a$ & $0,0709 a$ \\
\hline xyleborus obliques & 4,52 & 0,0037 & 28,63 & $0,1312 b$ & $0,1950 \mathrm{ab}$ & $0,1986 a b$ & $0,2500 a$ \\
\hline Hypothenenus bolivianus & 2,81 & 0,0382 & 23,41 & $0,1418 a$ & $0,1117 a b$ & $0,0993 \mathrm{ab}$ & $0,0780 b$ \\
\hline Hupothenenius obscurus & 0,38 & 0,7655 & 49,25 & $0,8475 a$ & $0,8954 a$ & $0,7624 a$ & $0,7996 a$ \\
\hline Hypothenenus eruditus & 3,68 & 0,0116 & 61,47 & $4,9078 b$ & $5,9025 a b$ & $5,4521 \mathrm{ab}$ & $6,5124 a$ \\
\hline Corthylus sp. 1 & 1,16 & 0,3254 & 8,72 & $0,0124 a$ & $0,0089 a$ & $0,0124 a$ & $0,0213 a$ \\
\hline Cruptocarenus hereac & 2,90 & 0,0340 & 59,07 & $1,9894 b$ & $2,4060 \mathrm{ab}$ & $2,7145 \mathrm{ab}$ & $2,6507 \mathrm{ab}$ \\
\hline Cryptocarénus diadematus & 2,32 & 0,0735 & 49,09 & $0,5674 a$ & $0,7216 a$ & $0,7518 a$ & $0,7606 a$ \\
\hline xyleborus biseriarus & 4,41 & 0,0042 & 15,74 & $0,0762 a$ & $0,0496 a b$ & $0,0319 b$ & $0,0284 b$ \\
\hline Xylebonus tolinasus & 3,69 & 0,0115 & 10,67 & $0,0372 a$ & $0,0160 \mathrm{ab}$ & $0,0124 a b$ & $0,0053 b$ \\
\hline Conthylocurus versaculus & 1,40 & 0,2397 & 5,05 & 0,0000 & $0,0071 \mathrm{a}$ & $0,0035 a$ & $0,0071 \mathrm{a}$ \\
\hline Cruptocarenus sp. 1 & 0,56 & 0,6396 & 38,11 & $0,4167 a$ & $0,3936 a$ & $0,4539 a$ & $0,3794 a$ \\
\hline Cruptocarenus sp. 2 & 5,21 & 0,0014 & 32,44 & $0,1791 b$ & $0,2642 a$ & $0,2908 a$ & $0,3032 a$ \\
\hline Cnesinus nova-teutonicus & 0,14 & 0,9341 & 4,07 & $0,0035 a$ & $0,0035 a$ & $0,0035 a$ & $0,0018 a$ \\
\hline crupptocarenus scriatus & 0,55 & 0,6466 & 16,43 & $0,0408 a$ & $0,0514 a$ & $0,0603 a$ & $0,0532 a$ \\
\hline Tricoius subincisuralis & 0,90 & 0,4398 & 18,67 & $0,0550 a$ & $0,0727 a$ & $0,0709 a$ & $0,0816 a$ \\
\hline Cnesinus disographus & 1,47 & 0,2198 & 4,85 & $0,0018 a$ & $0,0053 a$ & $0,0018 a$ & $0,0089 a$ \\
\hline xyrebcrus solitarius & 0,91 & 0,4344 & 13,42 & $0,0195 a$ & $0,0248 a$ & $0,0372 a$ & $0,0372 a$ \\
\hline Nicrecortlyeus murinus & 0,67 & 0,5718 & 3,76 & $0,0018 a$ & $0,0018 a$ & $0,0018 a$ & $0,0053 a$ \\
\hline Corthyeus sp. 2 & 2,23 & 0,0828 & 6,98 & $0,0035 a$ & $0,0071 \mathrm{a}$ & $0,0177 a$ & $0,0087 a$ \\
\hline xeleborus intricatus & 1,11 & 0,3422 & $3, ; 6$ & $0,0035 a$ & $0,0053 a$ & $0,0000 a$ & $0,0018 a$ \\
\hline Honartirum seminar2erss & 2,5ó & 0,0536 & $5, j i$ & 0,0053 & فa,053 & $0,012 \div a$ & ग,0000' \\
\hline Cortlueies convexicauca & 0,31 & 0,4901 & $21, ; 8$ & $0,0762 a$ & 0,099בa & $0, ; 082 a$ & $0,3922 a$ \\
\hline
\end{tabular}

'valores do cesce $\boldsymbol{Z}$ da analise de variäncia.

2 valores menores que 0,01 säo significarivos a $1:$, Jalores entre 0,01 e 0,05 säo significarivos

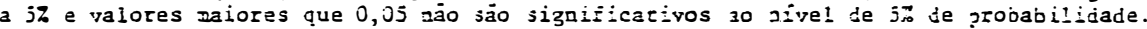

raioras do coeticience de rariaçāo da anălise de variäncia.

medias seguidas de mesma lecra aảo diferem estacisticamence pelo ceste de Tukey a j: je probabilicade. 
Tabela 5 - Resultado de análise de variância e teste de comparação de médias de capturas mensais de espécies de Scolytidae para di ferentes alturas de armadilhas de etanol. Agudos (SP), abril de 1986 a março de 1987.

MEDIAS DE CAPTURA - ALTURA DAS ARMADILHAS ${ }^{4}$

\begin{tabular}{|c|c|c|c|c|c|c|c|}
\hline ESPÉCIE & $F^{1}$ & SIGNIFICÂNCIA ${ }^{2}$ & $C v^{3}$ & $40 \mathrm{~cm}$ & $60 \mathrm{~cm}$ & $80 \mathrm{~cm}$ & $100 \mathrm{~cm}$ \\
\hline Xyleborus retusus & 18,95 & 0,0001 & 82,04 & $10,0585 b$ & $13,9078 b$ & $18,3369 a^{2}$ & $21,1933 a$ \\
\hline Xylebonus hagedorri & 1,97 & 0,1168 & 39,16 & $0,4060 a$ & $0,4592 a$ & $0,4326 a$ & $0,5319 a$ \\
\hline xylebores abfinis & 64,94 & 0,0001 & 71,02 & $133,7571 a$ & $92,6099 b$ & $65,7411 \mathrm{c}$ & $40,7411 b$ \\
\hline$x y c e b o r u s$ ferrugineus & 76,97 & 0,0001 & 62,82 & $5,9628 a$ & $4,2979 b$ & $2,5603 c$ & $1,8085 d$ \\
\hline xyleborus spinulosus & 21,31 & 0,0001 & 97,72 & $26,4805 c$ & $37,2996 b$ & $51,9486 a$ & $62,3812 a$ \\
\hline Premnobius cavipents & 0,33 & 0,8048 & 54,91 & $1,4255 a$ & $1,4504 a$ & $1,4929 a$ & $1,3277 a$ \\
\hline xylebonus gracilis & 8,82 & 0,0001 & 65,56 & $11,7784 a$ & $10,4504 \mathrm{ab}$ & $9,4291 b c$ & $=7,8457 \mathrm{c}$ \\
\hline xyleboress Rirearicollis & 1,32 & 0,2676 & 73,98 & $1,6507 a$ & $1,5053 a$ & $1,5000 a$ & $1,2004 a$ \\
\hline xyleborus obliquus & 6,98 & 0,0001 & 31,70 & $0,1791 \mathrm{~b}$ & $0,2624 \mathrm{ab}$ & $0,2553 a b$ & $0,3280 a$ \\
\hline Hypothenenus bolivianus & 0,90 & 0,4422 & 30,75 & $0,2234 a$ & $0,2110 a$ & $0,1773 a$ & $0,1844 a$ \\
\hline Hypothenemus obscures & 1,80 & 0,1289 & 61,75 & $3,4965 a$ & $3,1028 a$ & $2,8936 a$ & $3,2358 a$ \\
\hline Hypothenenus eruditus & 3,20 & 0,0226 & 39,04 & $21,5887 \mathrm{ab}$ & b $21,5248 a b$ & $21,5887 a b 2$ & $23,7518 a$ \\
\hline Corthy\&us sp., & 1,64 & 0,1779 & 12,15 & $0,0319 a$ & $0,0248 a$ & $0,0160 a$ & $0,0372 a$ \\
\hline Cruptccaresus hereac & 2,08 & 0,1013 & 67,91 & $7,8262 a$ & $9,7163 a$ & $9,9468 a$ & $9,2642 a$ \\
\hline Cryptocarenus diadentatus & 3,76 & 0,0104 & 40,37 & $0,3794 \mathrm{~b}$ & $0,5653 a$ & $0,5230 a$ & $0,4752 a b$ \\
\hline xyleborus biseriatus & 4,65 & 0,0030 & 14,71 & $0,0550 a$ & $0,0585 a$ & $0,0266 \mathrm{~d}$ & $0,0213 b$ \\
\hline Xuieborus tolinanus & 0,60 & 0,6128 & 5,92 & $0,0053 a$ & $0,0106 a$ & $0,0053 a$ & $0,0053 a$ \\
\hline Corthylocurses vernaculus & 3,70 & 0,0113 & 14,55 & $0,0248 b$ & $0,0319 b$ & $0,0443 \mathrm{ab}$ & $0,0638 a$ \\
\hline Cruptocaresus sp., & 1,34 & 0,2598 & 45,67 & $0,8138 a$ & $0,9486 a$ & $0,8298 a$ & $0,8191 a$ \\
\hline crupptocarenus sp. 2 & 2,26 & 0,0798 & 42,33 & $0,5709 a$ & $0,6170 a$ & $0,6844 a$ & $0,7216 a$ \\
\hline Cnesinus nova-teutonicus & 1,74 & 0,1563 & 4,85 & $0,0000 a$ & $0,0053 a$ & $0,0035 a$ & $0,0089 a$ \\
\hline Cryptocarenus seriatus & 0,46 & 0,7112 & 24,14 & $0,1436 a$ & $0,1135 a$ & $0,1223 a$ & $0,1241 \mathrm{a}$ \\
\hline Tricolus subincisuraris & 1,11 & 0,3427 & 13,57 & $0,0248 a$ & $0,0443 a$ & $0,0408 a$ & $0,0319 a$ \\
\hline Cnesinus drycgrapinus & 0,75 & 0,5235 & 23,91 & $0,1170 a$ & $0,0887 a$ & $0,1046 a$ & $0,0851 a$ \\
\hline Xyieboress solitarius & 3,04 & 0,0280 & 15,97 & $0,0301 b$ & $0,0319 a b$ & $0,0550 \mathrm{ab}$ & $0,0674 a$ \\
\hline Shicrecortrylus minzimus & 4,02 & 0,0073 & 14,48 & $0,02840^{\circ}$ & $0,0372 a b$ & $0,0301 b$ & $0,0674 a$ \\
\hline Cortiluius sp. 2 & 0,75 & 0,5216 & 9,05 & $0,0106 a$ & $0,0124 a$ & $0,0160 a$ & $0,0213 a$ \\
\hline xuiejorus ivericatus & 1,67 & 0,1708 & 4,06 & $0,0018 a$ & $0,0000 a$ & $0,0035 a$ & $0,0071 a$ \\
\hline Monarol:um senifarlers & 0,15 & 0,7284 & $: 2,90$ & $0,0372 a$ & $0,0301 a$ & $0,3301 a$ & $0,0319 a$ \\
\hline Curthyius csivexicauda & 1,32 & 0,2664 & 21,75 & $0,0798 a$ & $0,0833 a$ & $0,1099 a$ & $0,1135 a$ \\
\hline
\end{tabular}

'valores do teste $F$ da anàlise de variảncia.

2

2 ralores nenores que 0,01 sảo siznificarivos $a 1$, valores entre 0,01 e 0,05 säo signizicati-

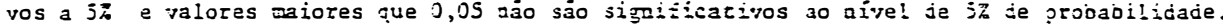

3.vaiores do coetricience de variaçäo da endiilse de variāncía.

"mèdia seguidas de mesma letra näo diferem escatisticamente zelo ceste de Tukey a jö de probaoilidade. 
Tabela 6 - Resultado de análise de variância e teste de comparação de médias de capturas mensais de espécies de Scolytidae para di ferentes alturas de armadilhas de etanol. Agudos (SP), estação Priver (outubro a março), abril de 1984 a março de 1987.

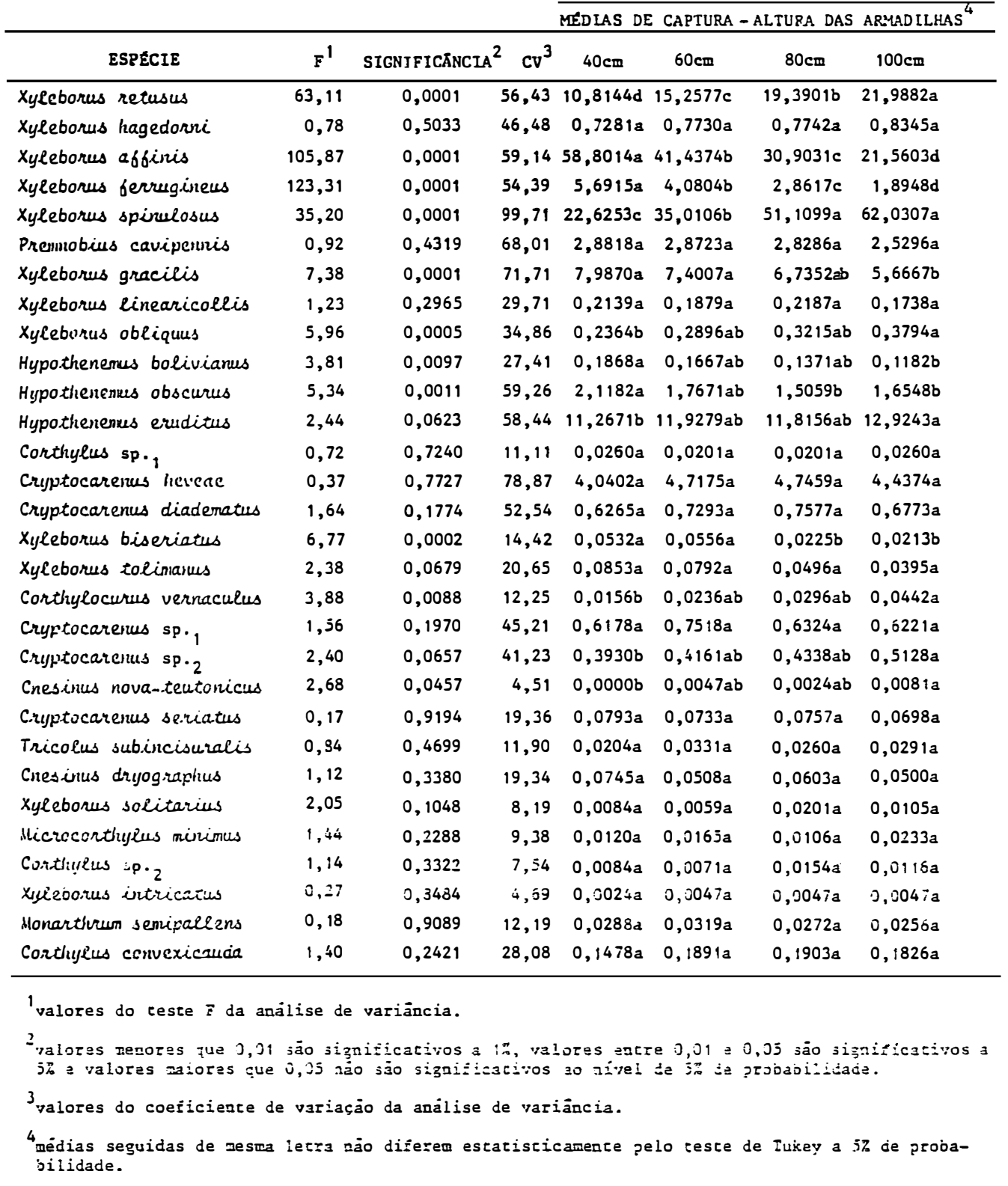


Tabela 7 - Resultado de análise de variância e teste de comparação de médias de capturas mensais de espécies de Scolytidae para di ferentes alturas de amadilhas de etanol. Agudos (SP), estação Priver (outubro a março), abril de 1984 a março de 1985.

MEDIAS DE CAPTURA - ALTURA DAS ARMADILHAS ${ }^{4}$

\begin{tabular}{|c|c|c|c|c|c|c|c|}
\hline ESPECIE & $F^{1}$ & SIGNIFICANCIA ${ }^{2}$ & $C v^{3}$ & $40 \mathrm{~cm}$ & $60 \mathrm{~cm}$ & $80 \mathrm{~cm}$ & $100 \mathrm{~cm}$ \\
\hline xylebonus retusus & 35,34 & 0,0001 & 43,24 & $6,8901 c$ & $10,0922 b$ & $12,9539 a$ & $14,1348 a$ \\
\hline xylebonus hagedorni & 0,67 & 0,5694 & 51,20 & $1,1241 a$ & $1,2518 a$ & $1,2766 \mathrm{a}$ & $1,3191 a$ \\
\hline xyleborus af́firis & 32,34 & 0,0001 & 58,99 & $60,3936 a$ & $44,1312 b$ & $32,7553 \mathrm{c}$ & $23,4681 d$ \\
\hline Xyleborus jerrugineus & 48,17 & 0,0001 & 49,83 & $6,1028 a$ & $4,5496 \mathrm{~b}$ & $3,3794 c$ & $1,9823 d$ \\
\hline Xyleborus spirulosus & 12,36 & 0,0001 & 108,00 & $25,4362 c$ & $44,4823 b c$ & $68,0461 \mathrm{ab} \varepsilon$ & $82,4823 a$ \\
\hline Premnobius cavipennis & 0,59 & 0,6189 & 60,79 & $5,9610 a$ & $5,9752 a$ & $5,7092 a$ & $5,2163 a$ \\
\hline xyleborus gracilis & 1,72 & 0,1604 & 65,41 & $5,8759 a$ & $5,6454 a$ & $5,6667 a$ & $4,4645 a$ \\
\hline xyleborus linearicollis & 0,28 & 0,8368 & 26,18 & $0,1596 a$ & $0,1738 a$ & $0,1560 a$ & $0,1454 a$ \\
\hline xyReboress obliquus & 4,78 & 0,0026 & 38,85 & $0,2872 b$ & $0,3759 a b$ & $0,4681 \dot{\phi}$ & $0,5461 a$ \\
\hline Hypothenemus bolivianus & 2,52 & 0,0568 & 25,96 & $0,1738 a$ & $0,1596 a$ & $0,1348 a$ & $0,0780 a$ \\
\hline Hypotheremus obscures & 0,60 & 0,6169 & 53,34 & $2,0674 a$ & $1,8227 a$ & $1,6135 a$ & $1,9894 a$ \\
\hline Hypothenenus eruditus & 3,16 & 0,0239 & 48,74 & $10,6312 b$ & $12,5000 a b$ & $12,7092 \mathrm{~d}$ & $13,5355 a$ \\
\hline Corthujeus sp. 1 & 0,12 & 0,9461 & 10,81 & $0,0248 a$ & $0,0213 a$ & $0,0248 a$ & $0,0177 a$ \\
\hline Crupptocaresus heveac & 0,22 & 0,8837 & 51,21 & $2,6489 a$ & $2,4716 a$ & $2,6702 a$ & $2,8404 a$ \\
\hline Cryptocarenus diadematus & 0,28 & 0,8411 & 61,06 & $1,2057 a$ & $1,3440 a$ & $1,3404 a$ & $1,2624 a$ \\
\hline Xyleborus biseriatus & 4,87 & 0,0023 & 14,99 & $0,0780 a$ & $0,0567 a b$ & $0,0213 b$ & $0,0177 b$ \\
\hline xylebores tolinanus & 1,20 & 0,3100 & 30,84 & $0,1978 a$ & $0,2092 a$ & $0,1241 \mathrm{a}$ & $0,1081 a$ \\
\hline Cortlylocures vernaculus & 1,59 & 0,1894 & 9,74 & $0,0112 a$ & $0,0071 a$ & $0,0213 a$ & $0,0304 a$ \\
\hline Cryptocarenus sp. 1 & 1,64 & 0,1787 & 43,69 & $0,6157 a$ & $0,7589 a$ & $0,5638 a$ & $0,5068 a$ \\
\hline Cruptocaresus sp. 2 & 2,29 & 0,0770 & 36,68 & $0,2873 a$ & $0,2837 a$ & $0,2908 a$ & $0,4223 a$ \\
\hline Cnesinus nova-teutonicus & 1,59 & 0,1899 & 6,82 & $0,0000 a$ & $0,0106 a$ & $0,0071 a$ & $0,0169 a$ \\
\hline C.ruptocarenus seriatus & 0,19 & 0,9021 & 18,32 & $0,0634 a$ & $0,0638 a$ & $0,0674 a$ & $0,0574 a$ \\
\hline Tricolus subincisuralis & 0,85 & 0,4658 & 13,79 & $0,0261 a$ & $0,0532 a$ & $0,0355 a$ & $0,0372 a$ \\
\hline Cnesinus drujograpius & 0,72 & 0,5389 & 4,34 & $0,0075 a$ & $0,0035 a$ & $0,0000 a$ & $0,0034 a$ \\
\hline Xlifeboress solitarius & 2,01 & 0,1112 & 3,07 & $0,0000 a$ & $0,0000 a$ & $0,0071 a$ & $0,0000 a$ \\
\hline llicrecortiurus misimus & 1,22 & 0,3023 & 0,11 & $0,0000 a$ & $0,0071 a$ & $0,0071 a$ & $0,0135 a$ \\
\hline Corticureus sp. 2 & 1,07 & 0,3609 & 2,18 & $0,0037 \mathrm{~d}$ & $0,0000 a$ & $0,000 \mathrm{Ga}$ & $J, 3000 a$ \\
\hline xurioscrus inticacatus & 0,53 & 0,5639 & 5,73 & $0,0037 a$ & $0,0071 \mathrm{a}$ & $0,0106 a$ & $3,0034 a$ \\
\hline Monarthrem semiparlens & 0,64 & 0,5920 & 13,51 & $0,0299 a$ & $0,0390 a$ & $0,0461 a$ & $0,0270 a$ \\
\hline Corthylus corndericauda & 0,32 & 0,8127 & 31,33 & $0,2201 \mathrm{a}$ & $0,2589 a$ & $0,244 i a$ & 0,2460 a \\
\hline
\end{tabular}

1 valores do casce $z$ da maälise de variāncia.

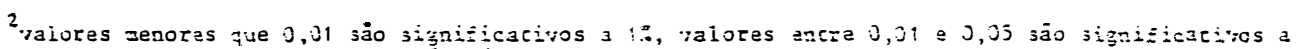

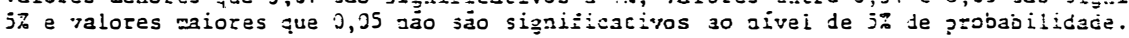

3 valores do coeficience de variaçào da anälise de variância.

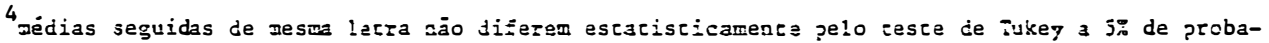
bilidade. 
Tabela 8 - Resultado de anāl.ise de variância e teste de cormaração de médias de capturas mensais de espécies de Scolytidae para di ferentes alturas de armadilhas de etanol. Agudos (SP), estação Priver (outubro a março), abril de 1985 a março de 1986.

MEDIAS DE CAPTURA - ALTURA DAS ARMADILHAS ${ }^{4}$

\begin{tabular}{|c|c|c|c|c|c|c|c|}
\hline ESPECIE & $F^{1}$ & SIGNIFICÃNCIA ${ }^{2}$ & $C v^{3}$ & $40 \mathrm{~cm}$ & $60 \mathrm{~cm}$ & $80 \mathrm{~cm}$ & $100 \mathrm{~cm}$ \\
\hline xyecborus retusus & 18,53 & 0,0001 & 58,84 & $16,5922 c$ & $22,6844 b$ & $28,6348 a$ & $32,3121 a$ \\
\hline xyleborus hagedorni & 0,83 & 0,4782 & 35,74 & $0,4362 a$ & $0,3794 a$ & $0,3830 a$ & $0,3511 a$ \\
\hline xyecborus affinis & 60,40 & 0,0001 & 38,44 & $37,4468 \mathrm{a}$ & $13,0000 b$ & $10,2943 c$ & $7,6525 d$ \\
\hline - $x$ ycebonus fenrugivieus & 30,32 & 0,0001 & 47,98 & $2,6418 a$ & $2,0000 \mathrm{~b}$ & $1,4043 c$ & $1,0071 c$ \\
\hline xyleborus spinulosus & 19,58 & 0,0001 & 70,16 & $9,8830 c$ & $14,3972 b$ & $22,0248 a$ & $23,4362 a$ \\
\hline Prenurobius cavipennis & 0,80 & 0,4290 & 38,58 & $0,5603 a$ & $0,6418 a$ & $0,5745 a$ & $0,5638 a$ \\
\hline xyleborws gracilis & 4,44 & 0,0042 & 51,87 & $2,4397 a$ & $2,1560 \mathrm{ab}$ & $2,0851 \mathrm{ab}$ & $1,7128 b$ \\
\hline xyleborus linearicollis & 1,00 & 0,3933 & 16,72 & $0,0709 a$ & $0,0674 a$ & $0,0390 a$ & $0,0567 a$ \\
\hline xyleborus obliquers & 0,34 & 0,7986 & 27,63 & $0,1667 a$ & $0,1702 a$ & $0,1773 a$ & $0,2092 a$ \\
\hline Hypothenemus bolivianus & 1,81 & 0,1444 & 22,71 & $0,1348 a$ & $0,1135 a$ & $0,0745 a$ & $0,0851 a$ \\
\hline Hypotherrenus obscures & 2,56 & 0,0533 & 52,73 & $1,1383 a$ & $1,0319 a$ & $0,7908 a$ & $0,7908 a$ \\
\hline Hypotrenenus eruditus & 0,49 & 0,6865 & 55,53 & $2,1986 a$ & $2,5603 a$ & $2,2447 a$ & $2,5177 a$ \\
\hline Corthysus sp., & 0,48 & 0,6958 & 9,32 & $0,0142 a$ & $0,0142 a$ & $0,0142 a$ & $0,0248 a$ \\
\hline Cryptocarciues hiciti & 0,15 & 0,9320 & 42,80 & $0,6418 a$ & $0,6596 a$ & $0,6631 a$ & $0,7021 \mathrm{a}$ \\
\hline Cryptocarenus diadenatus & 0,83 & 0,4765 & 36,18 & $0,2624 a$ & $0,2766 a$ & $0,3582 a$ & $0,2766 a$ \\
\hline Xisleborus biserictus & 0,51 & 0,6739 & 9,96 & $0,0142 a$ & $0,0248 a$ & $0,0106 a$ & $0,0213 a$ \\
\hline$x_{y}$ febones tolinarues & 4,10 & 0,0066 & 12,74 & $0,0603 a$ & $0,0213 a b$ & $0,0213 a b$ & $0,0071 b$ \\
\hline Corthylocurus vernaculus & 1,81 & 0,1435 & 4,84 & $0,0000 a$ & $0,0071 a$ & $0,0000 a$ & $0,0106 a$ \\
\hline Cryptocarenus sp. 1 & 0,28 & 0,8413 & 34,51 & $0,3085 a$ & $0,3262 a$ & $0,3511 a$ & $0,3511 a$ \\
\hline Cryptocarenus sp. 2 & 1,24 & 0,2931 & 27,01 & $0,1206 a$ & $0,1915 a$ & $0,1596 a$ & $0,1667 a$ \\
\hline Cnesirus nova-teutonicus & 1,00 & 0,3920 & 2,18 & $0,0000 a$ & $0,0000 a$ & $0,0000 a$ & $0,0035 a$ \\
\hline crrpptocarenus scriatus & 0,49 & 0,6894 & 12,90 & $0,0213 a$ & $0,0319 a$ & $0,0355 a$ & $0,0390 a$ \\
\hline Tricolus subincisuraris & 0,17 & 0,9143 & 8,56 & $0,0177 a$ & $0,0106 a$ & $0,0106 a$ & $0,0142 a$ \\
\hline Cres.inus drycgraphus & 2,45 & 0,0620 & 5,71 & $0,0000 a$ & $0,0106 a$ & $0,0000 a$ & $0,0142 a$ \\
\hline Xyiebcrus solitarius & 2,89 & 0,0344 & 4,84 & $0,0000 a$ & $0,0000 a$ & $0,0142 a$ & $0,0035 a$ \\
\hline Microcortryius mirinus & 1,00 & 0,3920 & 2,18 & $0,0000 a$ & $0,0035 a$ & $0,0000 a$ & $0,0000 a$ \\
\hline Cortluerus sp.2 & 2,16 & 0,0914 & 7,74 & $0,0071 \mathrm{a}$ & $0,0035 a$ & $0,0248 a$ & $0,0106 a$ \\
\hline xereoorus istricatiss & 2,01 & 0,1112 & 3,07 & $0,0000 a$ & $0,0071 a$ & $0,0000 a$ & $0,0000 a$ \\
\hline Monarthrum seninarens & 1,34 & 0,2505 & $\therefore, 34$ & $0,007 i a$ & $0,007 i_{3}$ & $0,00 \mathrm{GOa}$ & $0,0000 a$ \\
\hline Corthyius convexicauda & 0,43 & 0,7334 & 26,66 & $0,1383 a$ & $0,1773 a$ & $0,1667 a$ & $0,1489 a$ \\
\hline
\end{tabular}

'valores do ceste $F$ da analise de variäncia.

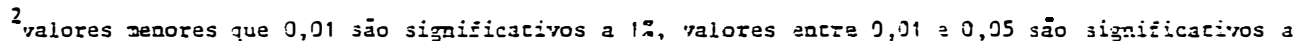

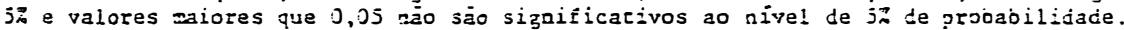

3 valores do coeticience de vazisço ja análise de rariância.

4 médias seguidas de mesma lecra nảo dirierm estatisticamente pelo taste de rukep a $5 \hat{\%}$ de prooabilidade. 
Tabela 9 - Resultado da anälise de variância e teste de comparação de médias de capturas mensais de espécies de Scolytidae para di ferentes alturas de annadilhas de etanol. Agudos (PS), estação Priver (outubro a março), abril de 1986 a março de 1987.

MEDDIAS DE CAPTURA - ALTURA DAS ARMADILHAS ${ }^{4}$

\begin{tabular}{|c|c|c|c|c|c|c|c|}
\hline ESPÉCIE & $F^{\prime}$ & SIGNIFIC.స్NCIA ${ }^{2}$ & $c v^{3}$ & $40 \mathrm{~cm}$ & $60 \mathrm{~cm}$ & $80 \mathrm{~cm}$ & $100 \mathrm{~cm}$ \\
\hline xyReborus retusus & 25,24 & 0,0009 & 53,61 & $8,9610 c$ & $12,9965 b$ & $16,5816 a$ & $19,5177 a$ \\
\hline xyleborus hagedonni. & 1,91 & 0,1264 & 41,51 & $0,6241 \mathrm{a}$ & $0,6879 a$ & $0,6631 \mathrm{a}$ & $0,8333 a$ \\
\hline xyleborus aófiris & 80,32 & 0,0001 & 43,24 & $98,5638 a$ & $67,1809 b$ & $49,6596 c$ & $33,5603 d$ \\
\hline xyleborus ferrugineus & 61,60 & 0,0001 & 52,09 & $8,3298 a$ & $5,6915 b$ & $3,8014 c$ & $2,6950 d$ \\
\hline xylebores spinulosus & 11,80 & 0,0009 & 94,97 & $32,5567 c$ & $46,1525 b c$ & $63,2589 a b$ & $80,1738 a$ \\
\hline Premnobius cavipenris & 0,85 & 0,4657 & 56,04 & $2,1241 \mathrm{a}$ & $2,0000 a$ & $2,2021 a$ & $1,8085 a$ \\
\hline xyleborus gracilis & 5,19 & 0,0015 & 60,14 & $15,6454 a$ & $14,4007 \mathrm{ab}$ & $12,4539 \mathrm{ab}$ & $10,8227 b$ \\
\hline xyleborus Rinearicollis & 2,40 & 0,0663 & 36,16 & $0,4 i 13 a$ & $0,3227 a$ & $0,4610 a$ & $0,3191 a$ \\
\hline xyReborus obliques & 1,90 & 0,1280 & 34,80 & $0,2553 a$ & $0,3227 a$ & $0,3191 a$ & $0,3830 a$ \\
\hline Hypothenenxes bolivianus & 0,80 & 0,4957 & 31,79 & $0,2518 a$ & $0,2270 a$ & $0,2021 a$ & $0,1915 a$ \\
\hline Hypothenenus obscurus & 3,85 & 0,0094 & 62,70 & $3,1489 a$ & $2,4468 \mathrm{ab}$ & $2,1135 b$ & $2,1844 \mathrm{~b}$ \\
\hline Hypothenenus enuditus & 2,08 & 0,1006 & 31,44 & $20,9716 a$ & $20,7234 a$ & $20,4929 a$ & $22,7199 a$ \\
\hline Corthylus sp., & 0,62 & 0,6017 & 12,90 & $0,0390 a$ & $0,0248 a$ & $0,0213 a$ & $0,0355 a$ \\
\hline Cryptocarenus heveac & 0,76 & 0,5185 & 68,96 & $8,8298 a$ & $11,0213 a$ & $10,9043 a$ & $9,7695 a$ \\
\hline Cryptocarenus diadenatus & 2,24 & 0,0820 & 42,06 & $0,4113 a$ & $0,5674 a$ & $0,5745 a$ & $0,4929 a$ \\
\hline xyleborus biseriatus & 3,48 & 0,0154 & 17,08 & $0,0674 \mathrm{ab}$ & $0,0851 \mathrm{a}$ & $0,0355 \mathrm{ab}$ & $0,0248 b$ \\
\hline xyleborus tolinasus & 0,67 & 0,5719 & 4,34 & $0,0035 a$ & $0,0071 \mathrm{a}$ & $0,0035 a$ & $0,0000 a$ \\
\hline Corthyrocures vernaculus & 2,26 & 0,0798 & 97,60 & $0,0355 a$ & $0,0567 a$ & $0,0674 a$ & $0,0922 a$ \\
\hline Cryptocarenus sp., & 0,86 & 0,4605 & 48,65 & $0,9291 \mathrm{a}$ & $1,1702 a$ & $0,9823 a$ & $1,0142 a$ \\
\hline Cruptocarenus sp. 2 & 1,20 & 0,3094 & 45,39 & $0,7660 a$ & $0,7730 a$ & $0,8511 a$ & $0,9539 a$ \\
\hline Cnesizus nova-teutonicus & 0,67 & 0,5726 & 3,08 & $0,0000 a$ & $0,0035 a$ & $0,0000 a$ & $0,0035 a$ \\
\hline Cryptocarerus seriatus & 0,41 & 0,7432 & 23,97 & $0,1525 a$ & $0,1241 \mathrm{a}$ & $0,1241 \mathrm{a}$ & $0,1135 a$ \\
\hline Tricolus subincisuraris & 0,61 & 0,6101 & 12,58 & $0,0177 \mathrm{a}$ & $0,0355 a$ & $0,0319 a$ & $0,0355 a$ \\
\hline Cresivius drucgraphus & 1,54 & 0,2032 & 29,76 & $0,2128 a$ & $0,1383 a$ & $0,1809 a$ & $0,1348 a$ \\
\hline xyleborus solitarius & 0,46 & 0,7075 & 12,80 & $0,0248 a$ & $0,0177 a$ & $0,0390 a$ & $0,0284 a$ \\
\hline Microcorthyrus ninimus & 0,9 & 0,3947 & 14,55 & 0,035 is & $0,0390 a$ & $0,0248 a$ & $0,0567 a$ \\
\hline Corthuluw sp.2 & 0,32 & $.0,811^{-}$ & 10,19 & $0,0142 a$ & $0,0177 a$ & $0,0213 a$ & $0,02 \div 3 a$ \\
\hline xurzoonus intricarius & $i, 2 j$ & 0,2825 & $\cdot 4,35$ & $0,0035 a$ & $0,0000 a$ & $0,0035 a$ & 0, ग10ба \\
\hline Monartirwm semiparrens & 0,26 & 0,3509 & 15,27 & $0,0496 a$ & $0,0496 a$ & $0,0035 a$ & $0,0496 a$ \\
\hline Cortiylus costuexicanda & 1,45 & 0,2265 & 25,04 & $0,0887 a$ & $0,1312 a$ & $0,1596 a$ & $0,1489 a$ \\
\hline
\end{tabular}

1 valores do ceste 5 da anälise de variāncia.

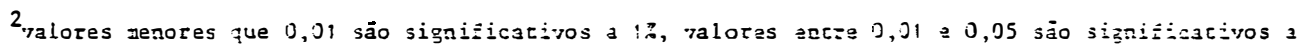

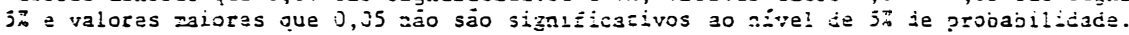

3 valores do coeficience de variaçāo da anälise de variäncia.

‘ mejdias seguidas de mesma letra zäo diferem estacisticamente pelo lasce de Tuxey a $5 \%$ de probajilidade 
Tabela 10 - Resultado de anālise de variância e teste de conparação de médias de capturas mensais de espécies de Scolytidae para di ferentes alturas de amadilhas de etanol. Agudos (SP), esta ção outinv (abril a setembro), abril de 1984 a março de 1987.

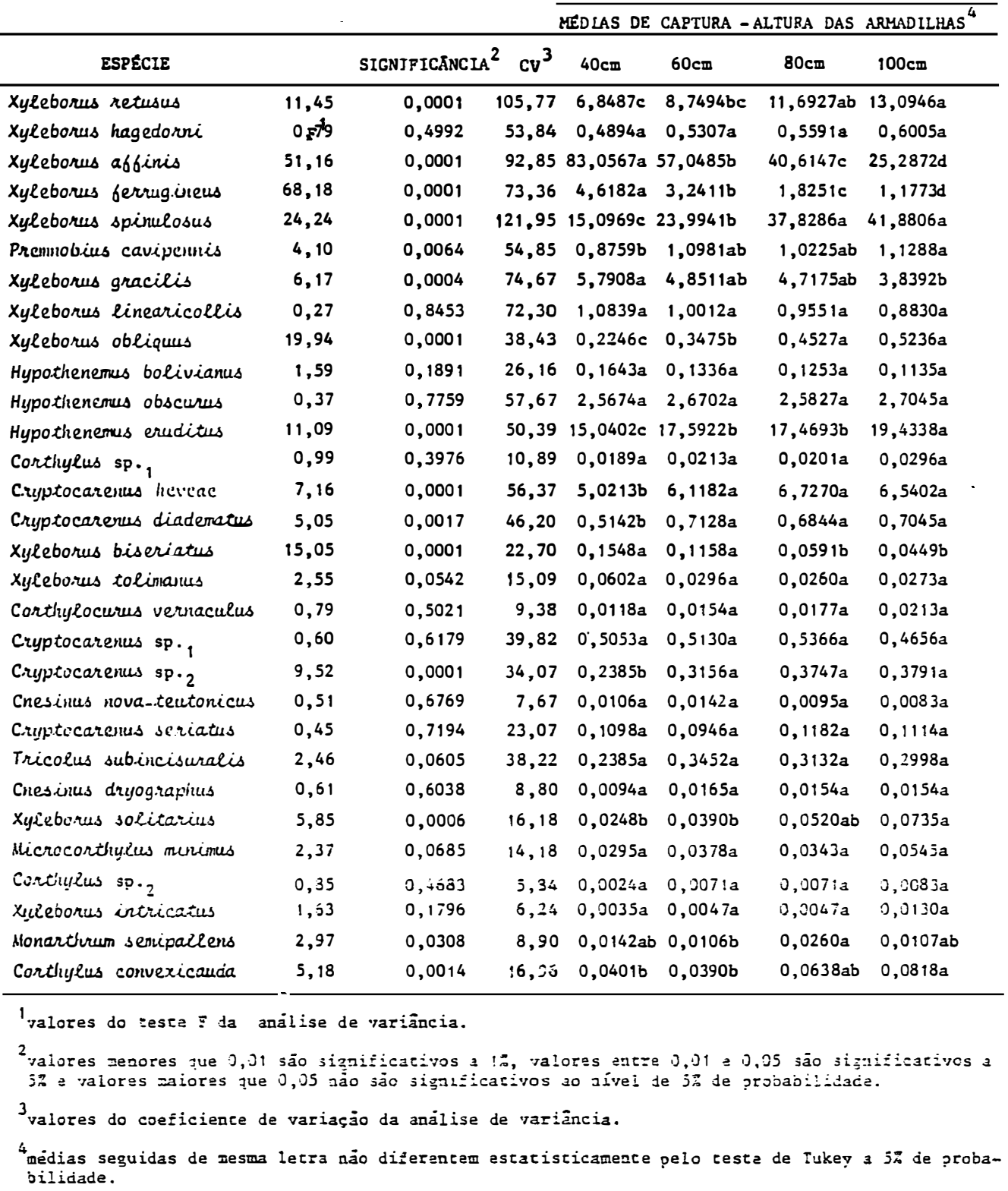


Tabela 11 - Resultado de análise de variância e teste de comparação de médias de capturas mensais de espécies de Scolytidae para di ferentes alturas de armadilhas de etanol. Agudos (SP), esta ção outinv (abril a setenbro), abril de 1984 a março de 1985.

\begin{tabular}{|c|c|c|c|c|c|c|c|}
\hline \multirow{2}{*}{\multicolumn{4}{|c|}{$p$}} & \multirow{2}{*}{\multicolumn{4}{|c|}{ MEDIAS DE CAPTURA - ALTURA DAS ARMADILHAS }} \\
\hline & & & & & & & \\
\hline ESPERCIE & $F^{1}$ & SIGN IFIC.INCLA ${ }^{2}$ & $\mathrm{Cv}^{3}$ & $40 \mathrm{~cm}$ & $60 \mathrm{~cm}$ & $80 \mathrm{~cm}$ & $100 \mathrm{~cm}$ \\
\hline$x_{y}$ leborus retusus & 6,76 & 0,0002 & 83,45 & $2,9078 c$ & 3,929 lbc & $5,1915 a b$ & $5,7872 a$ \\
\hline xyleborus hagedorri & 0,30 & 0,8265 & 66,25 & $1,1915 a$ & $1,1702 a$ & $1,3085 a$ & $1,4043 a$ \\
\hline xyReborus af́biris & 65,30 & 0,0001 & 47,68 & $72,2482 a$ & $47,6064 b$ & $35,2057 c$ & $24,1809 d$ \\
\hline xylebonus ferrug.ineus & 44,53 & 0,0001 & 63,74 & $9,2837 a$ & $6,1738 b$ & $3,7128 \mathrm{c}$ & $2,2695 d$ \\
\hline Xyleborus spinulosus & 17,08 & 0,0001 & 99,69 & $24,4149 b$ & $42,6702 b$ & $71,6915 a$ & $79,7482 a$ \\
\hline Premutobius cavipenuis & 1,79 & 0,1470 & 58,46 & $1,6525 a$ & $2,0142 a$ & $1,8404 a$ & $2,0674 a$ \\
\hline xylebores gracilis & 2,25 & 0,0811 & 66,22 & $8,5851 a$ & $7,3511 a$ & $7,0319 a$ & $6,0035 a$ \\
\hline xyleborus linearicollis & 1,92 & 0,1248 & 39,31 & $0,2801 a$ & $0,2695 a$ & $0,2766 a$ & $0,4823 a$ \\
\hline xyleborus obliques & 11,95 & 0,0001 & 43,80 & $0,4752 b$ & $0,6206 b$ & $0,9468 \mathrm{a}$ & $1,0071 a$ \\
\hline Hypothenenus bolivianus & 1,00 & 0,3924 & 23,88 & $0,1489 a$ & $0,9557 a$ & $0,0993 a$ & $0,0922 a$ \\
\hline Hejpothenenus obscurus & 1,28 & 0,2815 & 43,09 & $3,3014 a$ & $3,4029 a$ & $3,3404 a$ & $3,0177 a$ \\
\hline Hypothenenus eruditus & 12,30 & 0,0001 & 43,72 & $15,2979 b$ & $21,2057 a$ & $21,0638 a$ & $23,0107 a$ \\
\hline Corthyeus sp. 1 & 0,53 & 0,6587 & 12,59 & $0,0213 a$ & $0,0355 a$ & $0,0390 a$ & $0,0319 a$ \\
\hline C.zuptocarenus lisecue & 3,05 & 0,0278 & 46,01 & $4,9043 b$ & $5,7908 a b$ & $6,4255 a$ & $6,2624 a b$ \\
\hline Cryptocarenus diadeniatus & 1,37 & 0,2517 & 38,86 & $0,3227 a$ & $0,4184 a$ & $0,4362 a$ & $0,4113 a$ \\
\hline Xyleborus biseriatus & 8,92 & 0,0001 & 30,21 & $0,2837 a$ & $0,2411 a$ & $0,1064 b$ & $0,0816 b$ \\
\hline Xyleborus tolinasus & 2,97 & 0,0308 & 22,77 & $0,1590 a$ & $0,0638 a$ & $0,0674 a$ & $0,0679 a$ \\
\hline Corthylocures vernaculus & 0,23 & 0,8790 & 11,39 & $0,0212 a$ & $0,0319 a$ & $0,0248 a$ & $0,0250 a$ \\
\hline Cruptocarerus sp. & 1,09 & 0,3537 & 34,93 & $0,2933 a$ & $0,3511 a$ & $0,3759 a$ & $0,3643 a$ \\
\hline Cruptocarenus sp.2 & 3,96 & 0,0080 & 25,76 & $0,1025 b$ & $0,1489 a b$ & $0,1844 a b$ & $0,2071 \mathrm{a}$ \\
\hline Cnesinus nova-teutonicus & 0,84 & 0,4702 & 10,47 & $0,0247 \mathrm{a}$ & $0,0284 a$ & $0,0142 a$ & $0,0107 a$ \\
\hline cruppecocarenus seriatus & 0,25 & 0,8616 & 24,92 & $0,1343 a$ & $0,1099 a$ & $0,1489 a$ & $0,1321 \mathrm{a}$ \\
\hline Tricorus subincisuraris & 1,92 & 0,1240 & 46,20 & $0,5901 a$ & $0,8475 a$ & $0,7589 a$ & $0,7250 a$ \\
\hline Cnesinus drujographus & 0,67 & 0,5698 & 6,83 & $0,0035 a$ & $0,0106 a$ & $0,0142 a$ & $0,0071 \mathrm{a}$ \\
\hline xyreborus solitarius & 3,71 & 0,0113 & 10,76 & $0,0000 b$ & $0,0213 a b$ & $0,0248 \mathrm{ab}$ & $0,0429 a$ \\
\hline Nicrocortluges mininus & 0,16 & 0,9246 & 18,62 & $0,0636 a$ & $0,0780 a$ & $0,0638 a$ & $0,0750 a$ \\
\hline Corchulus sp. & 1,00 & 0,3926 & 2,18 & $0,0000 a$ & $0,0035 a$ & $0,0000 a$ & $0,0000 a$ \\
\hline xurzabous intricatus & 1,90 & 0,1282 & 9,33 & $0,0035 a$ & $0,0106 a$ & 0,01063 & $0,032: a$ \\
\hline Honarcirum semiparrzirs & 0,56 & 0,5 & 1,00 & $0,0141 a$ & 0,01773 & $0,0234 a$ & $0,0179 a$ \\
\hline Cortheress convexicauda & 4,78 & 0,0026 & 19,89 & $0,0353 b$ & $0,0603 b$ & 0,0816 ab & $0,1321 \mathrm{a}$ \\
\hline
\end{tabular}

ivalores do teste $F$ da analise de variäncia.

2 valores nenores que 0,01 sảo significativos a 1\%, valores entre 0,01 e 0,05 sajo significarivos a

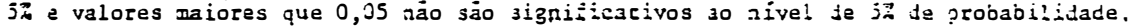

3 .ralores do coericience de variaçāo da andilise je variāncia,

† mëdias seguidas de mesma letra näo dižerem estacisticamence pelo reste de tukey a $5 \%$ fe probabilidade. 
Tabela 12 - Resultado de análise de variância e teste de comparação de médias de capturas mensais de espécies de Scolytidae para di ferentes alturas de armadilhas de etanol. Agudos (SP), estação outinv (abril a setembro), abril de 1985 amarço de 1986.

MEDIAS DE CAPTURA - ALTURA DAS ARMADILHAS ${ }^{4}$

\begin{tabular}{|c|c|c|c|c|c|c|c|}
\hline ESPÉCIE & $F^{1}$ & SIGNIFICÃNCIA ${ }^{2}$ & $\mathrm{cv}^{3}$ & $40 \mathrm{~cm}$ & $60 \mathrm{~cm}$ & $80 \mathrm{~cm}$ & $100 \mathrm{~cm}$ \\
\hline Xyfeborus retusus & 2,82 & 0,0376 & 97,96 & $6,4823 b$ & $7 ; 5000 a b$ & $9,7943 a b$ & $10,6277 a$ \\
\hline xylebones hagedorni & 2,89 & 0,0343 & 26,30 & $0,0887 b$ & $0,1915 a$ & $0,1667 a$ & $0,1667 a$ \\
\hline xylebores affiris & 22,33 & 0,0001 & 53,08 & $7,9716 a$ & $5,5000 b$ & $4,8157 b c$ & $3,7589 c$ \\
\hline xyleborus ferrug.ineus & 14,08 & 0,0001 & 46,40 & $0,9752 a$ & $0,6454 \mathrm{~b}$ & $0,4433 \mathrm{bc}$ & $0,3404 c$ \\
\hline Xyleborus spinulosus & 9,15 & 0,0001 & 57,22 & $0,4716 \mathrm{~b}$ & $0,8652 a$ & $1,1560 \mathrm{a}$ & $1,3050 a$ \\
\hline Premnobius cavipenis & 4,14 & 0,0063 & 39,58 & $0,2482 b$ & $0,3794 a b$ & $0,4433 a$ & $0,4823 a$ \\
\hline xyleborus gracilis & 1,55 & 0,2010 & 44,92 & $0,8759 a$ & $0,7021 a$ & $0,7163 a$ & $0,6454 a$ \\
\hline xyleborus Rinearicorris & 1,74 & 0,1564 & 17,74 & $0,0816 a$ & $0,0461 a$ & $0,0496 a$ & $0,0851 a$ \\
\hline xyleborus obliques & 6,28 & 0,0003 & 29,51 & $0,0957 \mathrm{~b}$ & $0,2199 a$ & $0,2199 a$ & $0,2908 a$ \\
\hline Hypothenemus bolivianus & 1,84 & 0,1385 & 24,10 & $0,1489 a$ & $0,1099 a$ & $0,1241 a$ & $0,0709 a$ \\
\hline Hypothenemus obscuress & 2,76 & 0,0410 & 44,61 & $0,5567 \mathrm{~b}$ & $0,7589 a$ & $0,7340 \mathrm{a}$ & $0,8085 a$ \\
\hline Hypothenenus eruditus & 4,73 & 0,0028 & 50,09 & $7,6170 \mathrm{~b}$ & $9,2447 a b$ & $8,6596 a b$ & $10,5071 \mathrm{a}$ \\
\hline Corthylus sp., & 0,80 & 0,4914 & 8,09 & $0,0106 a$ & $0,0035 a$ & $0,0106 a$ & $0,0177 a$ \\
\hline cryptocarcinus hereas & 4,72 & 0,0028 & 47,60 & $3,3369 b$ & $4,1525 a b$ & $4,7660 \mathrm{a}$ & $4,5993 a$ \\
\hline Cryptocarenus diadenatus & 2,62 & 0,0492 & 50,98 & $0,8723 b$ & $1,1667 a b$ & $1,1454 \mathrm{ab}$ & $1,2447 a$ \\
\hline xylebonus biseriatus & 5,85 & 0,0006 & 19,38 & $0,1383 a$ & $0,0745 a b$ & $0,0532 b$ & $0,0355 b$ \\
\hline xyceborus tolinasus & 0,29 & 0,8303 & 7,91 & $0,0142 a$ & $0,0906 a$ & $0,0035 a$ & $0,0035 a$ \\
\hline Cortrylocures vernaculus & 0,54 & 0,6567 & 5,25 & $0,0000 a$ & $0,0071 a$ & $0,0071 a$ & $0,0035 a$ \\
\hline Cryptocarenus sp., & 0,84 & 0,4741 & 40,79 & $0,5248 a$ & $0,4610 a$ & $0,5567 a$ & $0,4078 a$ \\
\hline Cryptocarenus sp. & 5,56 & 0,0009 & 35,37 & $0,2376 b$ & $0,3369 a b$ & $0,4220 a$ & $0,4397 a$ \\
\hline Cnesinus nova-teutonicus & 0,67 & 0,5711 & 5,31 & $0,0071 \mathrm{a}$ & $0,0071 \mathrm{a}$ & $0,0071 a$ & $0,0000 a$ \\
\hline Cryptocarenus serietus & 0,28 & 0,8386 & 19,12 & $0,0603 a$ & $0,0709 a$ & $0,0851 a$ & $0,0674 a$ \\
\hline Tricolus subincisuraris & 1,21 & 0,3058 & 23,60 & $0,0922 a$ & $0,1348 \mathrm{a}$ & $0,1312 a$ & $0,1489 a$ \\
\hline Cresinus drycgraphus & 0,33 & 0,8013 & 3,77 & $0,0035 a$ & $0,0000 a$ & $0,0035 a$ & $0,0035 a$ \\
\hline Xyleboreus solitarius & 0,53 & 0,6587 & 17,93 & $0,0390 a$ & $0,0496 \mathrm{a}$ & $0,0603 a$ & $0,0709 a$ \\
\hline Nicrccorturzus nininies & 1,27 & 0,2825 & 4,85 & $0,0035 a$ & $0,0000 a$ & $0,0035 a$ & $0,0106 a$ \\
\hline Cortiyzus 'sp.2 & 1,01 & 0,3892 & 6,11 & $0,0000 a$ & $0,0106 a$ & $0,01 r s a$ & $0,007 i a$ \\
\hline Xereocous iltiicatuj & $0,5 i$ & 0,5719 & 4,34 & $0,0071 \mathrm{a}$ & $0,0035 a$ & $0,0000 a$ & $0,0035 a$ \\
\hline Monarthrem senipazerss & 4,63 & 0,0032 & 6,45 & $0,0035 b$ & $0,0035 b$ & $0,0248 a$ & $0,0000 b$ \\
\hline Corthylus convexicauda & 1,95 & 0,1201 & 12,63 & $0,0142 a$ & $0,0213 a$ & $0,0496 a$ & $0,0355 a$ \\
\hline
\end{tabular}

1 valores do cesce $\tilde{z}$ da anälise de variânci.

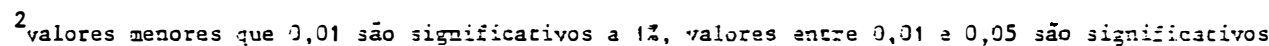

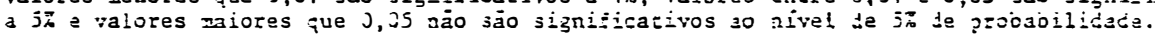

3 valores do coeficiente de variação da anälise de variāncia.

4 mèdias seguidas de mesma lecza não direrem escaristicamente pelo ceste de Tukey a jö de grobabilidade. 
Tabela 13 - Resultado de anālise de variāncia e teste de comparação de médias de capturas mensais de espécies de Scolytidae para di ferentes alturas de armadilhas de etanol. Agudos (SP), esta ção outinv (abril a setembro), abril de 1986 a março de 1987.

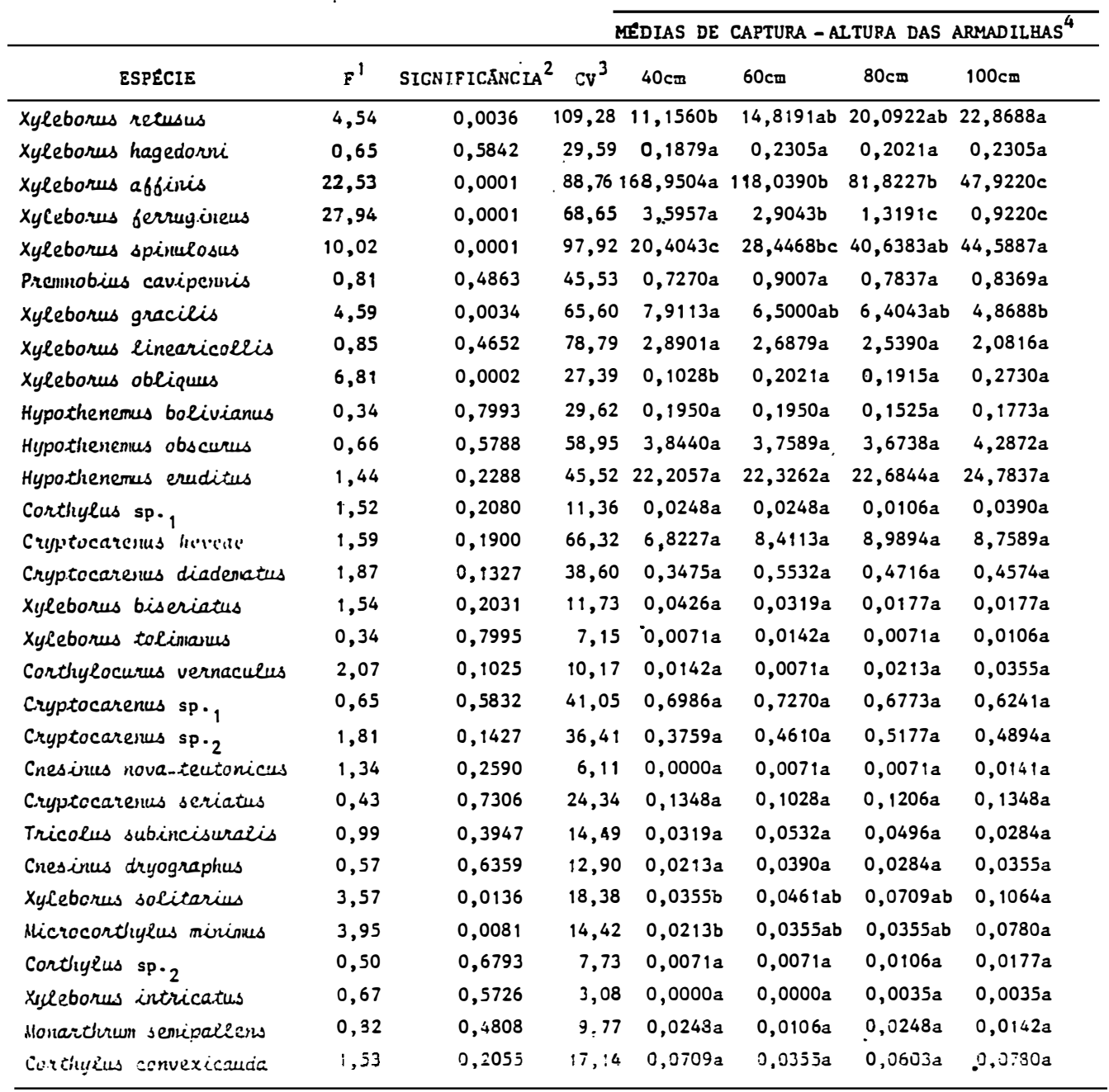

ivalores do reste $\vec{z}$ da anälise de variäncia.

2 valores menores que 0,01 säo significativos a 12 , valores encre $0,01: 0,05$ sảo significativos a $5 z$ e valores maiores que 0,05 năo são significarivos un aivei de $5 z$ de probabilidade.

3 valores do coericience de variaço da anaiise se rariäncia.

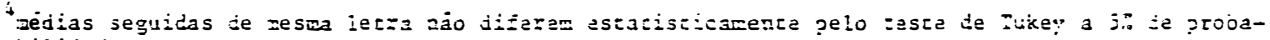
jilibiace. 


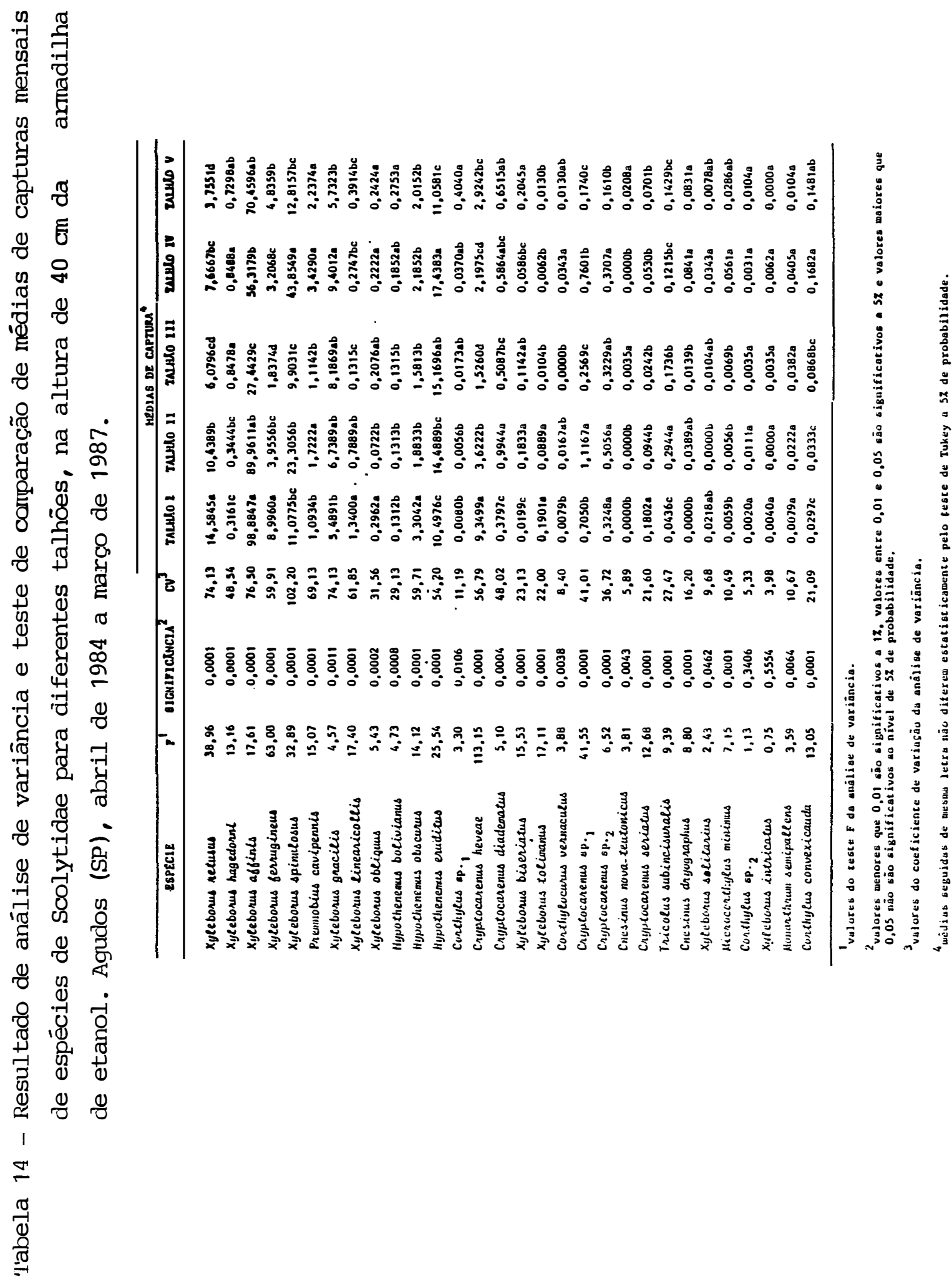




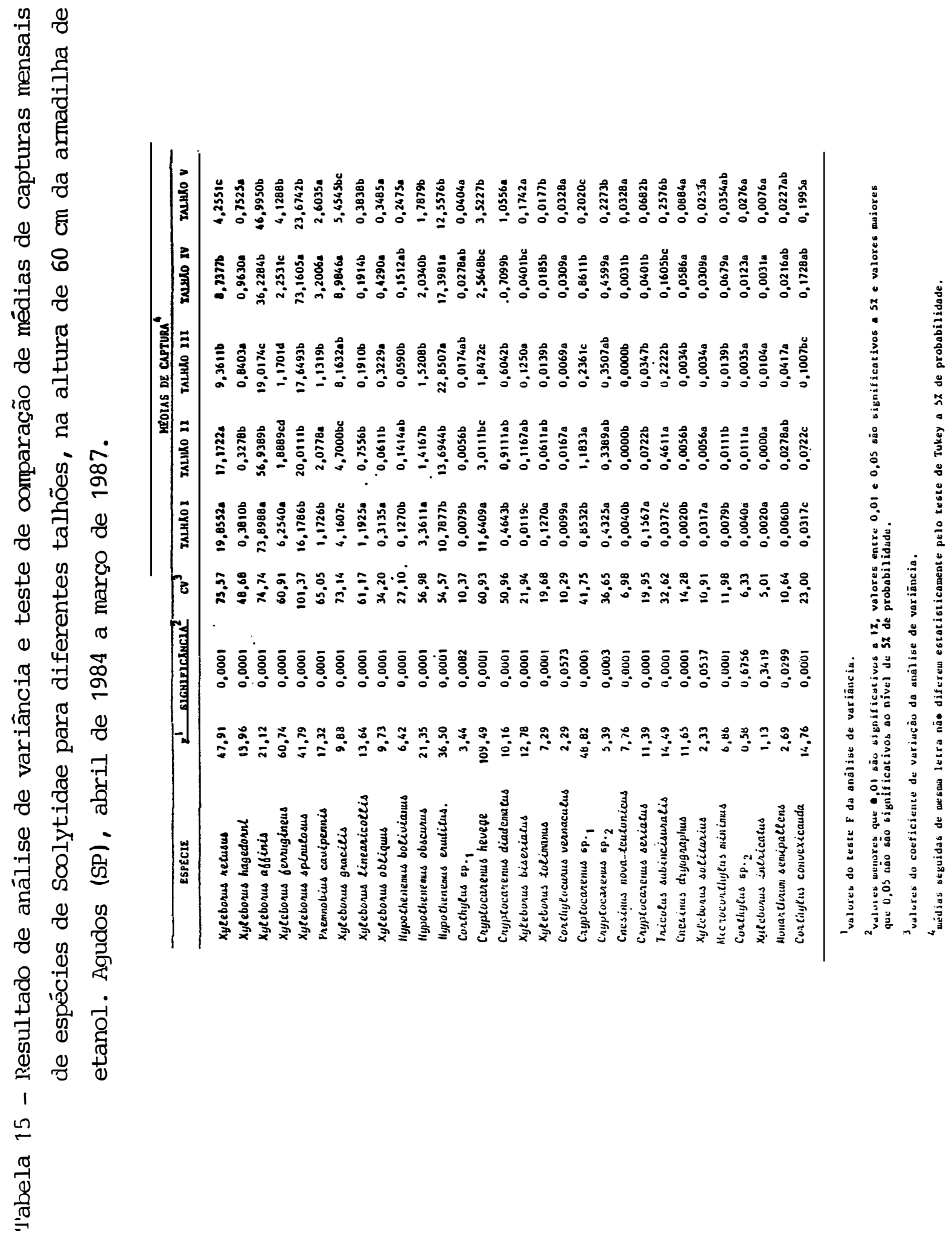




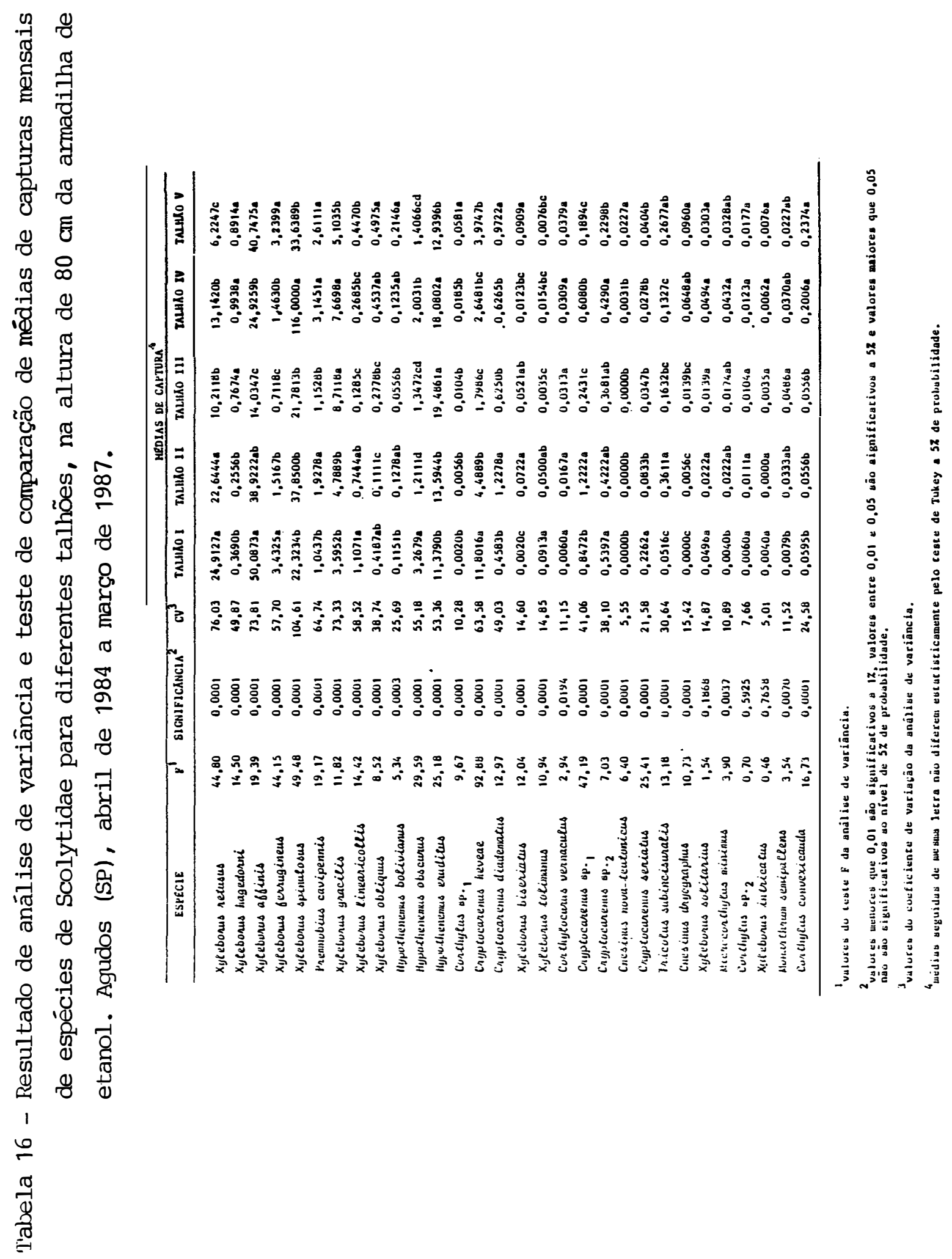




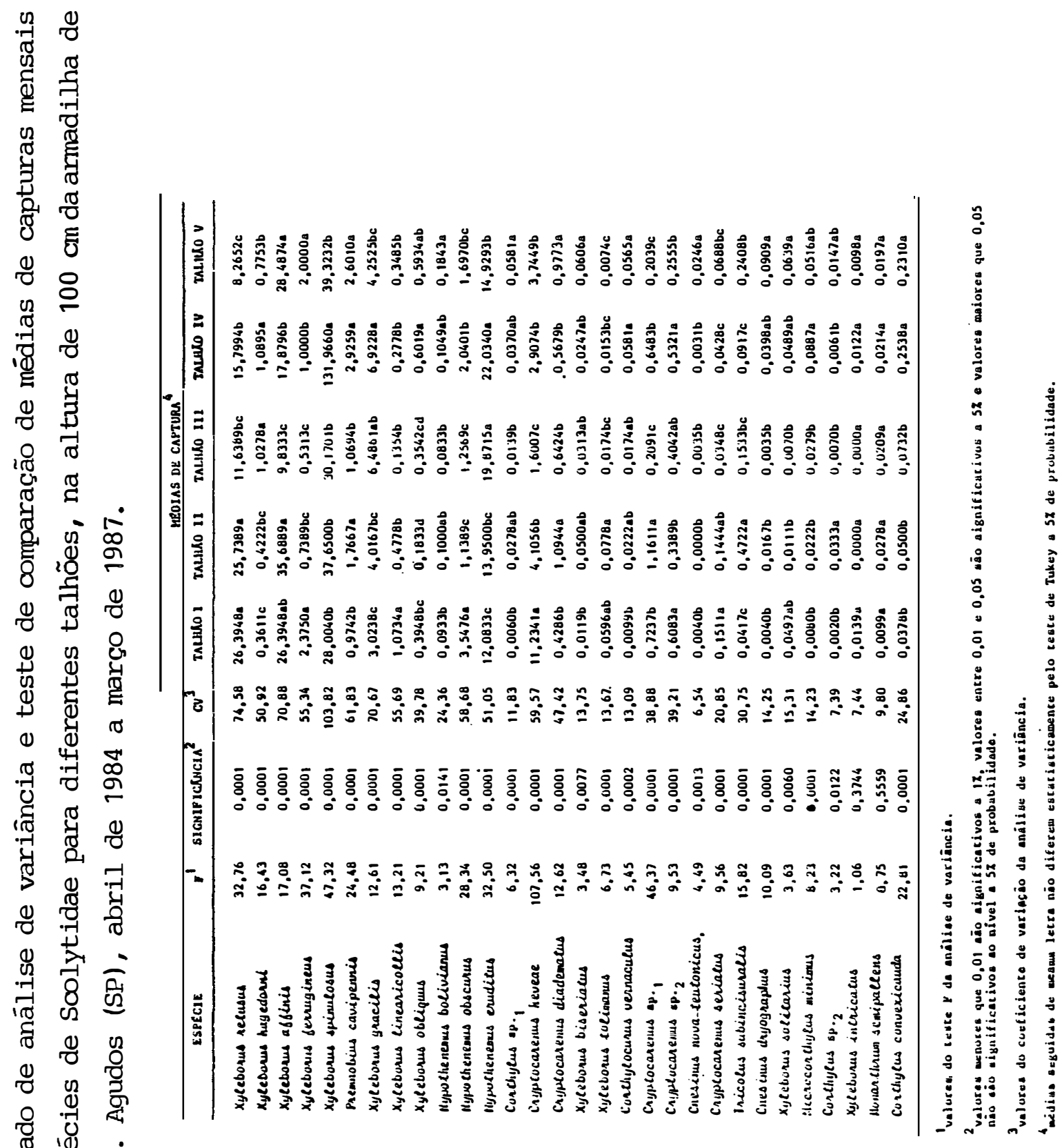


Tabela 18 - Resultado de análise de variância e teste de comparação de médias de capturas mensais do total de espécies de Scolyti dae para diferentes talhões e alturas de armadilhas de etanol. Agudos (SP), abril de 1984 a março de 1987.

\begin{tabular}{cccccccc}
\cline { 5 - 7 } & & & & \multicolumn{4}{c}{ MEDIAS DE CAPTURA - ALTURA DAS ARMADILHAS } \\
\hline IAIMAO & $F^{1}$ & SIGNIFICANCIA & $\mathrm{CV}^{3}$ & $40 \mathrm{~cm}$ & $60 \mathrm{~cm}$ & $80 \mathrm{~cm}$ & $100 \mathrm{~cm}$ \\
\hline 1 & 4,29 & 0,0050 & 53,08 & $165,6119 \mathrm{a}$ & $153,2480 \mathrm{ab}$ & $133,8532 \mathrm{ab}$ & $120,6342 \mathrm{~b}$ \\
2 & 0,47 & 0,7002 & 55,86 & $154,7389 \mathrm{a}$ & $135,6000 \mathrm{a}$ & $153,2000 \mathrm{a}$ & $132,7944 \mathrm{a}$ \\
3 & 0,23 & 0,8747 & 46,58 & $84,3993 \mathrm{a}$ & $83,0278 \mathrm{a}$ & $79,0799 \mathrm{a}$ & $86,8746 \mathrm{a}$ \\
4 & 3,96 & 0,0080 & 53,77 & $139,6480 \mathrm{~b}$ & $147,2037 \mathrm{ab}$ & $181,9691 \mathrm{ab}$ & $192,7890 \mathrm{a}$ \\
5 & 0,29 & 0,8337 & 52,07 & $121,6052 \mathrm{a}$ & $115,2879 \mathrm{a}$ & $117,2020 \mathrm{a}$ & $122,6536 \mathrm{a}$ \\
\hline
\end{tabular}

Tabela 19 - Resultado de análise de variância e teste de comparação cie médias de capturas mensais do total de espécies de Scolyti dae para diferentes alturas de armadilhas de etanol e total de talhöes. Agudos (SP), abril de 1984 a março de 1987.

\begin{tabular}{|c|c|c|c|c|c|c|}
\hline & \\
\hline & & & WIDIAS DE & CAPTURA - & ALTURA DAS & $\triangle R Y A D I Z$ NAS $^{4}$ \\
\hline$F^{\prime}$ & SIGNIFICANNCIA & $\mathrm{Cv}^{3}$ & $40 c s$ & $60 \mathrm{~cm}$ & $30 \mathrm{ctal}$ & $100 \mathrm{~cm}$ \\
\hline 0,10 & 0,9604 & 53,36 & $135,46610 a$ & $129,3765 a$ & $131,9048 a$ & 130,jó16a \\
\hline
\end{tabular}

'valores do ceste $\vec{F}$ da anälise de variância.

2 valores menores g̣ue 0,01 sāo signizicarivos a $1, \pi$, valores entze 0,01 e 0,05 säo signi

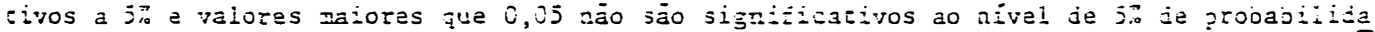
de.

3 valores do coeficiente de variaçào da anälise de variäncia.

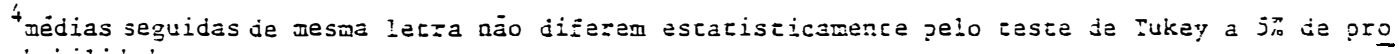
jabilidade. 
6. IITERATURA CITADA

ABRAHAMSON, I.P. \& NORRIS, D.M. Symbiotic interrelationships between microbes and ambrosia beetles (Coleoptera: Scoly tidae). V. Amino acids as a source of nitrogen to the fungi in the beetle. Annals of the Entomological Society of America, Columbus, 63(1): 177-80, 1970 .

ATKINS, M.D. A study of the flight of the douglas-fir beetle, Dendroctonus pseudotsugae Hopk. (Coleoptera: Scolytidae). I. Flight preparation and response. The Canadian Entomologist, Ottawa, 91(5): 283-91, 1959.

ATKINS, M.D. A study of the douglas-fir beetle Dendrocto nus pseudotsugae Hopk. (Coleoptera: Scolytidae). II. Flight movements. The Canadian Entomologist, Ottawa, $\underline{92}(12): 941-54,1960$.

ATKINS, M.D. A study of the ilight of the douglas-fir beetle Dendroctonus pseudotsugar Hopk. (Coleoptera: :Scolyticae). III. Flight capacity. Tile Cainatian En tomologist, Ottarva, 33(6): 467-74, 1961. 
ATKINS, M.D. Behavioural variation among scolytids in relation to their habitat. The Canadian Entomologist, Ottawa, $\underline{98}(3): 285-8,1966$.

ATKINS, M.D. Scolytid pheromones - ready or not. The Ca nadian Entomologist, Ottawa, 100(10): 1115-7, 1968.

ATKINSON, T.H. \& EQUIHUA-MARTINEZ, A. BiologY of bark and ambrosia beetles (Coleoptera: Scolytidae and Platypodidae) of a tropical rain forest in southeastern Mexico with an annotated checklist of species. Annals of the Entomological Society of America, Columbus, $\underline{79}(3)$ : : 414-9, 1986,

BASTOS, J.A.M. Ponteiro seco em maniçoba do Ceará, Manih glaziovii Muell. Arg. Fitossanidade, Fortaleza, $5(1)$ : : $47-9,1981$.

BATRA, I.R. Ecology of ambrosia fungi and their dissemination by beetles. Transactions of the Kansas Academy of Science, Topeka, $66(2): 213-36,1963$.

BATRA, I.R. Amorosia fungi: a taxonomic revision, anã nutri tional studies of some species. Mycologia, New York, 59 (6): $976-1017,1967$. 
BEAVER, R.A. Biological studies of brazilian Scolytidae and Platypopidae (Coleoptera). II. The tribe Bothrosternini. Papéis Avulsos de Zoologia, São Paulo, 26 (18): 227-36, 1973.

BEAVER, R.A. Biological studies of brazilian Scolytidae and Platypodidae (Coleoptera). V. The tribe Xyleborini. Zeit schrift fur angewandte Entomologie, Berlin, 80(1): 15-30, $1976 a$.

BEAVER, R.A. The biology of samoan bark and ambrosia beetles (Coleptera, Scolytidae and Platypodidae). Bulletin of Entomological Research, London, 65(4): 531-48, 1976b.

BERTI Filho, E. Coleópteros de importância florestal; 1 Scolytidae. IPEF, Piracicaba, (19): 39-43, 1979,

BERTI Filho \& FLECHTMANN, C.A.H, A model of ethanol trap to collect Scolytidae and Platypopidae (Insecta, Coleoptera). IPEF, Piracicaba, (34): 53-6, 1986.

BLETCHLY, T.D. A review of factors affecting ambrosia beetle attack in trees and felled logs. Embirr Forrstin Revirw, Londion, $\underline{40}(1): 13-8,1961$. 
BONDAR, G. Insectos nocivos e moléstias do coqueiro l cocos. nuciferal no Brasil. Salvador, Imprensa Official do Esta do, 1922. $113 \mathrm{p}$.

BONDAR, G. Insetos nocivos e moléstias do coqueiro lcocos. nuciferal no Brasil. Salvador, Tipografia Naval, 1940. $160 \mathrm{p}$

BORDEN, J.H.; IINDGREN, B.S.; CHONG, I. Ethanol and $\alpha$-pinene as synergists for the aggregation pheromones of two Gnatho trichus species. Canadian Journal of Forest Research, Ottawa, $10(3): 290-2,1980$.

BOUTZ, G.E.; BREWER, J.W.; BISHOP, J.N, Capture patterns of Scolytus multistriatus (Marsh.) (Col., scolytidae) attrac ted to a pheromone-baited trap. Zeitschrift fur angewand te Entomologie, Berlin, 99(4): 366-70, 1985.

BRIGHT Jr., D.E. Review of the tribe Xyleborini in America north of Mexico (Coleoptera: Scolytidae). The Canadian Entomologist, Ottawa, 100(12): 1288-323, 1968 .

BUCHANAN, N.D. Experiments with an amorosia beetle, xuldusan drus germanus (Blfd.). Jouriall of Economic Entomorogy, Nenasha, $3 \pm(3): 367-9,19 \pm 1$. 
CADE, S.C.; HRUTFIORD, B.F.; GARA, R.I. Identification of a primary attractant for Gnathotrichus sulcatus isolated from western hemlock logs. Journal of Economic Entomology, Menasha, $\underline{63}(3): 1014-5,1970$.

CARRANO-MOREIRA, A.F. Anālise faunistica de Scolytidae em co munidades florestais no Estado do Paranā. Recife, 1985. 90p. (Mestrado - Universidade Federal Rural de Pernambuco).

CARVALHO, M.B. Sobre dois inșetos nocivos à mangueira. Boletim da Secretaria de Agricultura, Indüstria e Comércio, Recife, $\underline{3}(2): 128-33,1938$.

CARVALHO, M.B. As pragas do coqueiro em Pernambuco, Boletim da Secretaria de Agricultura. Indūstria e Comércio, Recife, $\underline{5}(1): 47-51,1940$.

CARVALHO, M.B. Observações da secção de patologia vegetal do I.P.A. Boletim da Secretaria de Agricultura, Indūstria e Comércio, Recife, $8(1):$ 97-9, 1941.

CARVALHO, M.B, \& CARVALHO, R.F, Primeira contribuição para um catálogo dos insetos ae pernambuco. Arquivos du Instituto de Pesquisas Agronômicas, Recife: (2): 27-60, 1939. 
CHAPMAN, J.A. Field studies on attack flight and log selection by the ambrosia beetle Trypodendron lineatum (Oliv.) (Coleoptera: Scolytidae). The Canadian Entomologist, Ottawa, $\underline{94}(1): 74-92,1962$.

CHAPMAN, J.A. The effect of attack by the ambrosia beetle Trypodendron lineatum (Olivier) on log attractiveness. The Canadian Entomologist, Ottawa, 98(1): 50-9, 1966.

CHAPMAN, J.A. . Ommatidea numbers and eyes in scolytid beetles. Annals of the Entomological Society of America, Columbus, $\underline{65}(3): 550-3,1972$.

CHAPMAN, J.A. \& KINGHORN, J.M. Studies of flight and attack activity of the ambrosia beetle, Trypodendron lineatum (Oliv.), and other scolytids. The Canadian Entomologist, Ottawa, $\underline{90}(6): 362-72,1958 a$.

CHAPMAN, J.A. \& KINGFORN, J.M. WindOw flight traps for insects. The Canadian Entomologist, Ottawa, 87(1): 46-7, 1958b.

CHAPMAN, J.A. \& NIJHOLT, W. N. Time of atiack i.light oj ambro sia beetre Trupodenaron rineatum loriv. I lCozeptera : Scolytidarl in relation to weather in coastar British columbia. Victoria, Environment Canaäa, 1980. (Iorest serviCe, $B C-R-5)$. 
CHARARAS, C. Attraction chimique et sexuelile chez les Scolytidae des conifères. Comptes Rendus Hebdomadaires de Séan ces de l'Académie d'Agriculture de France, Paris, 57(11): : 845-54, 1971 .

CHARARAS, C. Etude de l'attraction secondaire et de l'élaboration des phéromones chez divers scolytidae polygames parasites des conifères. Comptes Rendus des Séances de la Societé de Biologie et de ses Filiales, Paris, 170(2): : $340-4,1976$.

CIANCIULli, P.L. Azulado da madeira. Divulgação Agronômica, Rio de Janeiro, (43): 15-22, 1978 .

COOK, S.P. \& HAIN, F. Qualitative examination of the hyper-. sensitive response of loblolly pine, Pinus taeda L., inoculated with two fungal associates of the southern pine beetle, Dendroctonus frontalis Zimmermann (Coleoptera:Sco lytidae). Environmental Entomology, College Park, 14 (4): : $396-400,1985$.

ESTADOS UNIDOS. DEPARTMENT OF AGRICULTURE. FOrest Service. Insects of eastin jorestis. washington, 1985. 608p. (Mis cellaneous publ, , 1975). 
DOUROJEANNI, M.J. Los gorgojos de ambrosia de las familias Scolytidae y Platypodidae (Coleoptera) en el Peru. Anales Cientéficos, Lima, $\underline{3}(1): 9-32,1965$.

DUNN, J.P.; KIMMERER, T.W.; NORDIN, G.L. Attraction of the twolined chestnut borer, Agrilus bilineatus (Weber) (Coleoptera: Buprestidae), and associated borers to volatiles of stressed white oak. The Canadian Entomologist, Ottawa, $118(6): 503-8,1986$.

FATZINGER, C.W. Attraction of the black turpentine beetle (Coleoptera: Scolytidae) and other forest Coleoptera to turpentine-baited traps. Environmental Entomology, college Park, 14 $(6): 768-75,1985$.

FISHER, R.C.; THOMPSON, G.H.; WEBB, W.E. Ambrosia beetles in forest and sawmill. Their biology; economic importance and control. Part I: Biology and economic importance. Forestry Abstracts, Oxford, $14(4): 381-9,1953$.

FRANCKE-GROSMANN, H. Some new aspects in forest entomology. Annual Review óf Entomology, Stanford, 8: 415-38, 1963. 
FRENCH, J.R.J. \& ROEPER, R.A. Interactions of the ambrosia beetle, Xyleborus dispar (Coleoptera: Scolytidae), with its symbiotic fungus Ambrosiella hartigii (Fungi Imperfecti). The Canadian Entomologist, Ottawa, 104(10): 1635-41, 1972.

FROST, S.W. \& DIETRICH, H. Coleoptera taken from bait-traps. Annals of the Entomological Society of America, Columbus, $\underline{22}(3): 427-37,1929$.

GAGNE, J.A. \& KEARBY, W.H. Host selection by Xyleborus celsus (Coleoptera: Scolytidae) in Missouri. The Canadian Entomologist, Ottawa, 110(10): 1009-13, 1978 .

GIESE, R.I. The columbian timber beetle, Corthylus columbianus (Coleoptera: Scolytidae). V. A description of the myce tangia. The Canadian Entomologist, Ottawa, 99(1): 54-8, 1967 .

GIL, J.; PAJARES, J.; VIEDMA, M.G. Estudios acerca de la atraccion primaria en Scolyticae (Coleoptera) parasitos de coniferas. Boletín de la Estación Central de Ecologia, Madrid, 14(27): 107-25, 1985. 
GOHEEN, D.J.; COBB Jr., F.W.; WOOD, D.L.; ROWNEY, D.L. Visitation frequencies of some insect species on Ceratocystis wageneri infected and apparently healthy ponderosa pines. The Canadian Entomologist, Ottawa, 117(12): 1535-43, 1985.

GRAHAM, K. Fungal-insect mutualism in trees and timber. Annual Review of Entomology, Stanford, 12: 105-26, 1967.

GRAHAM, K. Anaerobic induction of primary chemical attractancy for ambrosia beetles. Canadian Journal of Zoology, Ottawa, $\underline{46}(5): 905-8,1968$.

GRAY, B. Observations on insect flight in a tropical forest plantation. IV. Flight activity of Scolytidae (Coleoptera). Zeitschrift fur angewandte Entomologie, Berlin, $75(2)$ : 178$-86,1974$.

HOSKING, G.P. \& KNIGHT, F.B. Flight habits of some Scolytidae in the spruce-fir type of northern Maine. Annals of the En tomological Society of America, Columbus, 68(5): 917-21, 1975 . 
KABIR, A.K.M.F. \& GIESE, R.I. The columbian timber beetle, Corthylus columbianus (Coleoptera: Scolytidae). II. Fungi and staining associated with the beetle in soft maple. Annals of the Entomological Society of America, Columbus, $\underline{59}(5): 894-902,1966$.

KLIMETZEK, D.; KOHLER, J,; VITÉ, J.P.; KOHNLE, V. DOsage response to ethanol mediates host selection by "secondary" bark beetles. Naturwissenschaften, Berlin, 73(5): 270-2, 1986 .

KUMAR, A. \& CHANDRA, A. Hitherto little or unknown males of some indian species of Xyleborus (Scolytidae: Coleoptera). Oriental Insects, Delhi, 11(1): 31-48, 1977.

LARA, F.E. \& SHENEFELT, R.D. Some Scolytidae and Platypodidae associated with cacao in Costa Rica. Turrialba, San José, $\underline{15}(3): 169-77,1965$.

LEUSCHNER, W.A. Impacts of the southern pine beetle. In: TATCHER, R.C.; SEARCy, J.L.; COSTER, J.E.; HERTEL, G.D. The southern pine beetle. Pineville, USDA Forest Service, 1982. p. 137-50. 
LIMA, A.C. Coleópteros. In: __. Insetos do Brasil. Rio de Janeiro, ENA, 1956. V. 10, pt. 4. (Didática, 12).

MARQUES, E.N. Scolytidae e Platypodidae em Pinus taeda. Curitiba, 1984. 65p. (Mestrado - Universidade Federal do Paranā).

MILANEZ, J.M.; SORIA, S.J.; ABREU, J.M. Coleobrocas da família Scolytidae associadas ao cacaueiro. Informe Técnico. Centro de Pesquisas do Cacau, Itabuna, p. 76-80, 1982.

MOECK, H.A. Ethanol as the primary attractant for the ambrosia beetle Trypodendron lineatum (Coleoptera: Scolytidae). The Canadian Entomologist, Ottawa, 102(8): 985-95, 1970.

MOECK, H.A. Ethanol induces attack on trees by spruce beetles, Dendroctonus rufipennis (Coleoptera: Scolytidae). The Canadian Entomologist, Ottawa, 113(10): 939-42, 1981.

MONTGOMERY, M.E. \& WARGO, P.M. Ethanol and other host-derived volatiles as attractants to beetles that bore into hardwoods. Journal of Chemical Ecology, New York, $9(2):$ 181-90, 1983. 
MOSER, J.C. \& DELI, T.R. Predictors of southern pine beetle flight activity. Forest Science, Washington, 25(2): 217$-22,1979$.

NAKAYAMA, K. \& TERRA, P.S. Atratividade de substāncias e de ramos de cacaueiros sobre Xylosandrus morigerus (Blandford, 1894 ) (Coleoptera, Scolytidae). Revista Theobroma, Ilhéus, $\underline{16}(3): 155-60,1986$.

NIJHOLT, W.W. \& CHAPMAN, J.A. A flight trap for collecting living insects. The Canadian Entomologist, Ottawa, 100(11): : 1151-3, 1968 .

NOBUCHI, A. The Scolytidae (Coleoptera) of the Philippines. Jarq, Tokyo, 16(4): 296-305, 1983.

NUNBERG, M. Contribution to the knowledge of prothoracic glands of Scolytidae and Platypodidae (Coleoptera). Annales Musei Zoologici Polonici, Warszawa, 14(18): 261-5, 1951.

PAINE, T.D. Influence of the mycangial fungi of the western pine beetle on water conduction through poncerosa pine seedings. Canadian jouinal of Botany, Ottawa, 62(3): : 556-8, 1984. 
PEDROSA-MACEDO, J.H. Riscos da não utilização de resíduos florestais. In: CURSO DE ATUALIZAÇĀO SOBRE SISTEMAS DE EX PLORAÇĀO E TRANSPORTE FLORESTAL, 5., Curitiba, 1984, edita do por B.A.D. Lopez; S.A. Machado; J.H. Pedrosa-Macedo; J. B. Juvilar; C.C. Machado; J.R. Malinovski; C.B. Reissmann. Curitiba, FUPEF, 1984, p. 40-9.

PEDROSA-MACEDO, J.H. Insect pests and their control in pine plantations in Brazil. In: IUFRO WORKSHOP ON PROTECTION OF FORESTS IN THE TROPICS, Curitiba, 1985. Curitiba, Universidade Federal do Paraná, 1985. V. 2, p. 149-61.

PERSON, H.I. Theory in explanation of the selection of certain trees by the western pine beetle. Journal of Forestry, Washington, 29 (5): 696-9, 1931 .

PICKEL, B. Os insetos daninhos da cana de açücar em Pernambuco. Brasil Açucareiro, Rio de Janeiro, 13(3): 42-9, 1939.

PINHEIRO, J.V. Contribuição para o conhecimento de insetos dos eucaliptais no Brasil. Anuārio Brasileiro de Economia Floresial, Rio de Janeiro, 14 (4): 245-55, 1962. 
ROLING, M.P. \& KEARBY, W.H. Life stages and development of Monarthrum fasciatum (Coleoptera: Scolytidae) in dying and dead oak trees. The Canadian Entomologist, Ottawa, 106(12): : $1301-8,1974$.

ROLING, M.P. \& KEARBY, W.H. Seasonal flight and vertical dis tribution of Scolytidae attracted to ethanol in an oak-hickory forest in Missouri. The Canadian Entomologist, Otta wa, $107(12): 1315-20,1975$.

ROLING, M.P. \& KEARBY, W.H. Influence of tree diameter, aspect, and month killed on the behaviour of scolytids infesting black oaks. The Canadian Entomologist, Ottawa, $\underline{109}(9): 1235-8,1977$.

RUDINSKY, J.A. Ecology of Scolytidae. Annual Review of Ento mology, Stanford, 7: 327-48, 1962 .

RUDINSKY, J.A. \& DATERMAN, G.E. Field studies on flight patterns and olfactory responses of ambrosia beetles in douglas-fir forests of western Oregon. The Canadian Entumolo gist, Ottawa, 96 $(10): 1339-52,1964$. 
RUDINSKY, J.A. \& SCHNEIDER, I. Effects of light intensity on the flight pattern of two Gnathotrichus (Coleoptera: Scoly tidae) species. The Canadian Entomologist, Ottawa, 101(12): : 1248-55, 1969.

SAMANIEGO, A.V. \& GARA, R.I. Estudios sobre la actividad de vuelo y selección de huéspedes por Xyleborus spp. y Platy pus spp. (Coleóptera: Scolytidae y Platypodidae). Turrialba, San José, 20 (4): 471-7, 1970.

SAUNDERS, J.L. \& KNOKE, J.K. Diurnal emergence of Xyleborus ferrugineus (Coleoptera: Scolytidae) from cacao trunks in Ecuador and Costa Rica. Annals of the Entomological Society of America, Columbus, 60(5): 1094-6, 1967.

SCHMUTZENHOFER, H. Status of forest insects in pine and eucalypt plantations in the tropics. In: IUFRO WORKSHOP ON PROTECTION OF FORESTS IN THE TROPICS, Curitiba, 1985. Curitiba, Universidade Federal do Paraná, 1985a. V. 2, p. $12-9 a$.

SCFMUTZENHOFER, H. The use of pheromones for insect pest survey and pest control methods. In: IUFRO INORKSHOP ON PROTECTION OF FORESTS IN THE TROPICS, Curitioa, 1985. Curitiba, Universidade Federal do Płraná, 19850. v2, p. 208-13. 
SCHONHERR, J. Proposta para a criação de um serviço federal de reconhecimento de pragas florestais no Brasil. Brasil Florestal, Brasilia, $\underline{5}(19): 34-6,1974$.

SCHÖNHERR, J. Contribuição à taxonomia e ecologia dos escolí tídeos do Brasil. In: IUFRO WORKSHOP ON PROTECTION OF FORESTS IN THE TROPICS, Curitiba, 1985. Curitiba, Universidade Federal do Paraná, 1985. V. 2, p. 117-26.

SCHONHERR, J. Noxious insects of the araucaria. In: IUFRO WORID CONGRESS 18., Ljubljana, 1986. Vienna, IUFRO, 1986. V. 1, p. $278-85$.

SCHONHERR, J. \& PEDROSA-MACEDO, J,H, Tierische Schadlinge in forstlichen Monokulturen im Suden Brasiliens. Allgemeine Forstzeitschrift, Mulnchen, (29): 788-90, 1979.

SCHONHERR, J. \& PEDROSA-MACEDO, J.H. SCOlytoidea in den Aufforstungen Brasiliens. Ein Beitrag zur Kentnis der Borkenkafer Stdamerikas. Zeitschrift fur angewandte Entomologie, Berlin, $\underline{92}(1): 48-61,1981$,

TURNBOW Jr., R.H. \& ERANKLIN, R.T. Flight activity by Scoly tidae in the northeast Georgia Piedmont (Coleoptera). Jour nal ois the Georgia Eniomological Socizit, Athens, 15(1): 26-37, 1980 . 
WOOD, S.L. The bark and ambrosia beetles of North and Central America (Coleoptera: Scolytidae), a taxonomic monograph. Great Basin Naturalist Memoirs, Provo, n. 6, 1982. 1361 p.

WOOD, S.L. A reclassification of the genera of Scolytidae (Coleoptera). Great Basin Naturalist Memoirs, Provo, n. $10,1986.126$ p.

YAMASHIRO, T. \& MYAZAKI, I. Principais pragas e doenças da mangueira - Mangifera indica I, - no Estado de São Paulo e métodos analisados de controle. O Biológico, São Pau$10, \underline{51}(2): 41-50,1985$. 
.112.

APENDICES 


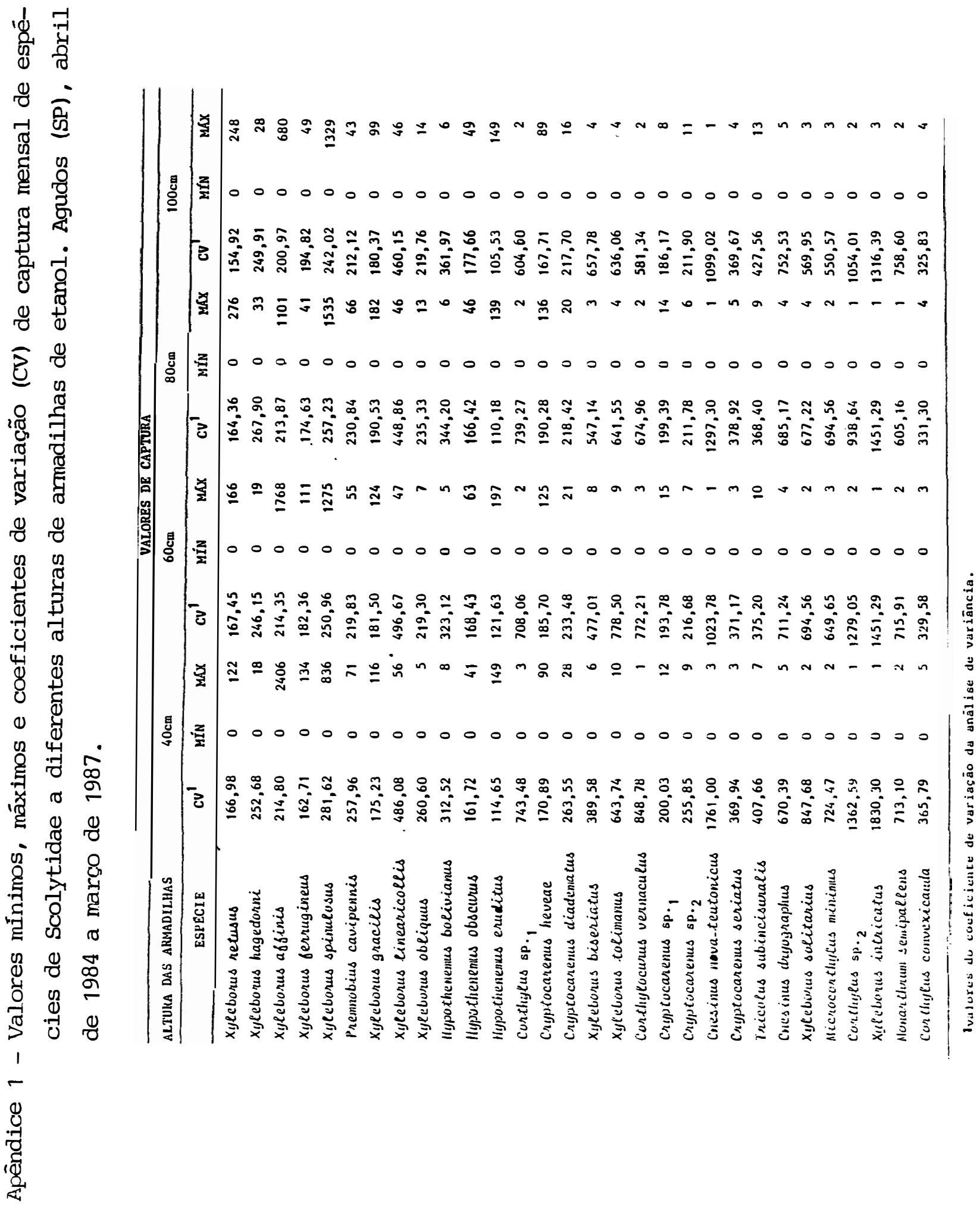


.114 .

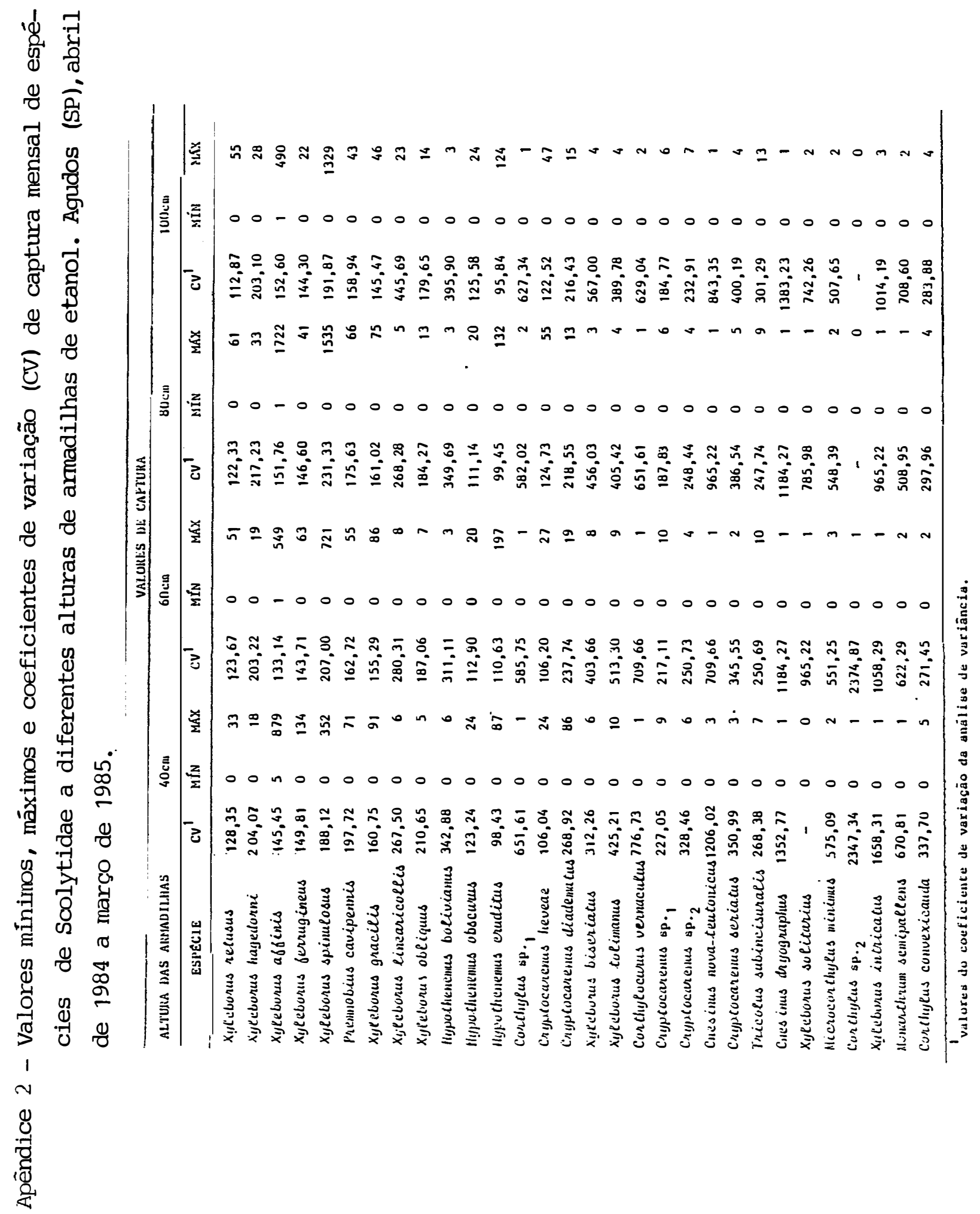


.115 .

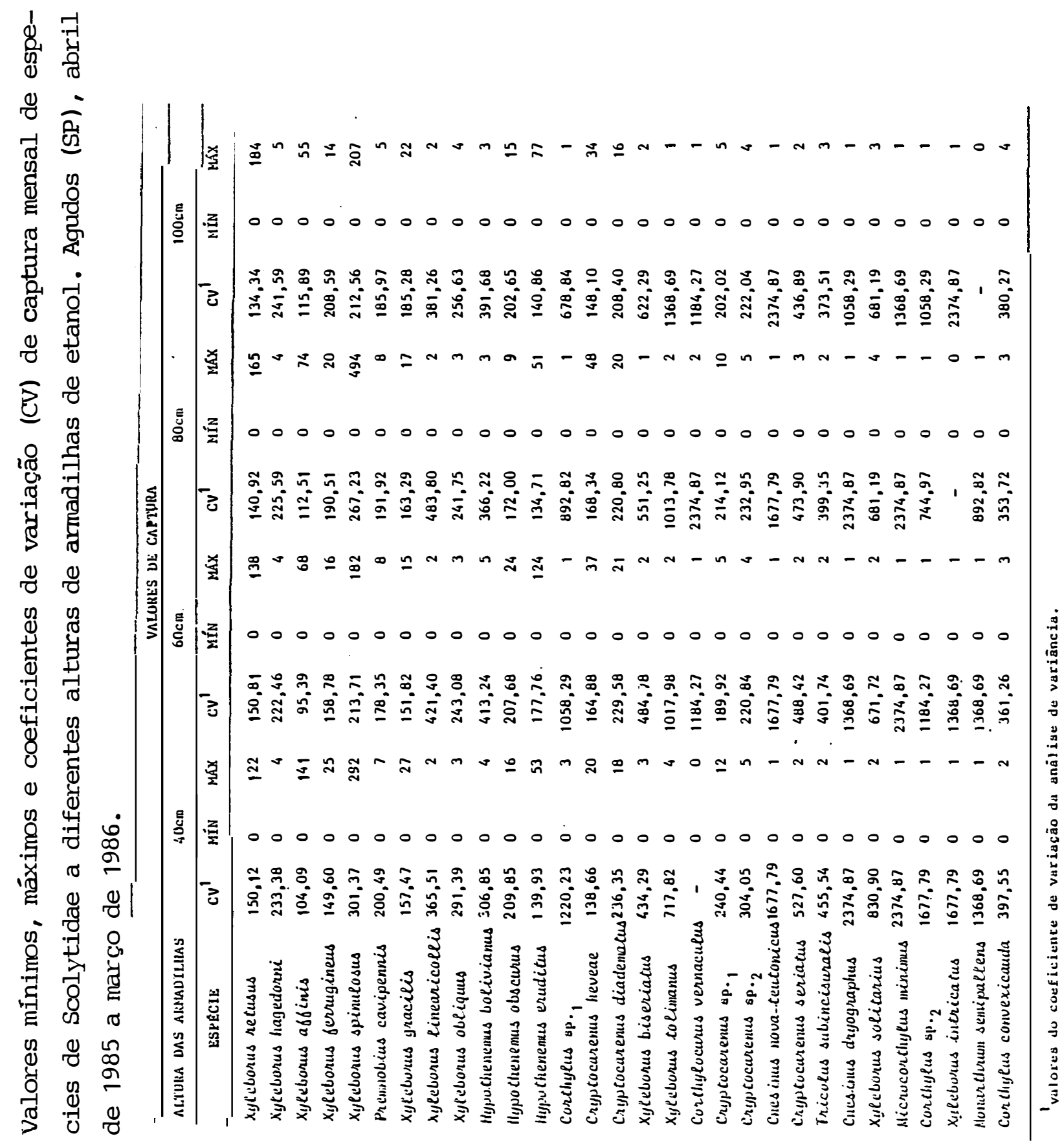


.116.

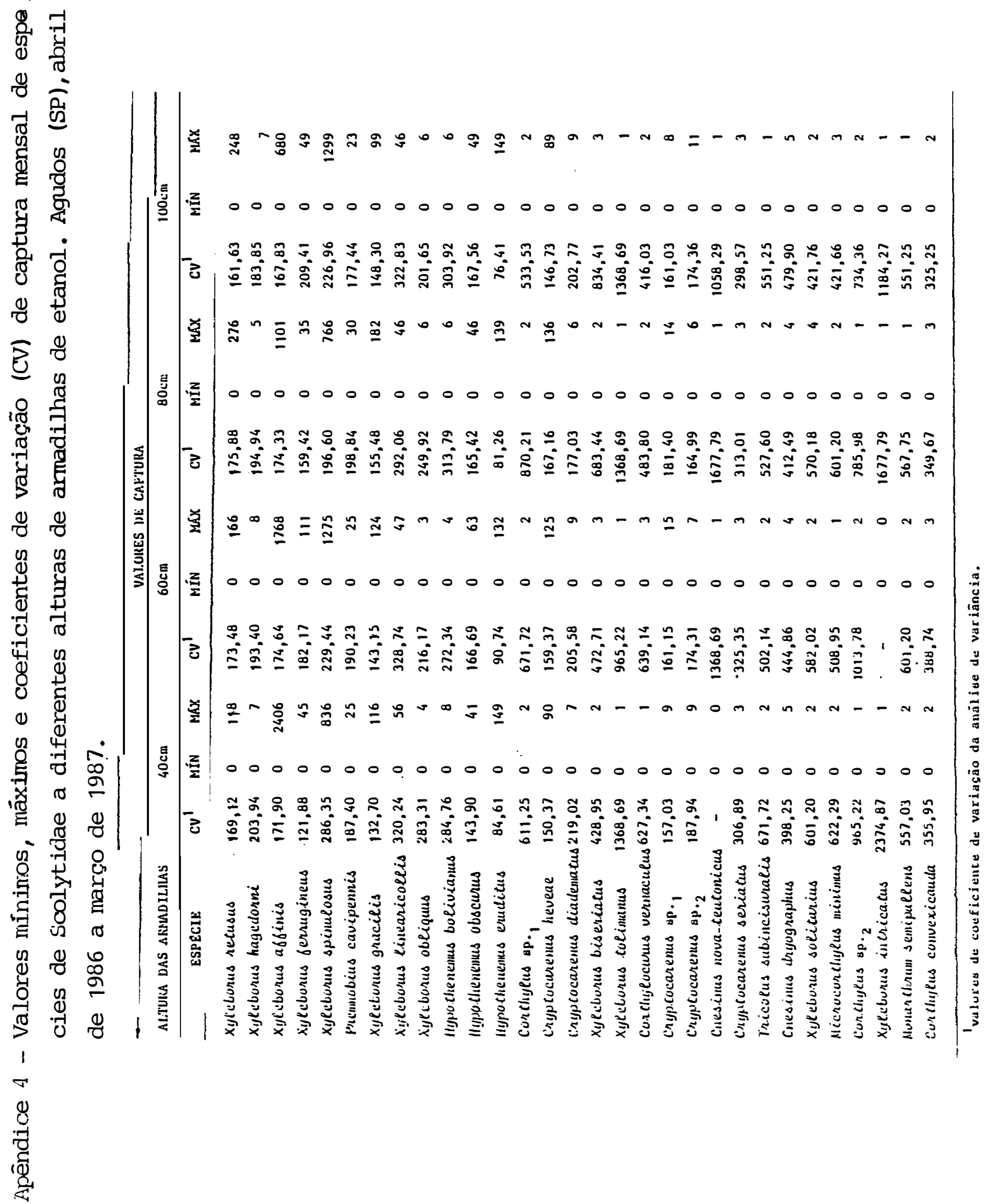




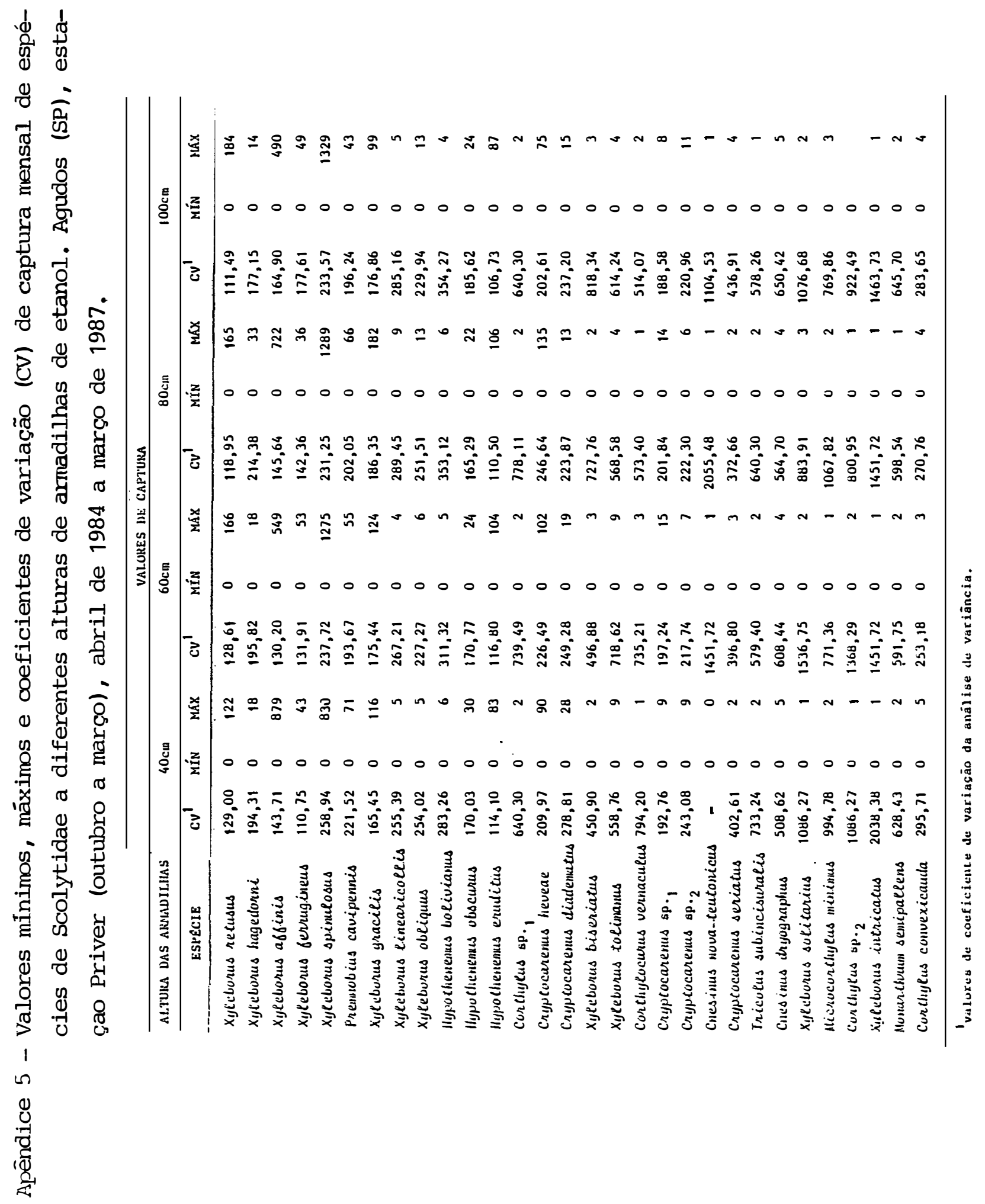


.118.

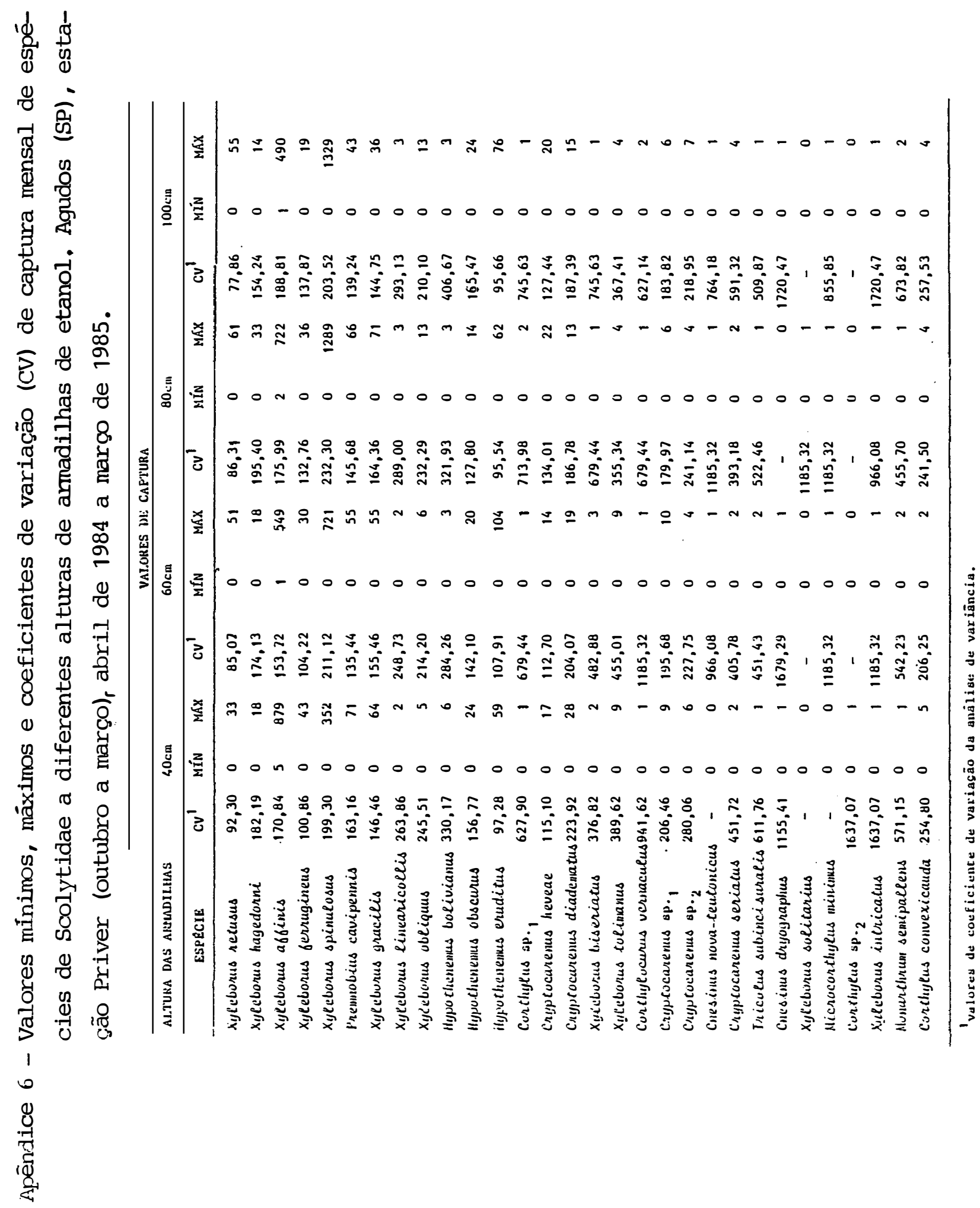




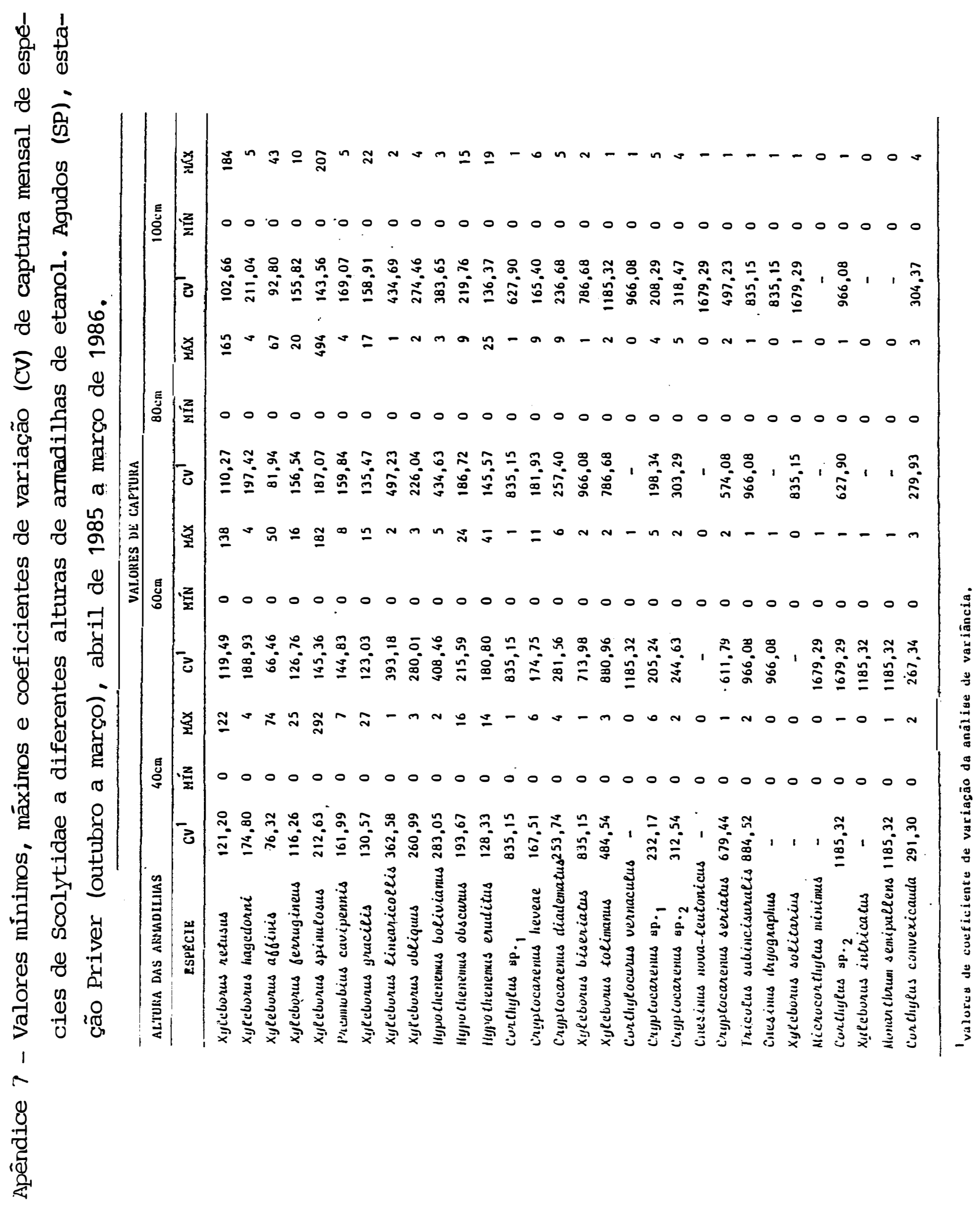




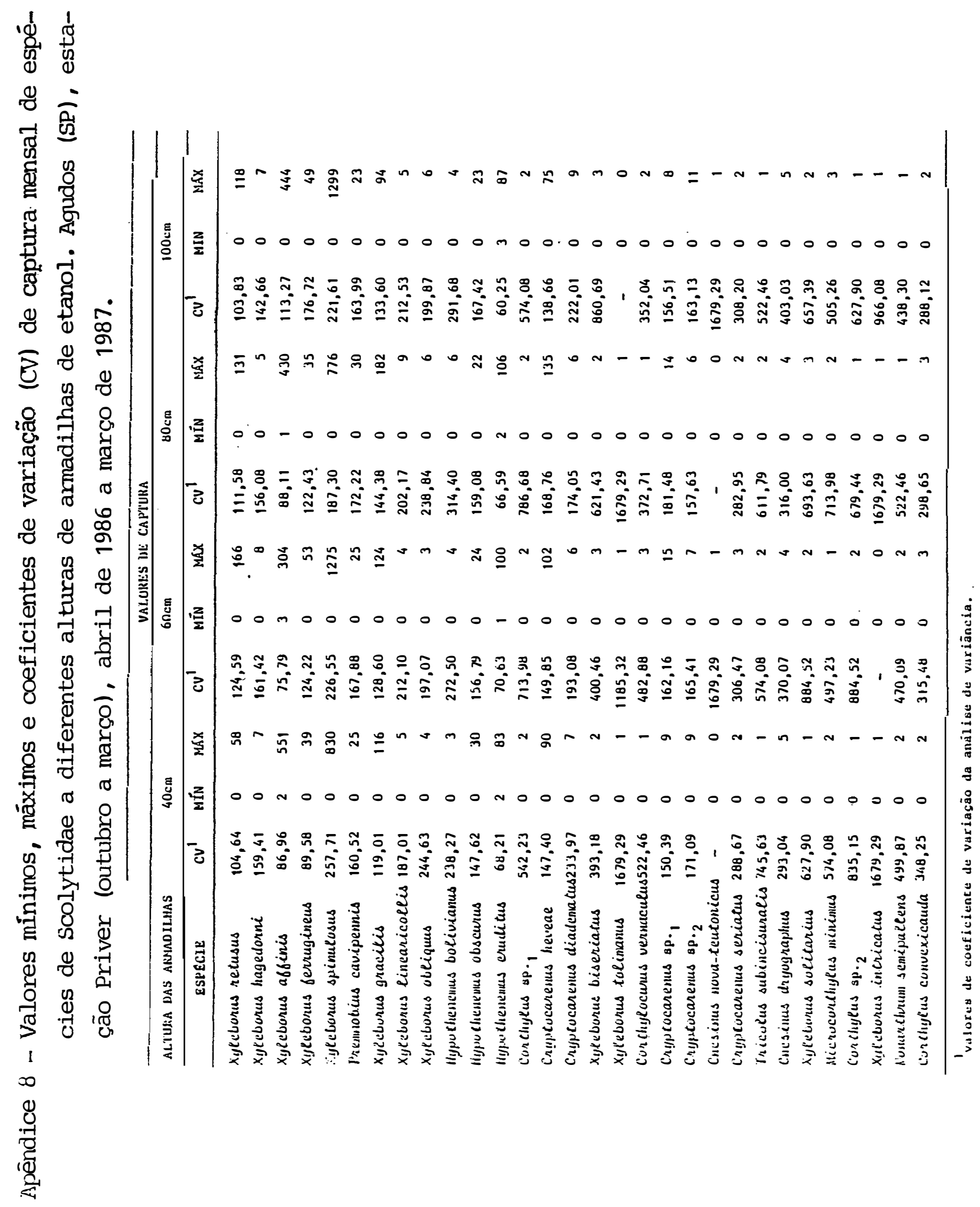




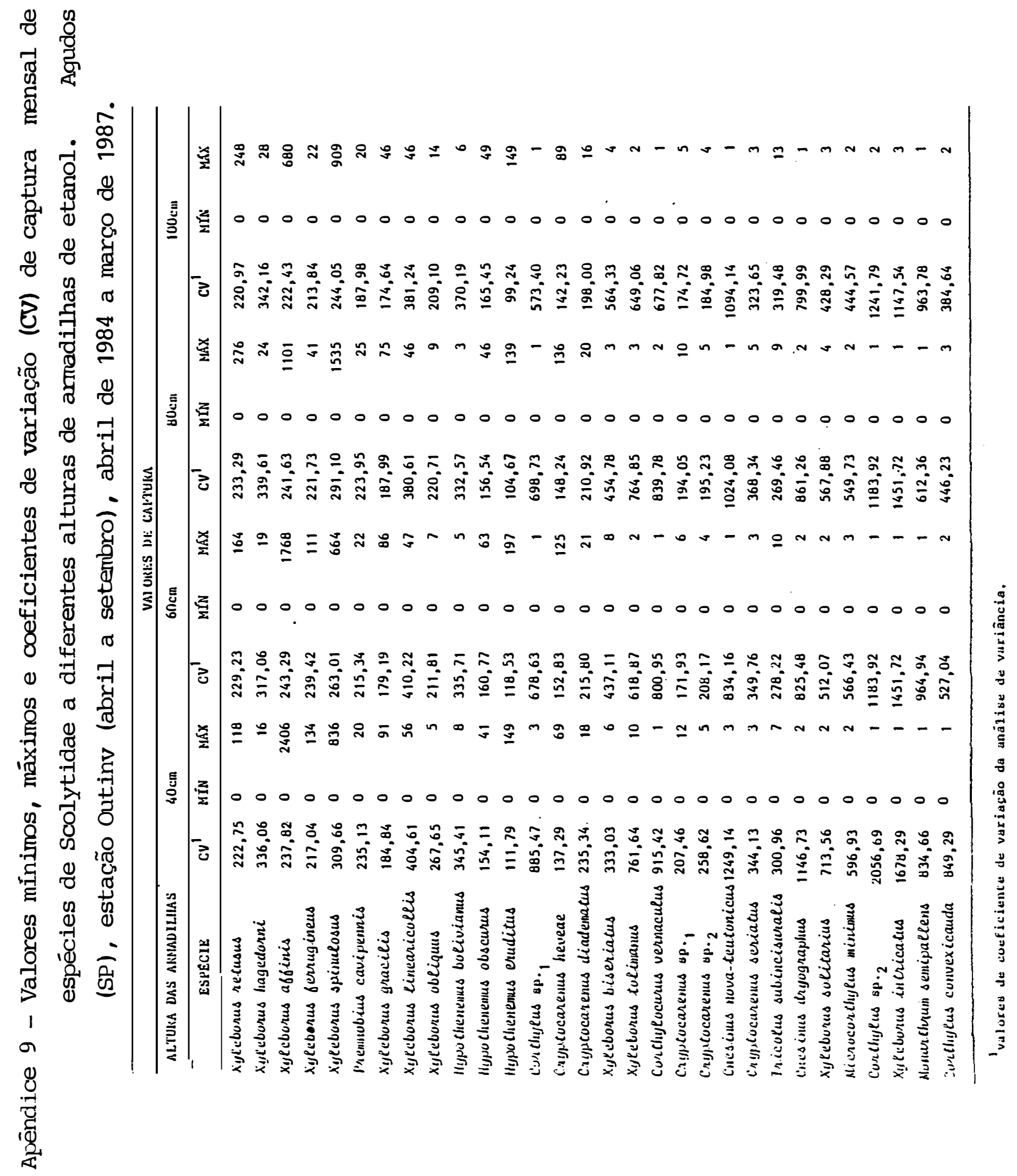




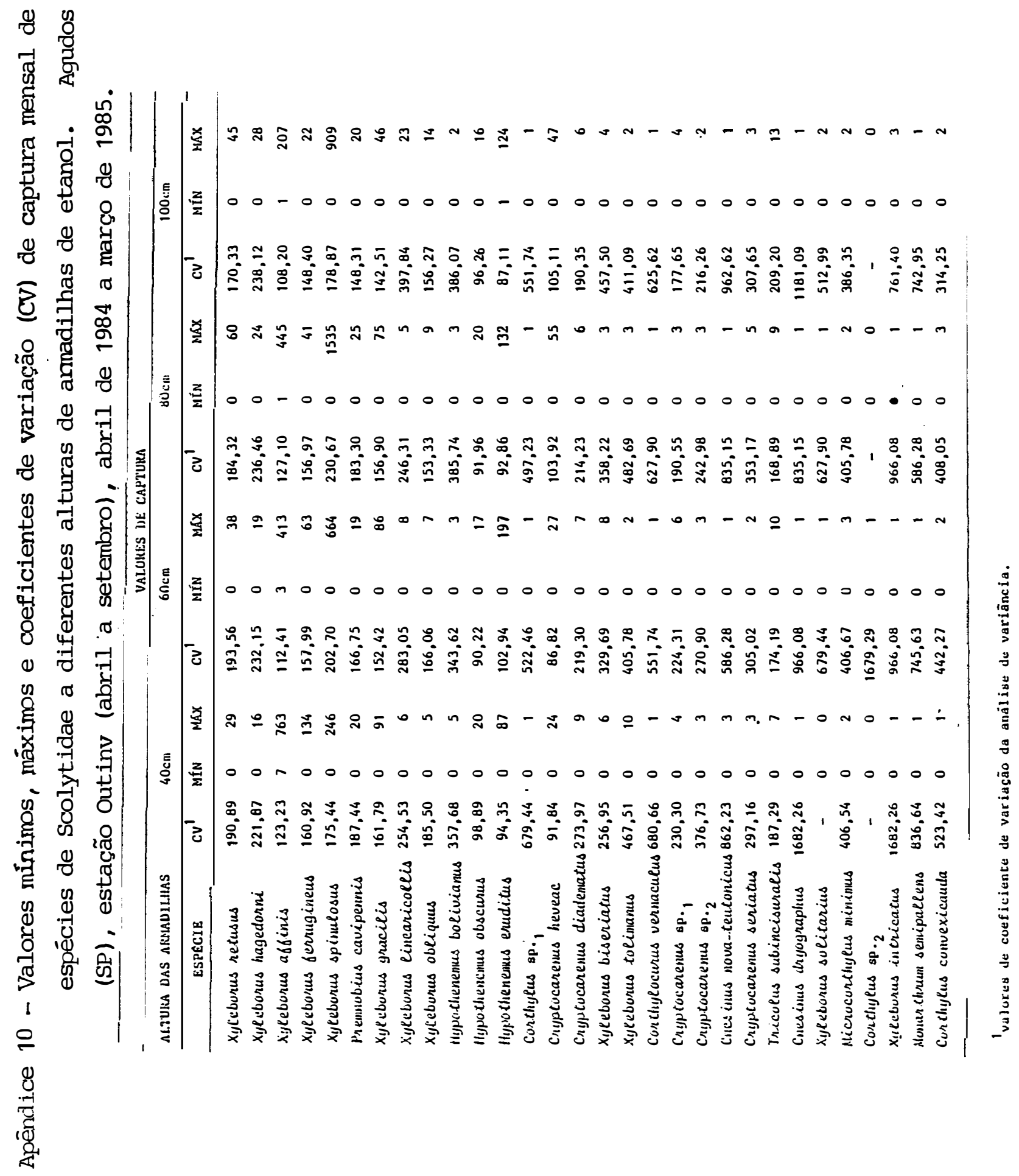




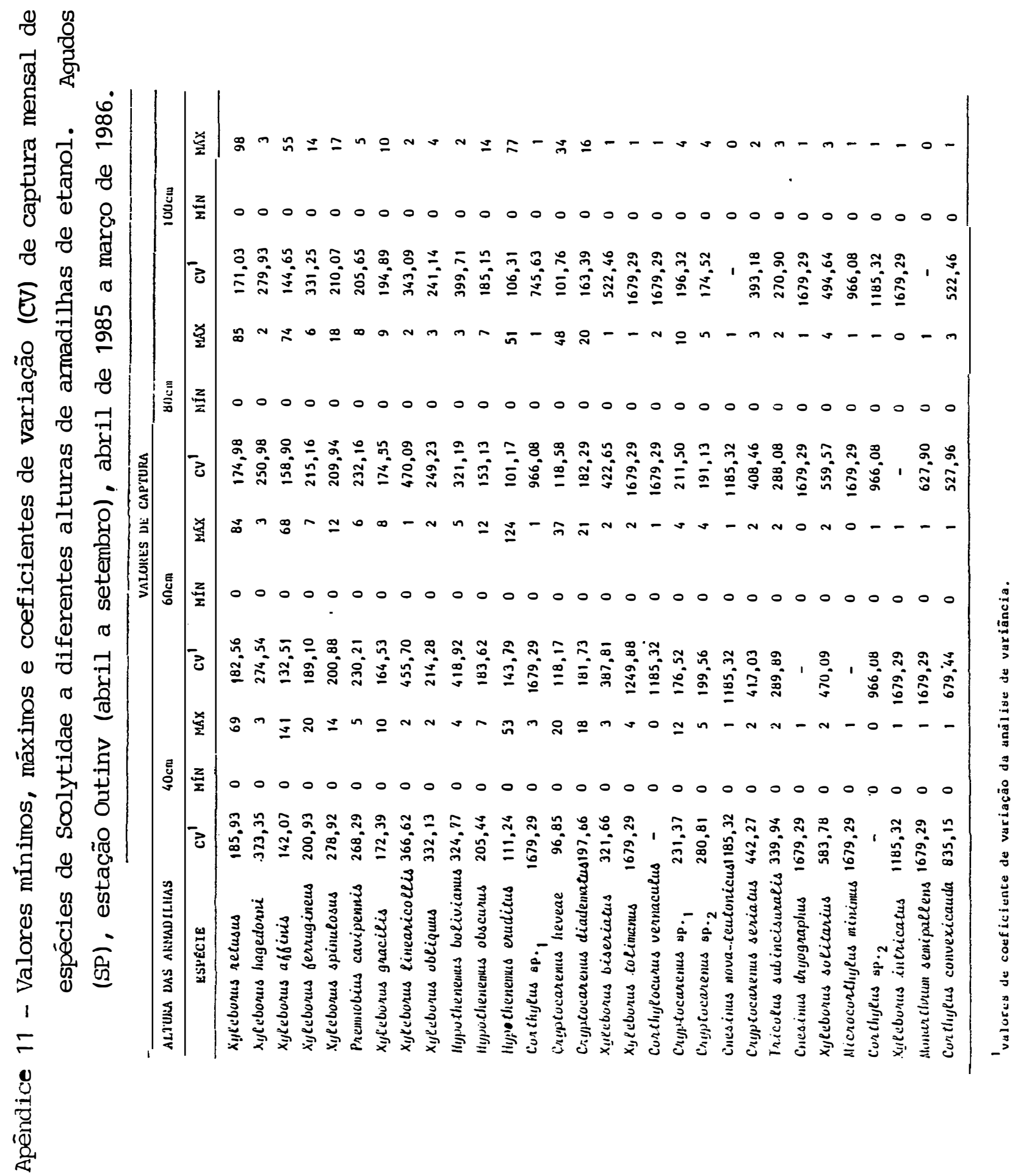


.124.

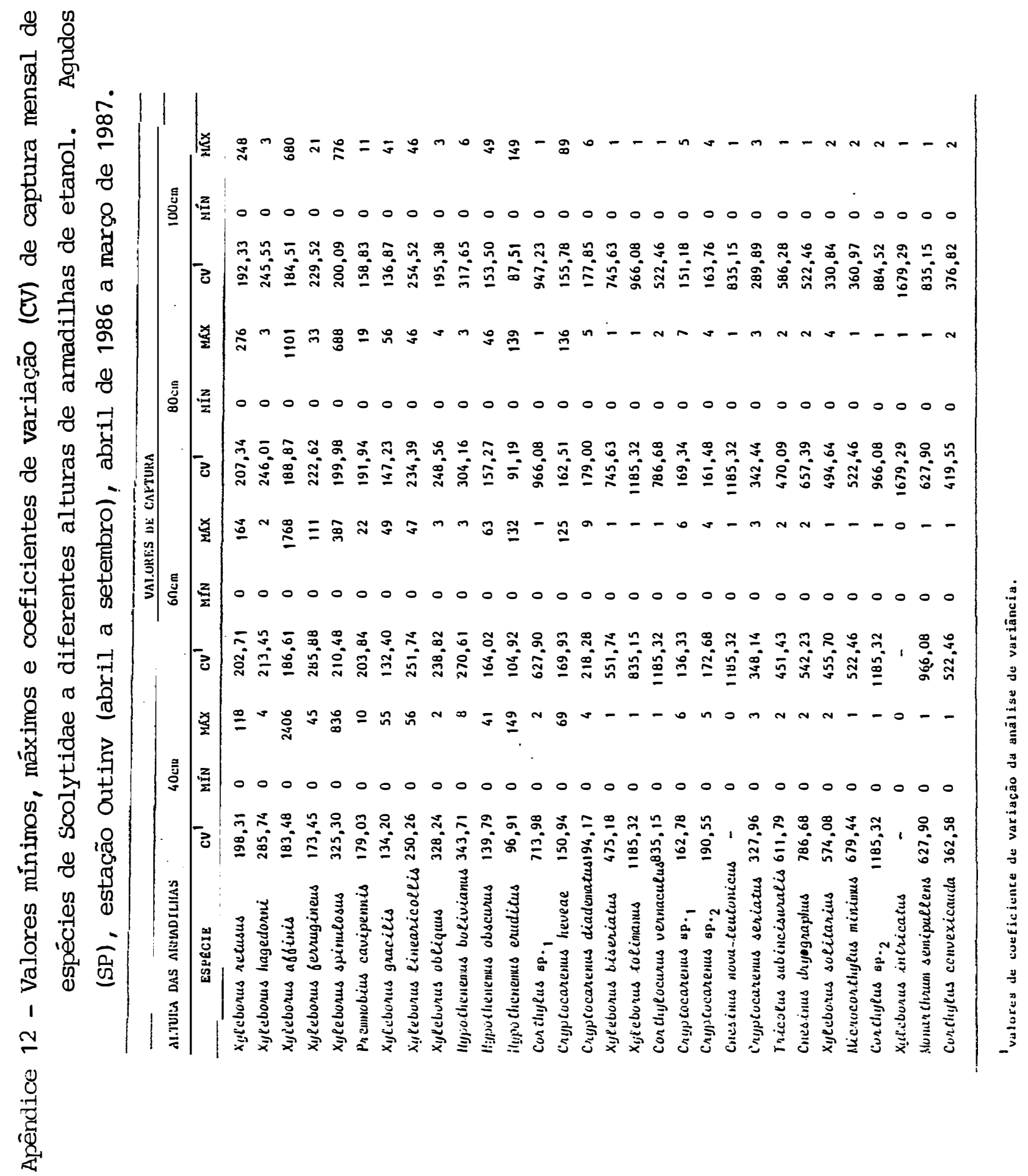




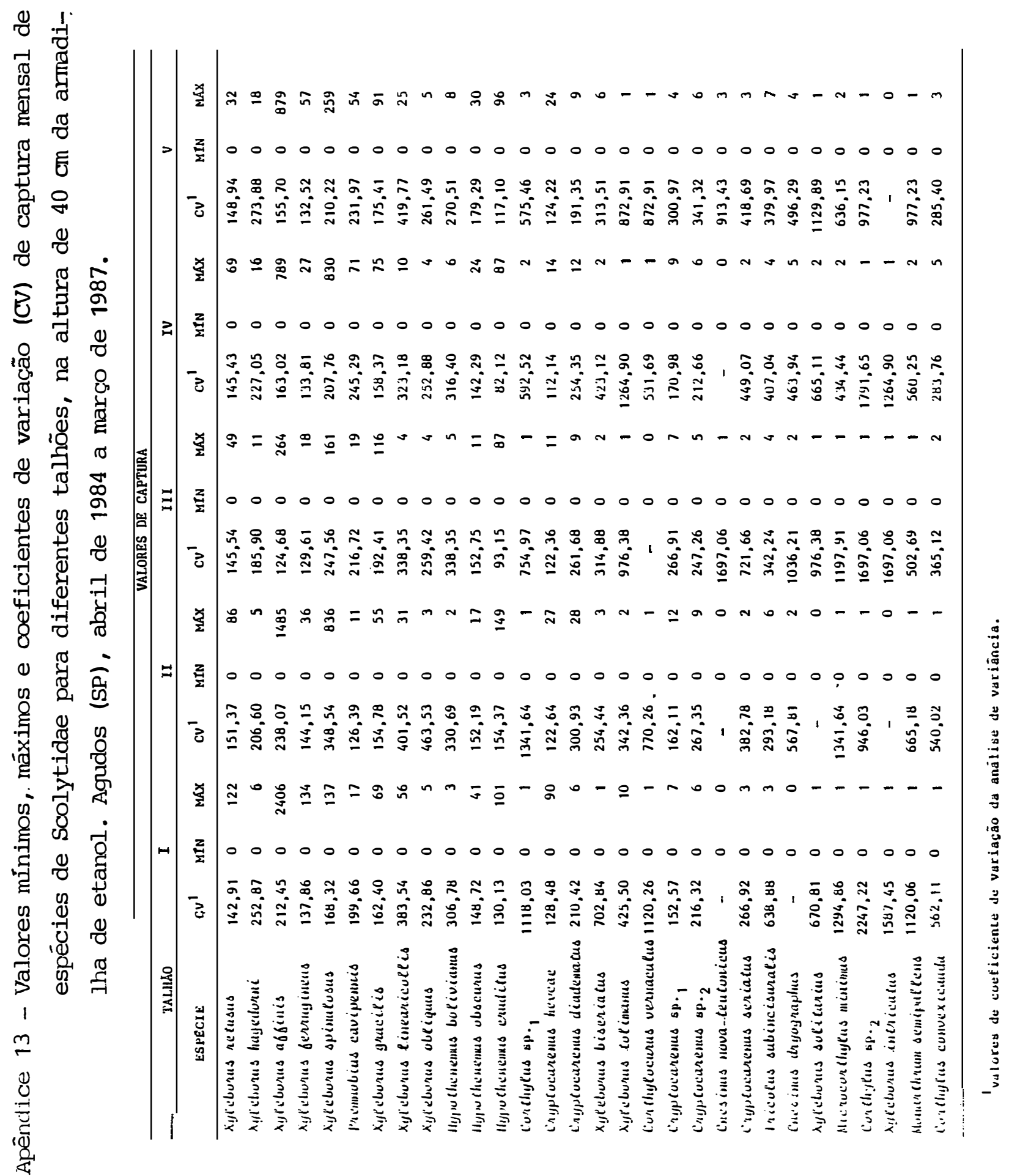




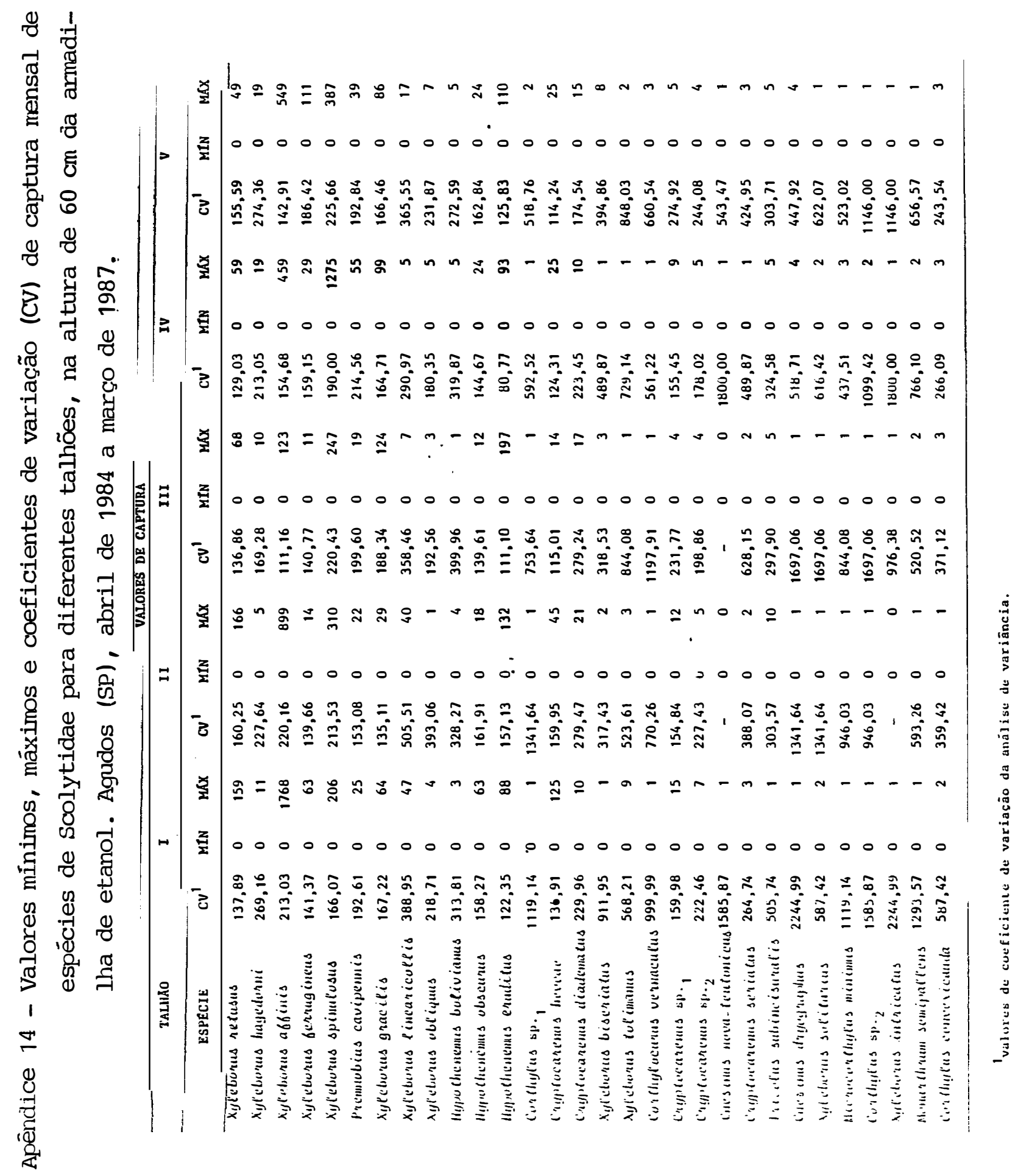




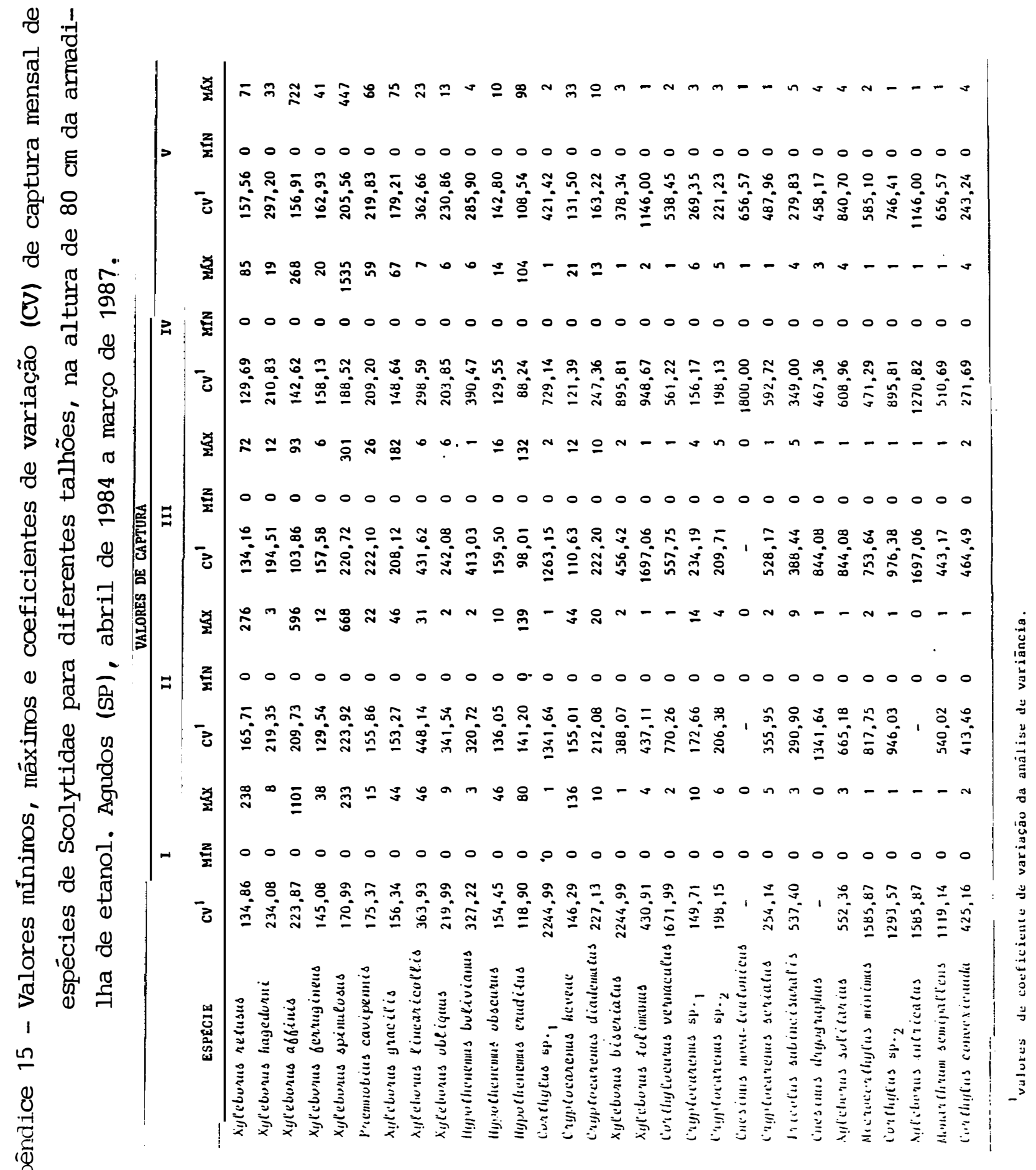




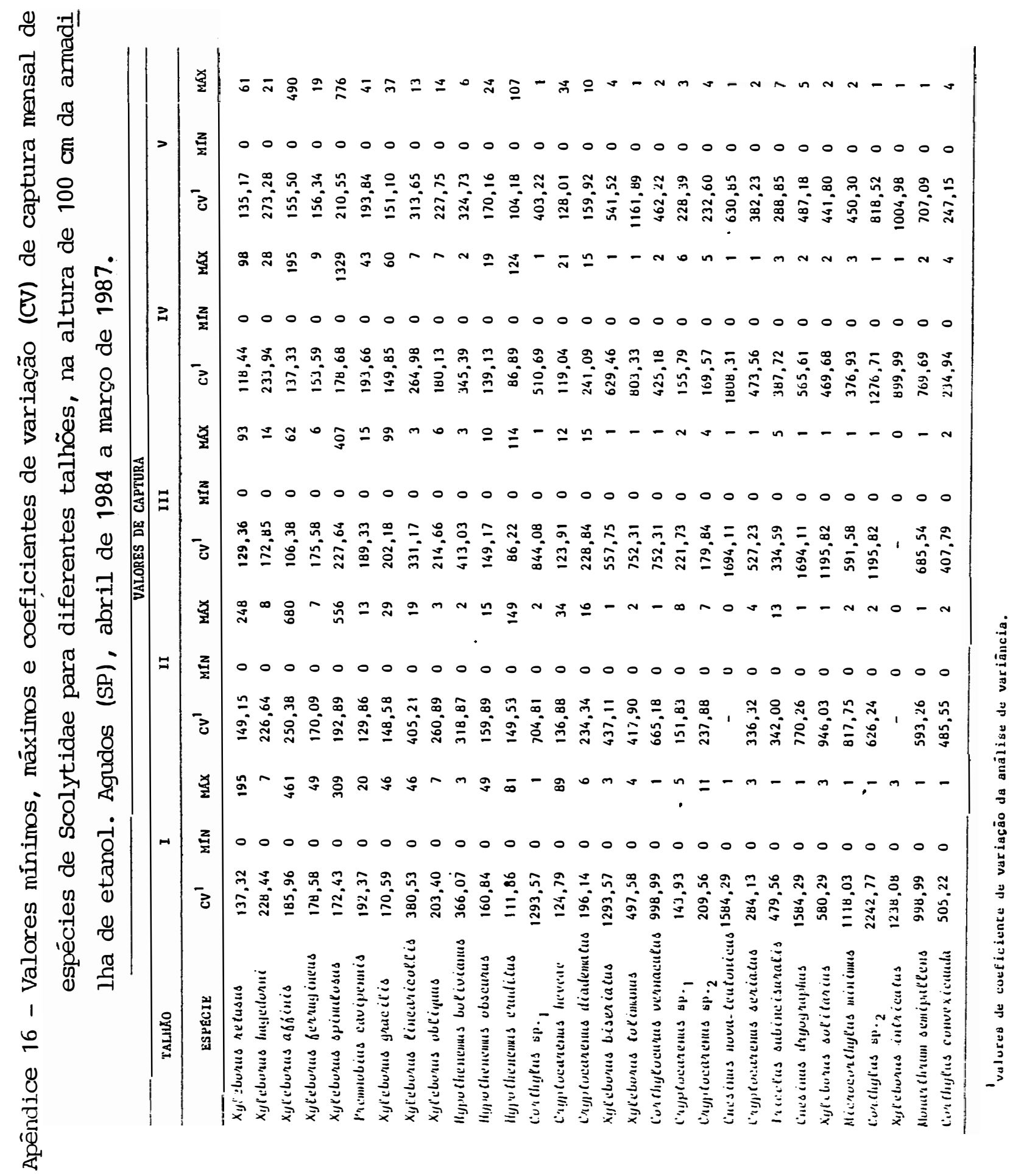


$$
\text { वृ }
$$$$
\text { ซึ }
$$$$
\text { 苟 }
$$$$
\text { ช }
$$$$
\text { उ ข }
$$$$
\text { อ }
$$

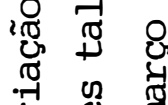

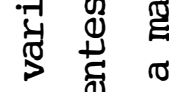$$
\text { व }
$$

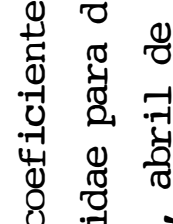$$
\text { 0 त्रे ह }
$$$$
\text { 零 }
$$$$
\text { D ब }
$$

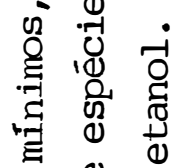

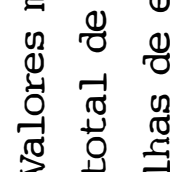$$
1
$$$$
\text { - }
$$

0

宅

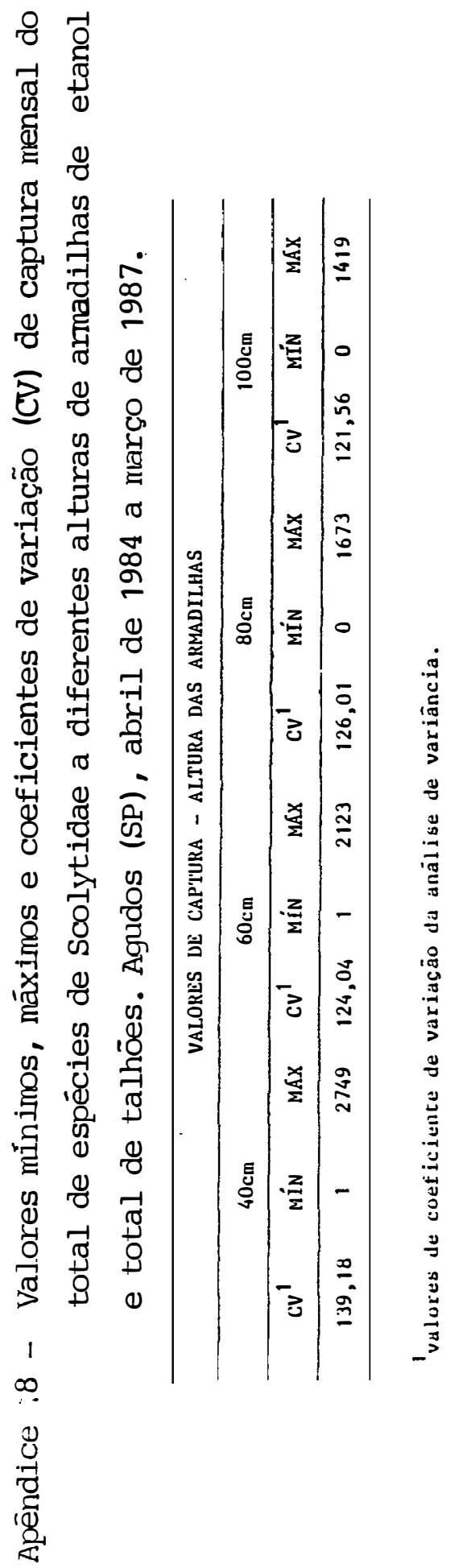


.130.

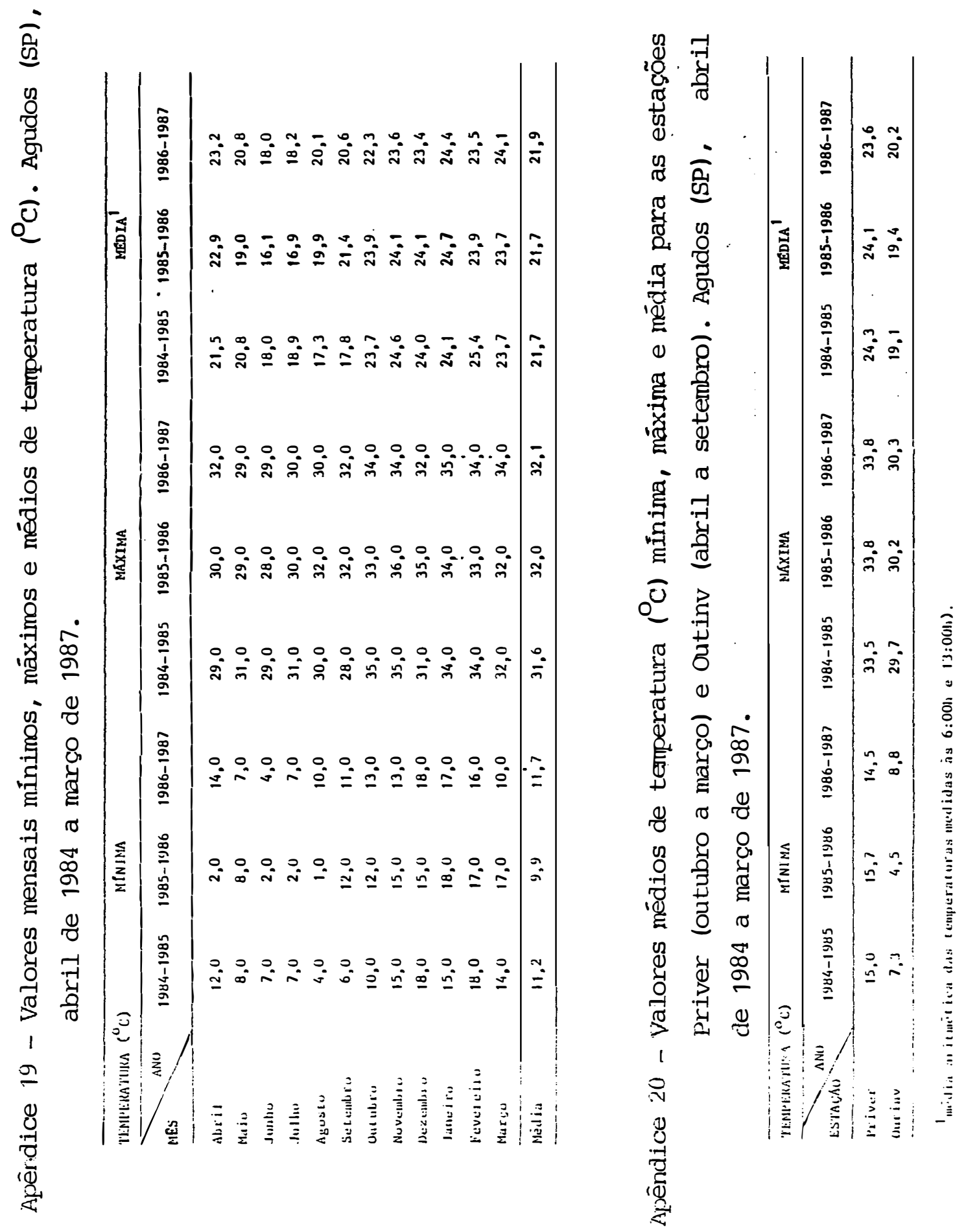


.131.

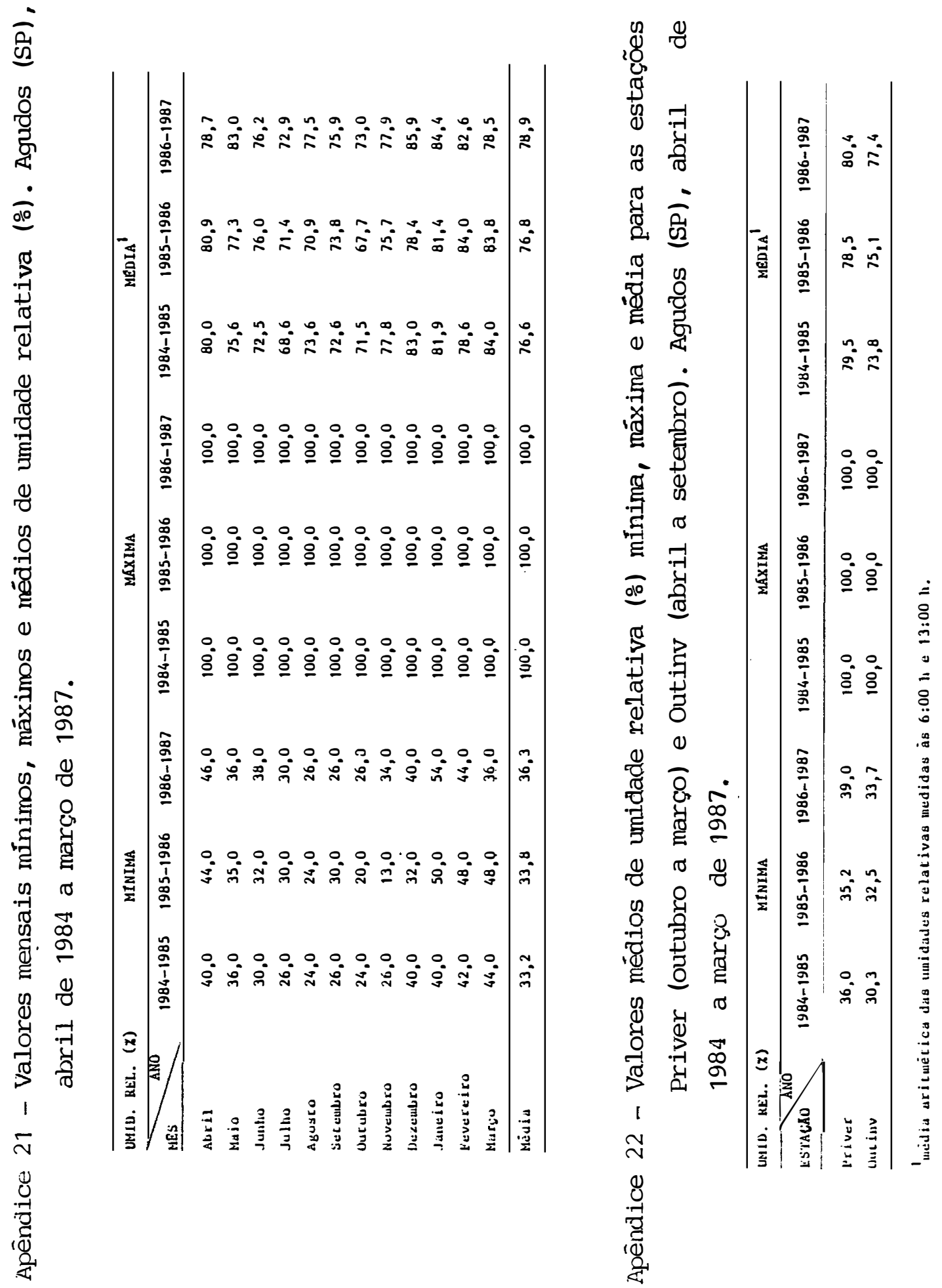


Apêndice 23 - Valores mensais de precipitação pluviométrica (man) e nūmero de dias com chuva. Agudos (SP), abril de 1984 a mar ço de 1987.

\begin{tabular}{lccccccc}
\hline & \multicolumn{2}{c}{ PRECIPITACAO TOTAI (mm) } & \multicolumn{3}{c}{ NOMERO DE DIAS COM CRUVA } \\
\hline MES & ANO & $1984-1985$ & $1985-1986$ & $1986-1987$ & $1984-1985$ & $1985-1986$ & $1986-1987$ \\
\hline Abril & 79 & 225 & 27 & 11 & 12 & 3 \\
Maio & 27 & 64 & 165 & 6 & 4 & 7 \\
Junho & 0 & 22 & 2 & 0 & 2 & 1 \\
Julho & 10 & 21 & 28 & 1 & 2 & 4 \\
Agosto & 112 & 16 & 168 & 7 & 2 & 11 \\
Setembro & 75 & 63 & 63 & 5 & 5 & 4 \\
Outubro & 60 & 25 & 51 & 2 & 5 & 6 \\
Novembro & 124 & 189 & 128 & 9 & 10 & 13 \\
Dezembro & 269 & 179 & 437 & 16 & 8 & 20 \\
Janeiro & 154 & 100 & 363 & 9 & 11 & 13 \\
Fevereiro & 260 & 261 & 149 & 13 & 13 & 15 \\
Março & 183 & 196 & 64 & 14 & 17 & 5 \\
\hline Média & 113 & 113 & 137 & 8 & 6 & 9 \\
\hline
\end{tabular}

Apêndice 24 - Valores médios de precipitação pluvionétrica e núneros de dias com chuva para as estaçōes Priver (outubro a março) e outinv (abril a setembro). Agudos (SP), abril de 1984 a março de 1987.

\begin{tabular}{lcccccc}
\hline & \multicolumn{2}{c}{ PRECIPITACSO TOTAL (Im) } & \multicolumn{2}{c}{ YOTERO DE DIAS COM CHUVA } \\
\hline ESTACFO ANO & $1984-1985$ & $1985-i 986$ & $1986-1987$ & $1984-i 985$ & $1985-i 986$ & $i 986-i 98 i$ \\
\hline Priver & 175 & 158 & 199 & 11 & 11 & 12 \\
Outinv & 61 & 69 & 76 & 5 & 5 & 10 \\
\hline
\end{tabular}

